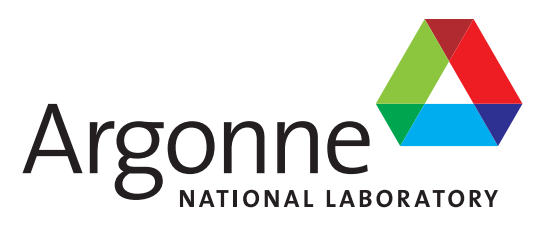

ANL-11/32

\title{
Modeling the Performance and Cost of Lithium-lon Batteries for Electric-Drive Vehicles
}

Chemical Sciences and Engineering Division 


\begin{abstract}
About Argonne National Laboratory
Argonne is a U.S. Department of Energy laboratory managed by UChicago Argonne, LLC under contract DE-AC02-06CH11357. The Laboratory's main facility is outside Chicago, at 9700 South Cass Avenue, Argonne, Illinois 60439. For information about Argonne and its pioneering science and technology programs, see www.anl.gov.
\end{abstract}

\title{
Availability of This Report
}

This report is available, at no cost, at http://www.osti.gov/bridge. It is also available on paper to the U.S. Department of Energy and its contractors, for a processing fee, from:

U.S. Department of Energy

Office of Scientific and Technical Information

P.O. Box 62

Oak Ridge, TN 37831-0062

phone (865) 576-8401

fax (865) 576-5728

reports@adonis.osti.gov

\begin{abstract}
Disclaimer
This report was prepared as an account of work sponsored by an agency of the United States Government. Neither the United States Government nor any agency thereof, nor UChicago Argonne, LLC, nor any of their employees or officers, makes any warranty, express or implied, or assumes any legal liability or responsibility for the accuracy, completeness, or usefulness of any information, apparatus, product, or process disclosed, or represents that its use would not infringe privately owned rights. Reference herein to any specific commercial product, process, or service by trade name, trademark, manufacturer, or otherwise, does not necessarily constitute or imply its endorsement, recommendation, or favoring by the United States Government or any agency thereof. The views and opinions of document authors expressed herein do not necessarily state or reflect those of the United States Government or any agency thereof, Argonne National Laboratory, or UChicago Argonne, LLC.
\end{abstract}




\section{Modeling the Performance and Cost} of Lithium-lon Batteries for Electric-Drive Vehicles

by

P.A. Nelson, K.G. Gallagher, I. Bloom, and D.W. Dees

Electrochemical Energy Storage Theme

Chemical Sciences and Engineering Division

Argonne National Laboratory

September 2011 
This Page Intentionally Left Blank 


\section{TABLE OF CONTENTS}

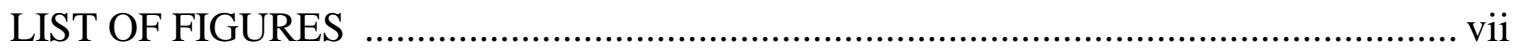

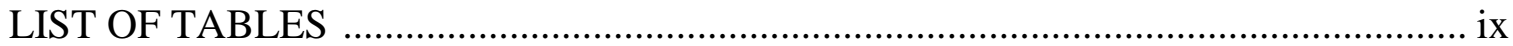

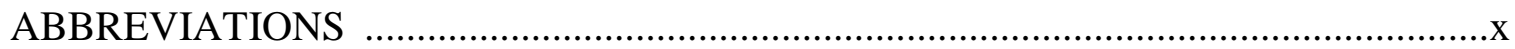

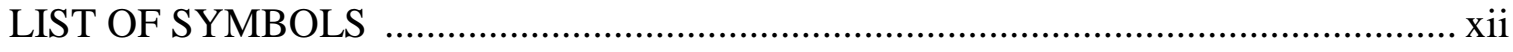

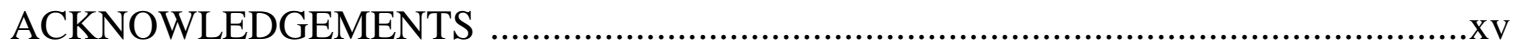

EXECUTIVE SUMMARY .............................................................................

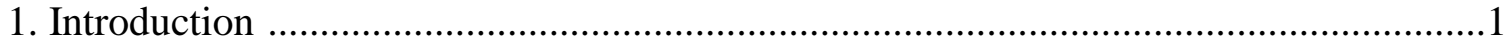

2. Battery and Cell Design Format …………………...............................................

2.1 Cell Design..............................................................................................

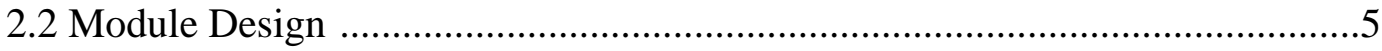

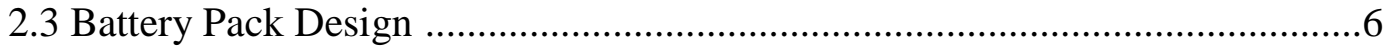

3. Modeling of Battery Design and Performance ………...............................................

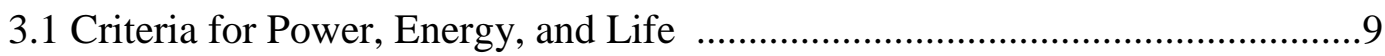

3.2 Voltage at Rated Power …………..........................................................11

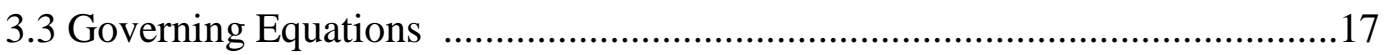

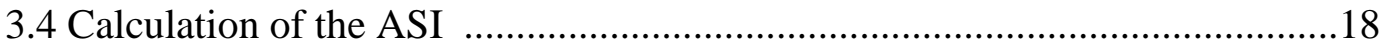

3.4.1 Current Collection Resistance .......................................................20

3.4.2 Potential and Current Distribution ....................................................22

3.4.3 Determination of Module Terminal Size ..........................................24

3.5 Calculation of Battery Dimensions .............................................................25

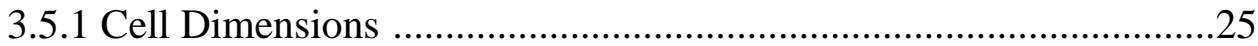

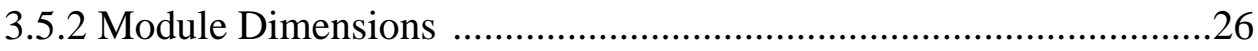


3.5.3 Battery Pack Dimensions ..............................................................26

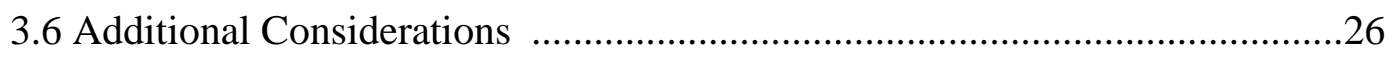

3.6.1 Maximum Electrode Thickness .....................................................27

3.6.2 Accounting for Parallel Cell Arrangements ……………….................33

3.6.3 Accounting for Parallel Module Arrangements .................................33

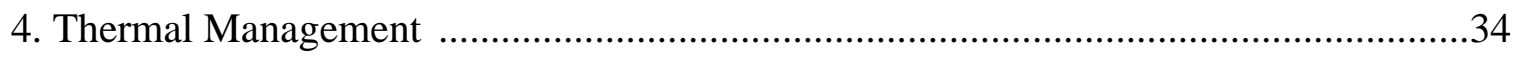

4.1 Heat Generation Rates in the Battery Pack during Driving ..............................34

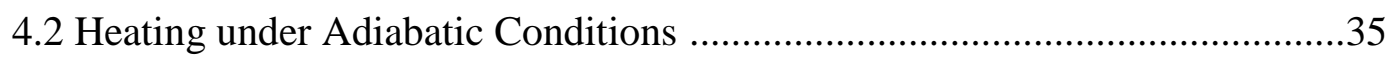

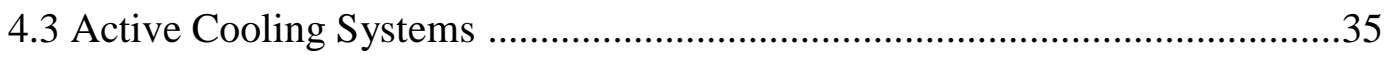

4.3.1 Heat Transfer from Cell to Module Wall ...........................................36

4.3.2 Heat Transfer from Module Wall to Flowing Coolant ......................38

4.4 Cooling and Heating Required to Maintain Pack Temperature ......................42

4.5 Heat-up from Cold Ambient Conditions …………..........................................43

5. Modeling of Battery Pack Manufacturing Cost ……………………….....................44

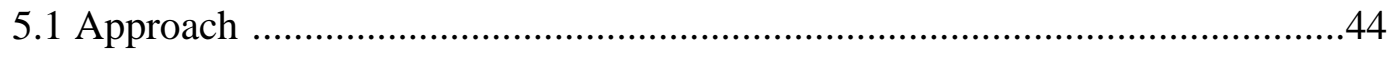

5.2 Materials Costs and Purchased Items ..........................................................45

5.2.1 Battery Specific Materials Cost ………………………………......4

5.2.2 Purchased Items Cost ………………………………...............50

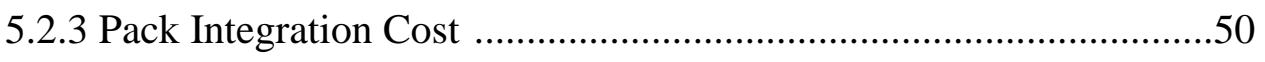

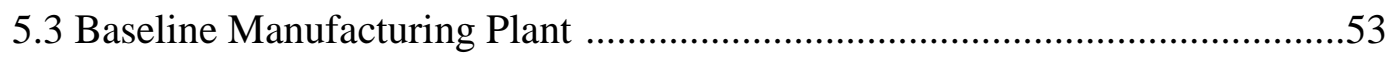

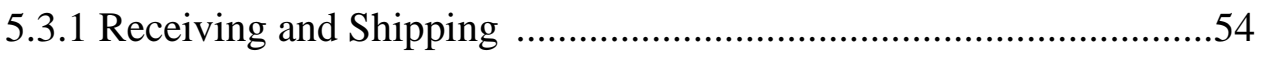

5.3.2 Electrode Materials Preparation ……………………………….......56

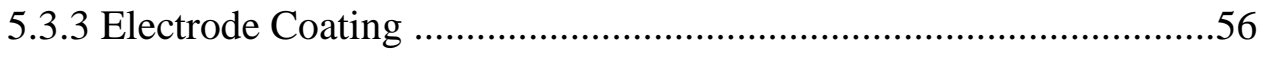




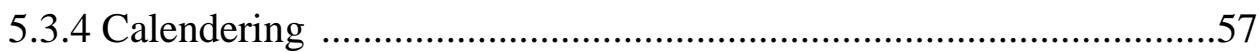

5.3.5 Inter-Process Materials Handling ...............................................57

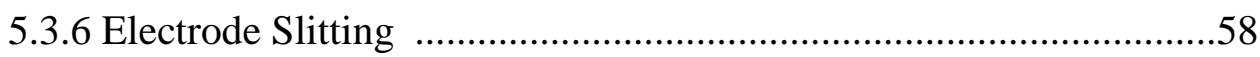

5.3.7 Final Electrode Drying ........................................................58

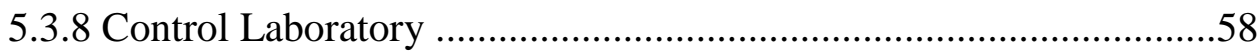

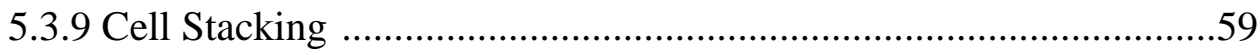

5.3.10 Current Collector Welding .....................................................59

5.3.11 Enclosing Cell in Container ................................................59

5.3.12 Electrolyte Filling and Cell Sealing .......................................60

5.3.13 Dry Room Management ....................................................60

5.3.14 Formation Cycling, Final Cell Sealing, etc ...............................60

5.3.15 Module and Battery Assembly ..............................................61

5.3.16 Rejected Cell and Scrap Recycle .........................................62

5.3.17 Baseline Plant Summary ….................................................63

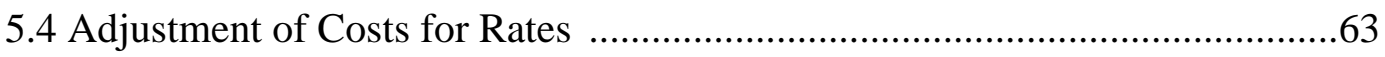

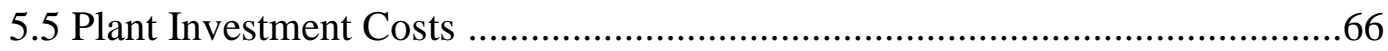

5.6 Unit Costs for Battery Pack .............................................................6

5.6.1 Variable Costs ..................................................................66

5.6.2 Fixed Expenses ............................................................67

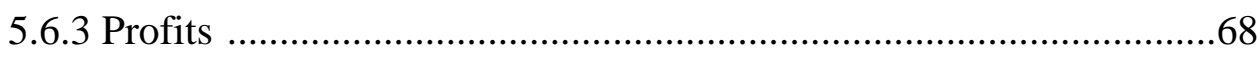

5.6.4 Battery Pack Warranty Costs ................................................68

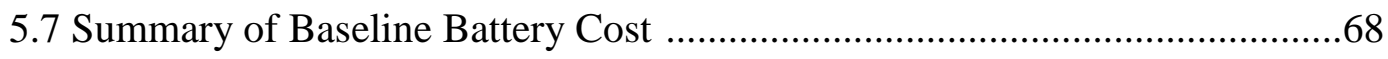

6. Description of Spreadsheet Model and Instructions for Use ...................................71 


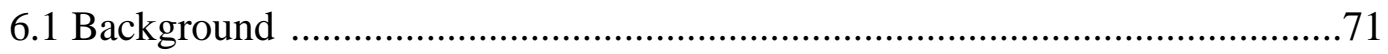

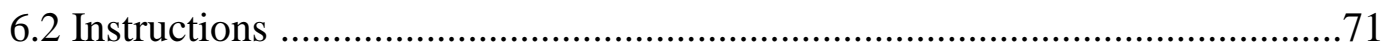

6.2.1 Enabling Calculation .......................................................... 71

6.2.2 System Selection Worksheet ................................................. 73

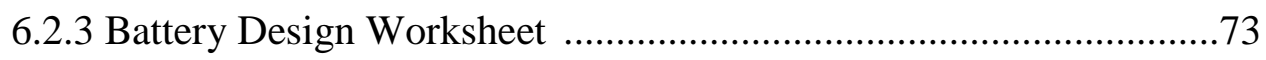

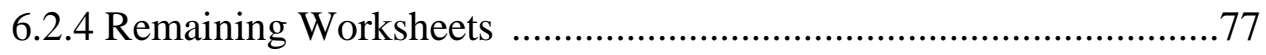

6.3 Battery Design Format Requirements .................................................. 80

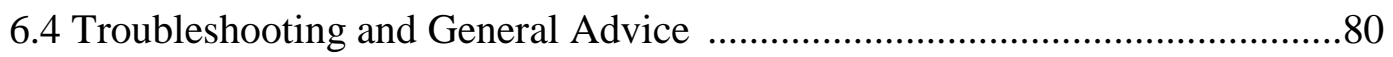

6.5 Suggested Number of Cells, Modules, and Performance Inputs ...................80

6.6 Entering a New Material Couple …...................................................... 81

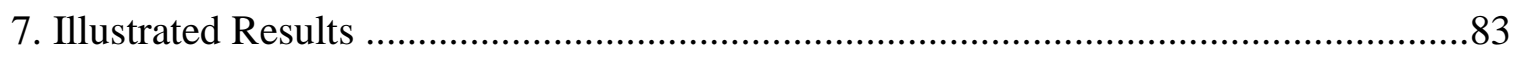

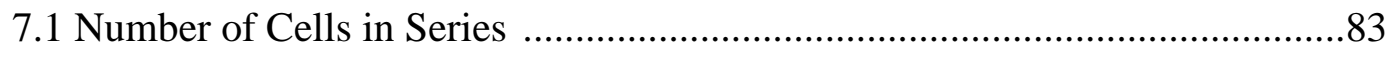

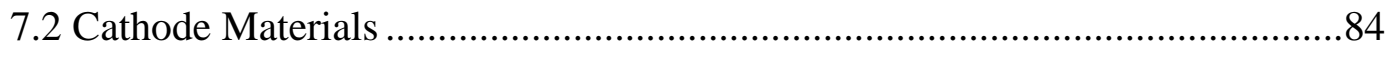

7.3 Parallel-Connected Cell Groups and Electrode Thickness ..........................84

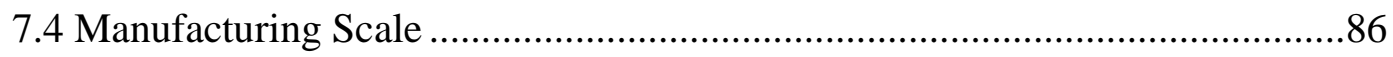

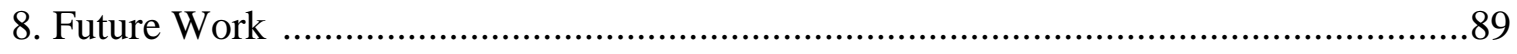

8.1 Initial Power Designed at Differing Fractions of the Open-Circuit Voltage ...89

8.2 Optimum Battery Voltage for Minimum Drivetrain Cost ...........................89

8.3 Multipurpose Battery Manufacturing Plants ..........................................90

8.4 Stand-Alone Graphical User Interface for Model ...................................90

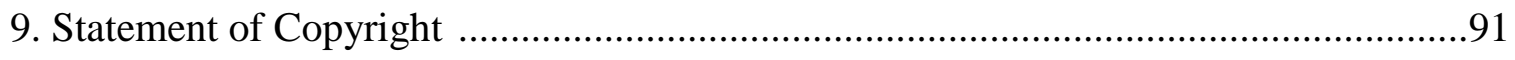

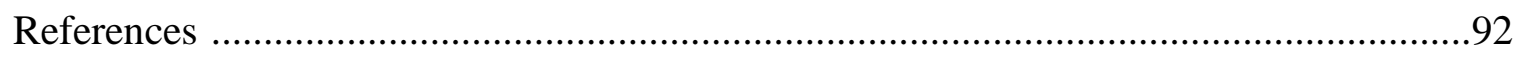

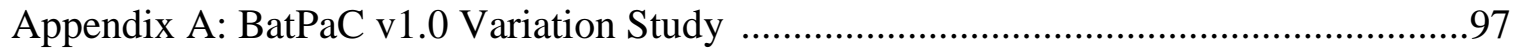




\section{LIST OF FIGURES}

2.1 Prismatic cell and module design for battery packs ................................................

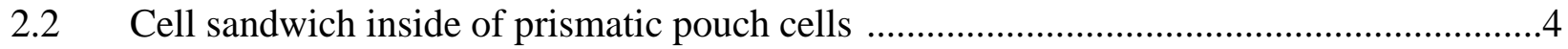

2.3 Coated current collector foil for prismatic electrodes ................................................5

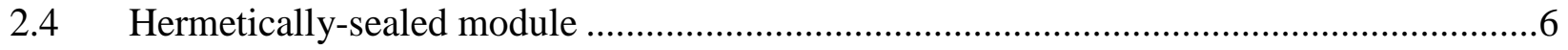

2.5 Insulated battery jacket with enclosed modules that are cooled on their upper and lower surfaces by ethylene glycol-water solution.........................................................

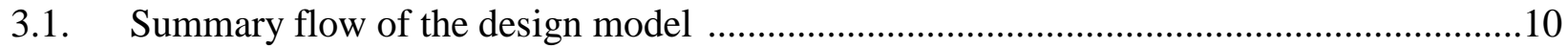

3.2 a) Required change in $[\mathrm{V} / \mathrm{U}]$ to maintain rated power with increases in internal resistance over the life of the battery. b) Increase in current due to lowered [V/U] ........13

3.3 Change in heat rejection requirement from increases in resistance for batteries with different designed voltages at rated power

3.4 Efficiencies for batteries designed to achieve rated power at different fractions of their open-circuit voltage .16

3.5 The change in current and potential within the positive and negative foils. The current collection design results in a uniform current distribution along the length of the foil ....23

3.6 Cell capacity simulated at the $\mathrm{C} / 1$ and $\mathrm{C} / 3$ rate as a function of electrode thickness (loading) for NCA-Gr.

3.7 Normalized electrolyte salt concentration at the end of discharge at the $\mathrm{C} / 1$ and $\mathrm{C} / 3$ discharge rates.

3.8 Calculated ASI from a simulated 10-s, 5C discharge pulse for the NCA-Gr cell couple at $60 \%$ SOC.

3.9 The potential of the negative electrode versus a hypothetical lithium reference electrode located in the center of separator during a 5C charge pulse for the NCA-Gr couple ........31

4.1 Plot comparing the estimated resistance to heat transfer from the cell center to the cooled surface of the module to that calculated by the FlexPDE model

4.2 Heat transfer from the module wall to the laminar flow heat transfer fluid. The temperature profile of the fluid is shown at different lengths down the path. 
4.3 Temperature profile in the heat transfer fluid for various fractions of the dimensionless path length.

4.4 Correlation of model simulation results relating the Graetz number and mean Nusselt number for laminar flow between an insulated surface and the module casing.....

5.1 Metal ingot cost contribution to the current collector foils over a 20 year period 49

5.2 Baseline lithium-ion battery manufacturing plant schematic diagram ………..................54

5.3 Breakdown of installed capital equipment costs for the baseline plant ...........................65

5.4 Breakdown of unit costs for baseline battery with total price to OEM of $\$ 2428 \ldots \ldots \ldots \ldots . . .70$

6.1 Iteration must be enabled for the spreadsheet model to function .....................................72

6.2 The specific cell chemistry for the battery design is selected on the System Selection

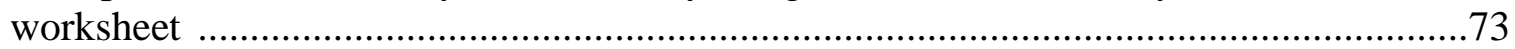

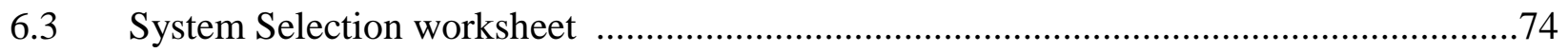

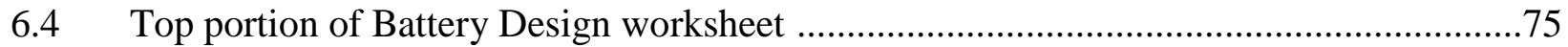

6.5 Middle portion of Battery Design worksheet …………....................................................76

6.6 Bottom portion of Battery Design worksheet ……….................................................78

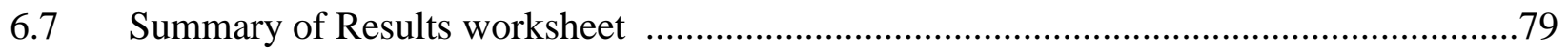

7.1 The effect of the number of cells for NMC441-Gr, 60-kW, PHEV25 packs with 10.7 $\mathrm{kWh}$ total energy ( $70 \%$ useable)

7.2 Mass and volume of electric vehicle battery packs with lithium iron phosphate (LFP), lithium manganese-spinel (LMO) and lithium nickel-manganese-cobalt oxide (NMC441) positive electrodes versus graphite designed to deliver $150 \mathrm{~kW}$ of power at $360 \mathrm{~V}$ ( $25 \%$ SOC).

7.3 Battery pack price to OEM for LFP-Gr, LMO-Gr and NMC441-Gr battery packs for same designs as in Fig. 7.2. NMC441-Gr and LMO-Gr result in nearly the same price...85

7.4 Battery pack cost as a function of number of parallel cells and for different maximum electrode thicknesses.

7.5 The effects of manufacturing rate on the price calculated by the model for battery packs of various cell chemistries, power capabilities and vehicle types 


\section{LIST OF TABLES}

3.1 Criteria for designing batteries for a specific end-use application ..............................

3.2 The effect of electrode loading on the price of a $17 \mathrm{kWh}$ NCA-Gr PHEV40 battery with 96 cells

4.1 Sample calculations of composite thermal conductivities of cell structures

across layer and parallel to layers

4.2 Range of parameter values for calculating heat transfer rates in FlexPDE model

5.1 Details of stated costs for cathodes, anodes, electrolyte, and separator

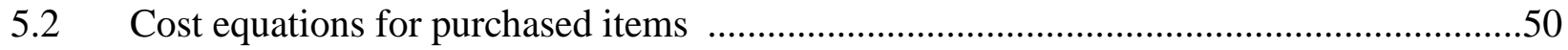

Costs to integrate battery pack into vehicle drivetrain...............................................51

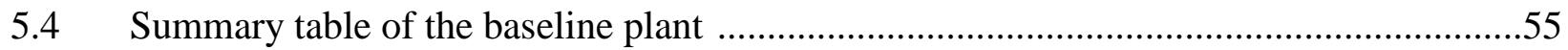

5.5 Materials yields during electrode and cell fabrication ...........................................62

5.6 The effect of processing rate $(\mathrm{R})$ on cost for various scale factors .............................64

5.7 Battery pack manufacturing investment costs $\quad$...................................................66

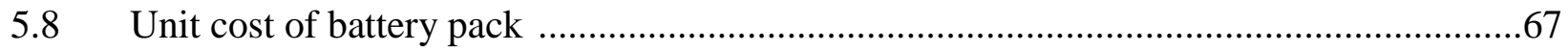

5.9 Summary of results for cost of baseline battery and that of similar batteries with double the power and double the capacity of the baseline battery

6.1 General suggestions for range of input parameters that change with battery type 


\section{ABBREVIATIONS}

ASI area specific impedance

BOL beginning of life

DMC dimethyl carbonate

EC ethylene carbonate

EMC ethyl methyl carbonate

EOL end of life

EV electric vehicle

Gr graphite

GSA General, Sales, and Administration

HEV hybrid electric vehicle

HEV-HP high-power assist hybrid electric vehicle

LCO lithium cobalt oxide

LFP lithium iron phosphate

Li lithium

Li-ion lithium-ion

LMO lithium manganese spinel

LMR lithium and manganese rich

LTO lithium titanate spinel

microHEV micro or mild power assist hybrid electric vehicle

MW molecular weight

NCA lithium nickel cobalt aluminum oxide

NMC lithium nickel manganese cobalt oxide 


$\begin{array}{ll}\text { NMP } & \text { N-Methyl-2-pyrrolidone } \\ \text { OCV } & \text { open-circuit voltage } \\ \text { OEM } & \text { original equipment manufacturer } \\ \text { PE } & \text { polyethylene } \\ \text { PET } & \text { polyethylene terephthalate } \\ \text { PHEV } & \text { plug-in hybrid electric vehicle } \\ \text { PP } & \text { polypropylene } \\ \text { R\&D } & \text { research and development } \\ \text { SOC } & \text { state of charge } \\ \text { USGS } & \text { United States Geological Survey }\end{array}$




\section{LIST OF SYMBOLS}

\section{Section 3, 4 and 6}

a ratio of interfacial area to electrode volume, $\mathrm{cm}^{-1}$

$A_{\text {pos }}$ area of the positive electrode, $\mathrm{cm}^{2}$

$A_{\text {term }}$ area of the terminal, $\mathrm{cm}^{2}$

$A S I_{\text {energy }}$ area specific impedance for energy, ohm $\mathrm{cm}^{2}$

$A S I_{\text {power }}$ area specific impedance for power, $\mathrm{ohm} \mathrm{cm}^{2}$

C cell capacity, Ah.

$C_{1}$ parameter

$C_{p}$ specific heat capacity, J/g K

$d_{H}$ hydraulic radius, $\mathrm{cm}$

E total energy, Wh

$\dot{E}$ energy usage rate, $\mathrm{Wh} / \mathrm{mile}$ F Faraday constant, $96485.3 \mathrm{C} / \mathrm{mol}$

G mass flowrate, g/s

$h$ heat transfer coefficient, $\mathrm{W} / \mathrm{cm}^{2} \mathrm{~K}$

$H_{j} \quad$ height of $j, \mathrm{~cm}$

H/W $\quad$ aspect ratio of pouch cell

$i_{o} \quad$ exchange current density related to the interfacial area, $\mathrm{A} / \mathrm{cm}^{2}$

I average current density, $\mathrm{A} / \mathrm{cm}^{2}$

$I_{\text {lim }}{ }^{\text {ionic } \quad \text { ionic limiting current density, } \mathrm{A} / \mathrm{cm}^{2}}$

$I_{n} \quad$ local current density, $\mathrm{A} / \mathrm{cm}^{2}$

Itotal total current density, A

$k \quad$ thermal conductivity, W/cm K 


\begin{tabular}{|c|c|}
\hline$l_{j}$ & length of ${ }_{j}, \mathrm{~cm}$ \\
\hline$L_{j}$ & thickness of $j, \mathrm{~cm}$ \\
\hline$m_{j}$ & mass of $j, \mathrm{~g}$ \\
\hline$n$ & parameter \\
\hline$N_{j}$ & number of $j$ \\
\hline$[\mathrm{N} / \mathrm{P}]$ & negative to positive capacity ratio \\
\hline$P$ & battery power, $\mathrm{W}$ \\
\hline$P_{\text {batt }}$ & maximum designed battery power (rated power), $\mathrm{W}$ \\
\hline$q$ & heating rate, $\mathrm{W}$ \\
\hline$Q$ & specific capacity of the electrode, $\mathrm{mAh} / \mathrm{g}$ \\
\hline$r_{C}$ & C-rate, $\mathrm{h}^{-1}$ \\
\hline$r_{C, \text { lim }}$ & limiting C-rate, $\mathrm{h}^{-1}$ \\
\hline$r_{j}$ & radius of $j, \mathrm{~cm}$ \\
\hline $\bar{R}$ & universal gas constant, $8.3144 \mathrm{~J} / \mathrm{mol} \mathrm{K}$ \\
\hline$R_{j}$ & resistance of $j, \mathrm{ohm}$ \\
\hline$t$ & time, $\mathrm{s}$ \\
\hline$T$ & temperature, $\mathrm{K}$ \\
\hline$U_{o c v, P}$ & open-circuit voltage at SOC for power, V \\
\hline$U_{o c v, E}$ & open-circuit voltage at SOC for energy, V \\
\hline$v$ & square root of dimensionless exchange current \\
\hline$V_{\text {cell }}$ & cell voltage, $\mathrm{V}$ \\
\hline$[\mathrm{V} / \mathrm{U}]$ & fraction of the open-circuit voltage \\
\hline$W_{j}$ & width of $j$ \\
\hline
\end{tabular}




$\begin{array}{ll}x & \text { Cartesian coordinate, } \mathrm{cm} \\ X_{\text {comp }} & \text { compression factor } \\ \alpha & \text { constant, ohm cm } \\ \beta & \text { constant, ohm cm } \\ \varepsilon_{\text {act }} & \text { volume fraction of active material } \\ \eta^{1 \mathrm{st}} & \text { first cycle efficiency } \\ \mu & \text { fluid viscosity, } \mathrm{g} / \mathrm{cm} \mathrm{s} \\ \Phi_{1, \mathrm{k}} & \text { metal potential of foil } k, \mathrm{~V} \\ \rho_{\mathrm{j}} & \text { density of } j, \mathrm{~g} / \mathrm{cm}^{3} \\ \sigma_{\mathrm{j}} & \text { conductivity of } j, \mathrm{~S} / \mathrm{cm}\end{array}$

\section{Section 5.1}

C final cost of lithiated oxide, $\$ / \mathrm{kg}$

$C_{i} \quad$ cost of raw material for component i, $\$ / \mathrm{kg}$

$C_{o} \quad$ baseline cost of lithiated oxide, $\$ / \mathrm{kg}$

$x_{i} \quad$ molar stoichiometry of component $\mathrm{i}$

$M W_{i} \quad$ molecular weight of component i, g/mol

MW molecular weight of lithiated compound, $\mathrm{g} / \mathrm{mol}$

\section{Section 5.4}

C

capital cost of an installed equipment for the designed battery, $\$$

$C_{o} \quad$ capital cost of an installed equipment for the baseline plant battery, $\$$

power factor

$R \quad$ designed battery processing rate for specific process step

$R_{o} \quad$ baseline plant processing rate for specific process step 


\section{ACKNOWLEDGEMENTS}

Support from the Vehicle Technologies Program, Hybrid and Electric Systems, initially under Tien Duong and now David Howell, at the U.S. Department of Energy, Office of Energy Efficiency and Renewable Energy, is gratefully acknowledged. The submitted manuscript has been created by UChicago Argonne, LLC, Operator of Argonne National Laboratory ("Argonne"). Argonne, a U.S. Department of Energy Office of Science laboratory, is operated under contract no. DE-AC02-06CH11357. The U.S. Government retains for itself, and others acting on its behalf, a paid-up nonexclusive, irrevocable worldwide license in said article to reproduce, prepare derivative works, distribute copies to the public, and perform publicly and display publicly, by or on behalf of the Government. We especially thank Danilo Santini of Argonne's Transportation R\&D Center for his support and suggestions in carrying out this study. Ralph Brodd reviewed our baseline plant and made several suggestions which we have incorporated in the present design. Fritz Kalhammer and Haresh Kamath of the Electric Power Research Institute have reviewed our work over several years and made suggestions that resulted in improvements. The work was done under the direction of Dennis Dees and Gary Henriksen of Electrochemical Energy Storage who provided guidance in carrying out the work and preparing this manuscript. 


\section{EXECUTIVE SUMMARY}

This report details the Battery Performance and Cost model (BatPaC) developed at Argonne National Laboratory for lithium-ion battery packs used in automotive transportation. The model designs the battery for a specified power, energy, and type of vehicle battery. The cost of the designed battery is then calculated by accounting for every step in the lithium-ion battery manufacturing process. The assumed annual production level directly affects each process step. The total cost to the original equipment manufacturer calculated by the model includes the materials, manufacturing, and warranty costs for a battery produced in the year 2020 (in 2010 US\$). At the time this report is written, this calculation is the only publically available model that performs a bottom-up lithium-ion battery design and cost calculation. Both the model and the report have been publically peer-reviewed by battery experts assembled by the U.S. Environmental Protection Agency. This report and accompanying model include changes made in response to the comments received during the peer-review.

The purpose of the report is to document the equations and assumptions from which the model has been created. A user of the model will be able to recreate the calculations and perhaps more importantly, understand the driving forces for the results. Instructions for use and an illustration of model results are also presented. Almost every variable in the calculation may be changed by the user to represent a system different from the default values pre-entered into the program.

The distinct advantage of using a bottom-up cost and design model is that the entire power-toenergy space may be traversed to examine the correlation between performance and cost. The $\mathrm{BatPaC}$ model accounts for the physical limitations of the electrochemical processes within the battery. Thus, unrealistic designs are penalized in energy density and cost, unlike cost models based on linear extrapolations. Additionally, the consequences on cost and energy density from changes in cell capacity, parallel cell groups, and manufacturing capabilities are easily assessed with the model. New proposed materials may also be examined to translate bench-scale values to the design of full-scale battery packs providing realistic energy densities and prices to the original equipment manufacturer.

The model will be openly distributed to the public in the year 2011. Currently, the calculations are based in a Microsoft ${ }^{\oplus}$ Office Excel spreadsheet. Instructions are provided for use; however, the format is admittedly not user-friendly. A parallel development effort has created an alternate version based on a graphical user-interface that will be more intuitive to some users. The version that is more user-friendly should allow for wider adoption of the model. 


\section{Introduction}

The recent penetration of lithium-ion (Li-ion) batteries into the vehicle market has prompted interest in projecting and understanding the costs of this family of chemistries being used to electrify the automotive powertrain. The model described here-in is a calculation method that was developed at Argonne National Laboratory (Argonne) for estimating the manufacturing cost and performance of Li-ion batteries for electric-drive vehicles including hybrid-electrics (HEV), plug-in hybrids (PHEV), and pure electrics (EV). To date, a number of cost models of various levels of detail have been published in different forms. ${ }^{1-11}$ The cost of a battery will change depending upon the materials chemistry, battery design, and manufacturing process. ${ }^{12-14}$ Therefore, it is necessary to account for all three areas with a bottom-up cost model. Other bottom-up cost models exist but are not generally available and have not been explicitly detailed in a public document. The motivation for this work is based on a need for a battery cost model that meets the following requirements:

1. Open and available to the entire community

2. Transparent in the assumptions made and method of calculation

3. Capable of designing a battery specifically for the requirements of an application

4. Accounts for the physical limitations that govern battery performance

5. Based on a bottom-up calculation approach to account for every cost factor

The Battery Performance and Cost model (BatPaC) described here-in is the product of long-term research and development at Argonne. Over a period of years, Argonne has developed methods to design Li-ion batteries for electric-drive vehicles based on modeling with Microsoft ${ }^{\circledR}$ Office Excel spreadsheets. ${ }^{12-20}$ These design models provided all the data needed to estimate the annual materials requirements for manufacturing the batteries being designed. This facilitated the next step, which was to extend the effort to include modeling of the manufacturing costs of the batteries. In the following sections of this document, a model is presented that meets the above criteria and may be used to analyze the effect of battery design and materials properties on the cost of the final battery pack. Use of BatPaC requires some basic knowledge of battery packs; however, a user does not need to be an expert. For instance, the number of cells and thus battery pack voltage must be specified by the user. However, default values are available for more specific requirements such as experimentally measured values. In this way, a person with reasonable knowledge of batteries may be able to conduct cost comparisons and "what if" studies.

The battery pack design and cost calculated in $\mathrm{BatPaC}$ represent projections of a 2020 production year and a specified level of annual battery production, 20,000-500,000. As the goal is to predict the future cost of manufacturing batteries, a mature manufacturing process is assumed. The model designs a manufacturing plant with the sole purpose of producing the battery being modeled. The assumed battery design and manufacturing facility are based on common practice today but also assume some problems have been solved to result in a more efficient production process and a more energy dense battery. Our proposed solutions do not have to be the same methods used in the future by industry. We simply assume the leading battery manufacturers, those having successful operations in the year 2020, will reach these ends by some means. 
Establishing the validity of the model calculation is important in justifying the conclusions drawn from exercising the model. The report and model have been subjected to a public peerreview by battery experts assembled by the U.S. Environmental Protection Agency. Changes have been made in response to the comments received during the peer-review. The design methodology used has been previously validated against cylindrical wound cell formats. ${ }^{15}$ The calculated materials quantities agreed with the actual values within $3 \%$. Moving to a prismatic format simplifies the current collection calculation while leaving the governing equations unchanged. The new approach developed for calculating the cell impedance has been validated against experimental measurements from electrodes up to $100 \mu \mathrm{m}$ in thickness. ${ }^{20}$ The module and battery jacket construction is of lighter construction compared to contemporary designs. The battery pack energy density calculated in $\mathrm{BatPaC}$ is higher than the battery packs used in the first versions of the Nissan Leaf and Chevrolet Volt for equivalent cell designs (calculated value of $100 \mathrm{Wh} / \mathrm{kg}$ compared to a reported value near $84 \mathrm{Wh} / \mathrm{kg}$ for the $\mathrm{Volt}^{21}$ ). Significant engineering advances are necessary to minimize the current inactive material burden in the commercial pack designs, thereby reducing the cost, mass and dimensions of future automotive battery packs. We have assumed a design that we believe will be representative of the engineering progress achieved by successful manufacturers in the year 2020.

Validation of the input material and capital costs are more difficult to achieve as few values are publically available. We have relied, to a large extent, on private communications from equipment manufacturers, materials suppliers, cell manufacturers, and original equipment manufacturers. Variation does exist amongst the communicated values and we have maintained a practical level of skepticism for their accuracy. Experts from all aspects of battery development have reviewed the model both privately and as part of a formal peer-review process. While the largest uncertainty in calculated values will exist in point cost estimates, the most instructive information may be gained by examining ranges in parameter values and relative changes between material properties (e.g. the advantage of moving to a manganese spinel cathode from a layered-oxide material or from increases in cell capacity, etc). An initial variation study may be found in Appendix A.

The battery pack price to the OEM calculated by the model inherently assumes the existence of mature, high-volume manufacturing of Li-ion batteries for transportation applications. Therefore, the increased costs that current manufacturers face due to low scale of production, higher than expected cell failures in the field, and product launch issues are not accounted for in the calculation. The model results for year 2020 could be considered very optimistic if the transportation Li-ion market fails to develop as a result of insufficient investment in product research and development, reduced motivation for lowering petroleum consumption and greenhouse gas emissions, and/or a series of high-profile safety incidents. 


\section{Cell and Battery Pack Design Format}

Various cell and battery design concepts are under development at battery manufacturers. Based upon experience gained from extensive previous work, we have found the exact design of the battery does not have an important effect on the cost for a set cell chemistry; the amounts of electrode materials and the number, capacity and electrode area of the cells, are the determining cost factors. The most common cell designs for batteries nearing large-scale production are cylindrical wound cells, flat wound cells, and prismatic cells with flat plates. Cylindrical cells probably have a slight advantage for the assembly of the electrode-separator unit because of the ease of making a cylindrical winding. For the different cell designs, there are small differences in the weights of the terminal extensions and the procedures for connecting these extensions to the current collector sheets, with a small advantage for flat plate cells. The flat-wound and flat-plate cells form a more compact module and have better heat rejection capabilities than the cylindrical cells. These small differences would have minor effects on the cost of batteries produced in high volume in a mature, automated production plant and all of the cell designs can be adequately cooled for most applications. We conclude that the BatPaC cost calculations would be relevant for batteries differing considerably from the selected design approach.

To provide a specific design for the calculations, a prismatic cell in a stiff-pouch container was selected (Fig. 2.1). For this design, calculations of the current collector and terminal resistances are easily done with a one-dimensional model, because the terminals are almost the same width as the electrodes.

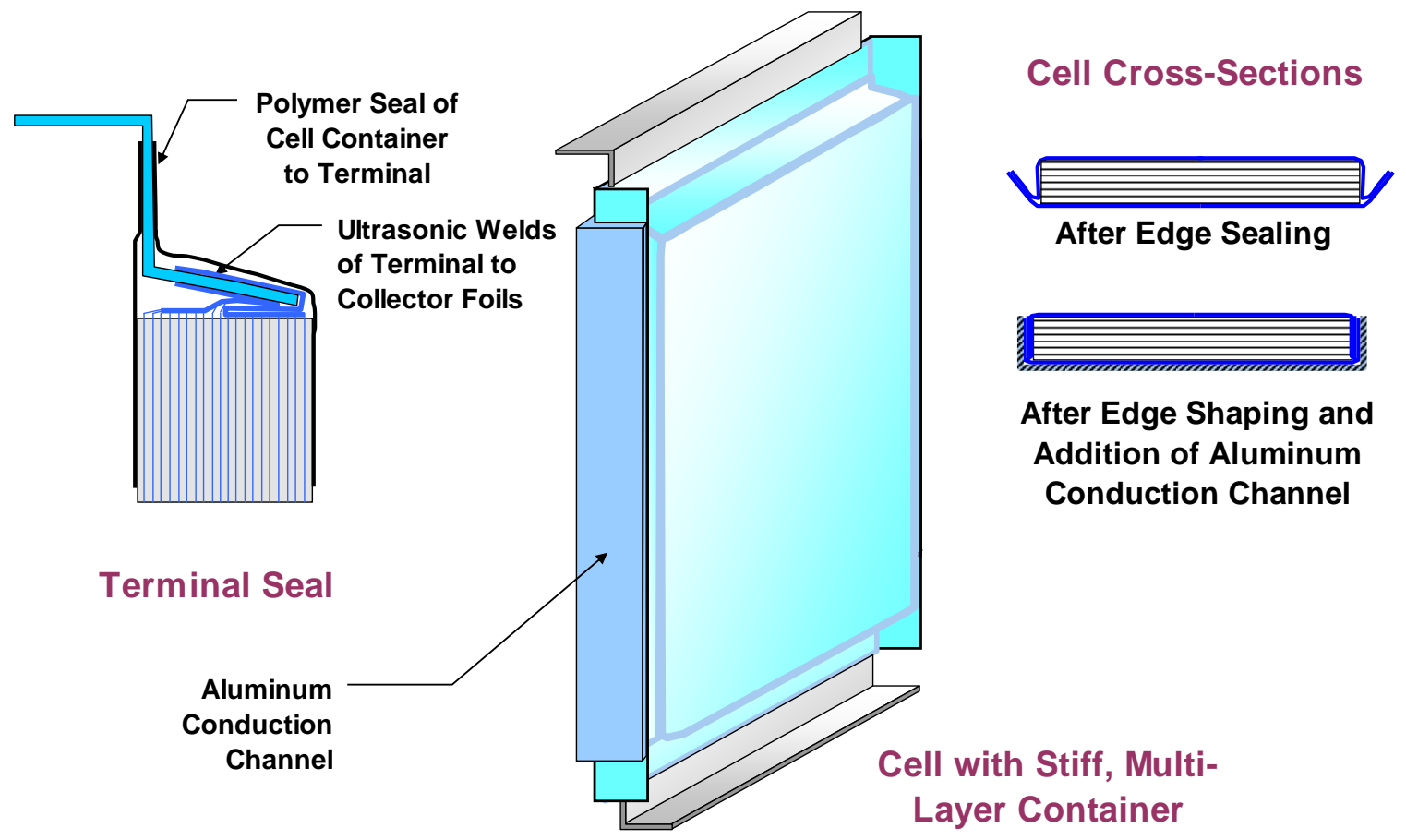

Figure 2.1 Prismatic cell in stiff pouch container with aluminum conduction channel added for heat rejection 
The cells are hermetically sealed in module containers, which are then enclosed in an insulated jacket. The module enclosure provides added protection of the cell seals from the diffusion of moisture from the external environment into the interior of the cells or alternatively loss of electrolyte solvent from the cells. The exterior surfaces of the modules are cooled by ethylene glycol-water solution. The calculated electrical performance of a battery of this construction is near optimum and the configuration is compact and light-weight. We have not likely selected the most viable design in this short study; there may be serious flaws in some details. However, the calculated overall performance and low cost for the selected design will be challenging to match in actual production and will only be met by the most successful manufacturers, those that will dominate the market.

\subsection{Cell Design}

The prismatic cell of this design embodies individual positive and negative electrodes consisting of current collector foils coated with electrode materials on both sides. The current collectors are usually solid copper and aluminum foils for the positive and the negative. An illustration of a segment of the cell is detailed in Figure 2.2. Each electrode is made up of active material particles held together by a polymeric binder. A conductive additive, carbon black and/or graphite, is added to the positive electrode and sometimes to the negative electrode. The electrodes and separator each have porosity that is filled with the electrolyte solution. During discharge, the Li-ions move from the electrode particles into the electrolyte, across the separator, and then insert into the particles composing the opposite electrode. The electrons simultaneously leave the cell through the current collection system and then enter through the opposite side after doing external work. The materials currently used in Li-ion cells are based on an intercalation process. In this process, the Li-ion is inserted into or removed from the crystal structure of the active material. The oxidation state of the active material, or host, is concurrently changed by gaining or losing an electron. Other electrode materials based on conversion reactions or electrodeposition could be implemented into the model if the user desired.

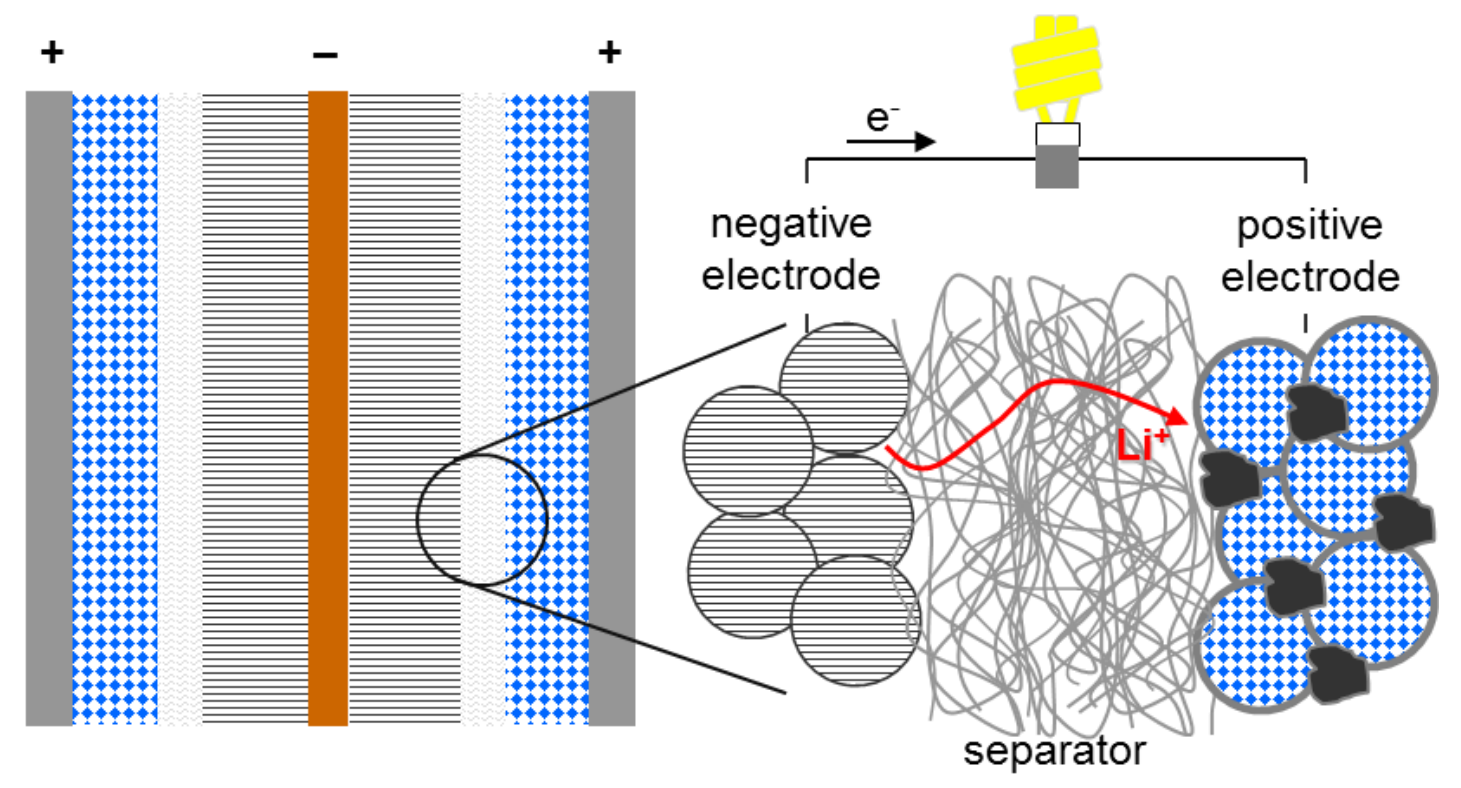

Figure 2.2 Cell sandwich inside of prismatic pouch cells. 
The electrodes are easily and efficiently prepared by coating wide sheets of foil (up to 2-meters in width) with uncoated strips running the lengths of the foil being coated. The individual electrodes can be cut from these sheets with little waste of electrode coating material or foil (Fig. 2.3). The separator for these cells can be handled as a single sheet that is folded back and forth as the electrodes are inserted. The electrodes are inserted so that all of the positive tabs extend beyond the separator sheet in one direction and the negative tabs extend in the opposite direction. The design model selects the number of electrodes to meet a set cell thickness determined by the type of cell: HEV, $6 \mathrm{~mm}$; PHEV, $8 \mathrm{~mm}$; EV, $12 \mathrm{~mm}$. These cell thicknesses are default values and may be changed to suit the designer. The cell terminals are formed from flat stock to be almost as wide as the entire cell. They are bent to the shape shown in Fig. 2.1 and ultrasonically welded to the current collector tabs. The cell stack is then sealed between the two halves of the cell container. The cell housing material is a tri-layer consisting of an outer layer of polyethylene terephthalate (PEP) for strength, a middle layer of $0.1-\mathrm{mm}$ aluminum for stiffness and impermeability to moisture and electrolyte solvent vapors and an inner layer of polypropylene (PP) for sealing by heating. ${ }^{22,23}$ The two halves of the cell container are pre-shaped to facilitate assembly. The aluminum foil in the cell container material provides stiffness and it may be increased in thickness to assist in conducting heat to the module container. After sealing the edges of the cell, the edges are flattened along the sides of the cell to form a compact shape and an aluminum conduction channel is added to assist in heat rejection at the sides of the cells.

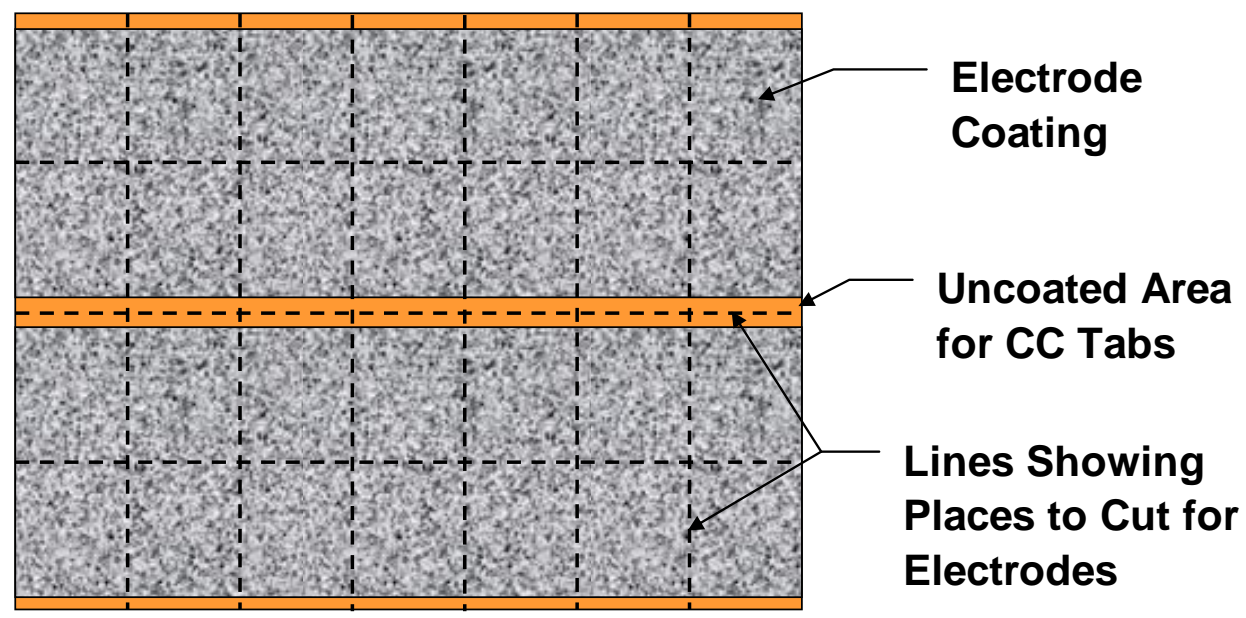

Figure 2.3 Illustration of coated current collector foil showing four rows of prismatic electrodes before slitting or stamping into individual electrodes

\subsection{Module Design}

The module format is based on a casing of $0.5-\mathrm{mm}$ thick aluminum that is sealed by double seaming, a process that is well established and inexpensive because it is automated, rapid, and uses low-cost equipment that is common in the container industry. The sealing of the module provides an additional barrier to the loss of electrolyte solvent from the cells and the entrance of water vapor. These deleterious transfers through the seals of pouch cells may shorten their lives to less than the desired fifteen years. ${ }^{22}$ 


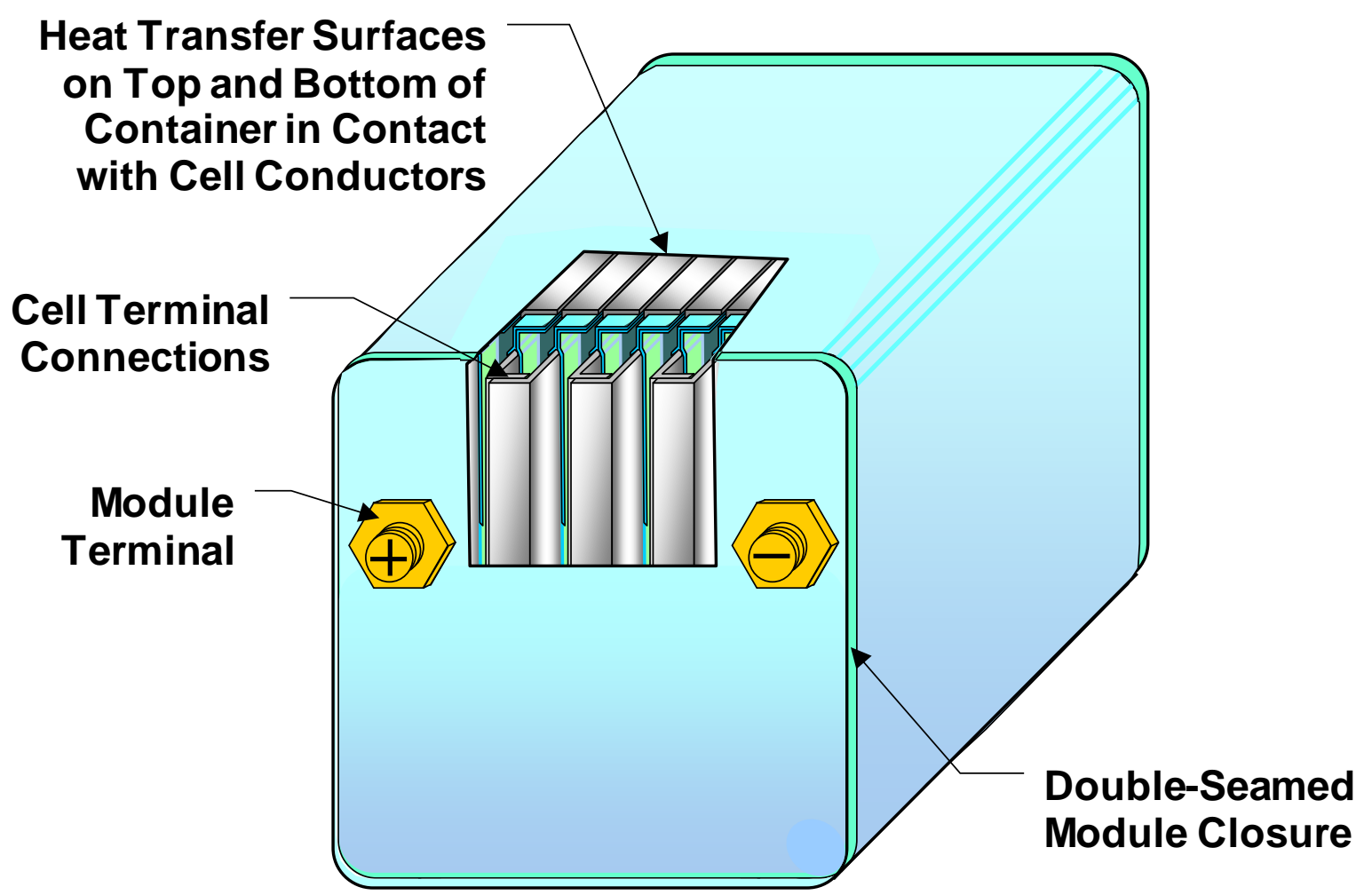

Figure 2.4 Hermetically-sealed module

The cells are placed on their sides in the module and the terminals of adjacent cells are connected either mechanically with small bolts and flat springs to maintain contact or by laser welding. Space is provided within the module casing on the left side, as sketched in Fig. 2.4, for an electronics package that includes cell monitoring for malfunctions (temperature and voltage) and for state-of-charge (SOC) control. The SOC control is activated when ever the battery is at rest and it diverts charge from the cells at highest voltage to those at lowest voltage.

\subsection{Battery Pack Design}

The model designs the battery pack (Fig 2.5) in sufficient detail to provide a good estimate of the total weight and volume of the pack and the dimensions of the battery jacket so that its cost can be estimated. The modules are arranged within the battery jacket either in a single row, with the terminals facing the same side of the pack, or in an even number of rows with the terminals in one row facing the terminal of an adjacent row. For a pack with a single row of modules, a busbar must be provided to carry the current to the front of the battery pack. This feature results in an additional cost for the busbar. For batteries with more than one row of modules (Fig. 2.5), the terminals are laid out on the module so as not to interfere with those on the opposite row of modules, thus conserving space in the battery pack. The modules in a row are interconnected, negative to positive terminals, by copper connectors. The module casings are compressed together by two steel sheets bound with steel straps at the front and back of the battery pack. The compression is necessary to ensure intimate contact between the active layers that make up the pouch cells that are tightly fit into the modules. For selected chemistries that change volume slightly during cycling, pressure can be maintained by employing a load-following tension approach using a leaf spring or spring washers. 


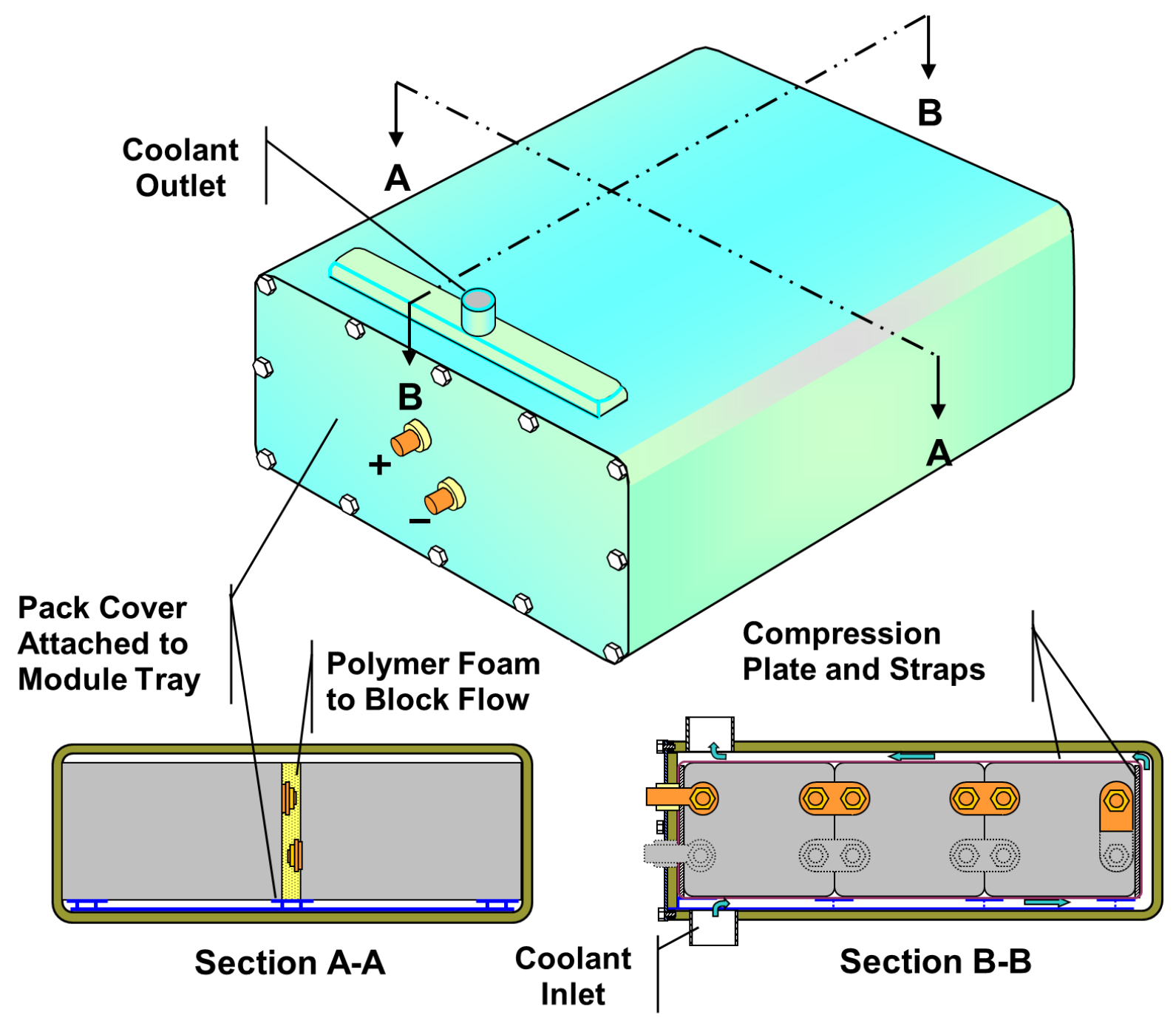

Pack with Two Rows of Modules

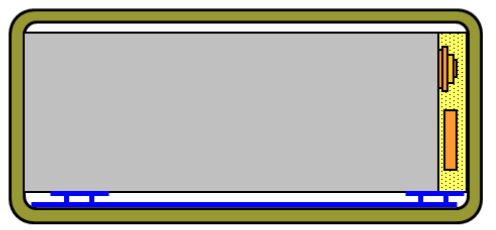

Section A-A

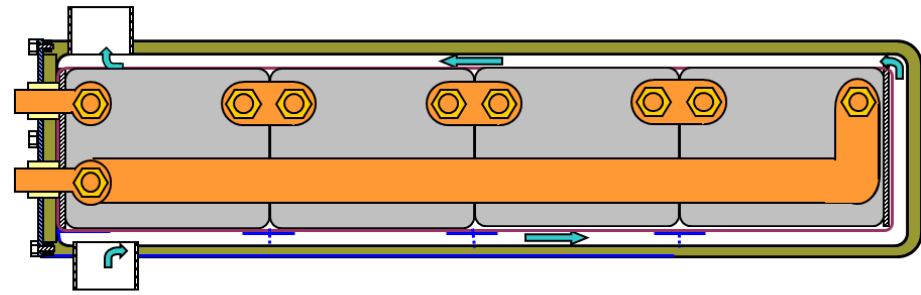

Section B-B

\section{Pack with One Row of Modules}

Figure 2.5 Insulated battery jacket with enclosed modules that are cooled on their upper and lower surfaces by ethylene glycol-water solution

The modules are supported by a tray that provides space for the heat transfer fluid (ethylene glycol-water solution) to flow against the top and bottom of each module. All connections to the pack terminals that lead to the exterior of the pack and signal wire feedthroughs can be made 
before inserting the attached modules into the jacket and making the final closure. The bolts depicted in the diagram (Fig 2.5) for making this closure are for illustrative purposes only.

The battery jacket consists of a sheet of aluminum on each side of a 10-mm thick layer of ridged, light-weight high-efficiency insulation. The thickness of each of the aluminum layers is selected by the modeling program to be 1- to 2-mm thick, depending on the total volume of the modules. The insulation slows the interaction of the battery with the external environment that cools the battery in the winter and heats it in the hot summer weather. ${ }^{16}$

Although the main purpose of the battery pack design for the model is to provide a plausible list of materials to estimate the manufacturing cost of the battery, the overall design approach permits the battery to be shaped by the designer to fit dimensional objectives. If there is a height restriction for the battery pack, a high ratio of height-to-width for the positive electrode will result in a battery of low height (the cells are placed on their side in the pack). 


\section{Modeling of Battery Design and Performance}

The design portion of the model calculates the physical properties of a battery based on userdefined performance requirements and minimal experimental data. An illustration of the model is shown in Figure 3.1. The user is asked to enter a number of design parameters such as the battery power, number of cells and modules, and target voltage at maximum power, etc. In addition, the user must enter one of the following three measures of energy: battery pack energy, cell capacity, or vehicle electric range. Defining one of these values will determine the value of the other two. An iterative procedure then solves for the user defined energy parameter (energy, capacity, or range) and remaining battery properties by varying the cell capacity and electrode thickness. The result is the dimensions, mass, volume, and materials requirements for the cells, modules, and battery pack.

The model has been designed to allow the user to enter as many customized values as desired. In this way, the model allows flexibility in the battery chemistries studied and some of the cell, module, and battery design aspects. Hence, the focus of this report is on the method of calculation and not the exact values chosen for a specific capacity or cell thickness. However, the default cell design parameters as well as experimental data measured at Argonne National Laboratory, for a number of different battery chemistries both commercial and developed at Argonne, are available for use within the model. There are five governing equations for battery performance that calculate the current density, battery energy, electrode area, electrode thickness, and resistance. The voltage at maximum power and the area specific impedance (ASI) are two important parameters in the design model for calculating the battery performance. Most of the discussion will be spent on these two properties.

\subsection{Criteria for Power, Energy, and Life}

In order to fully specify a battery design, the user of BatPaC must supply criteria for power, energy, and life. These criteria will depend on the application for which the battery will be used. While the users may change some of the settings as they prefer, we list our suggestions in Table 3.1. The battery type is defined by the end-use application. Hybrid electric vehicles (HEVs), plug-in hybrid electric vehicles (PHEVs), and electric vehicles (EVs) have increasing levels of electrical energy storage for use by the vehicle drivetrain. The model will use Table 3.1 or the user's explicit inputs to size the battery correctly for the chosen application.

Table 3.1 Criteria for designing batteries for a specific end-use application

\begin{tabular}{|l|c|c|c|c|}
\hline Battery Type & microHEV & HEV-HP & PHEV & EV \\
\hline SOC for Rated Power, $\%$ & 50 & 50 & 25 & 25 \\
\hline Power Duration, sec & 2 & 10 & 10 & 10 \\
\hline SOC Range for Useable Energy, \% & $40-65$ & $40-65$ & $25-95$ & $15-95$ \\
\hline Cell Thickness, mm & 6 & 6 & 8 & 12 \\
\hline
\end{tabular}

The microHEV is a micro or mild-hybrid that provides a moderate power level, $\sim 25 \mathrm{~kW}$, for two seconds. This design is best suited for cell chemistries capable of very high power-to-energy $(\mathrm{P} / \mathrm{E})$ ratios. The HEV-HP is a power-assist hybrid that provides the rated power for a full 10 
second pulse. The power for both HEV applications is rated at $50 \%$ state-of-charge (SOC). The energy available for discharge and charging is $25 \%$ of the total energy to ensure long cycle life. As the capacity of the HEV cells is typically small, a cell thickness of $6 \mathrm{~mm}$ is used. The PHEV utilizes a much larger portion of the total energy, $70 \%$. At the end of discharge, the PHEV battery is operated in a charge sustaining mode. Therefore, the power rating for the battery is determined at $25 \%$ SOC. PHEV cells should be much larger than HEV cells and thus a cell thickness of $8 \mathrm{~mm}$ is assumed. Finally, EV batteries use $80 \%$ of their total energy with their power rated near the end of discharge. EV cell thicknesses are set to $12 \mathrm{~mm}$.

\section{Battery Design Model}

\section{Pack Requirements}

- power

- energy or range

- number of cells
Key Constraints

- max electrode thickness

- target cell potential, $\mathrm{V}$, at peak power

- assumed cell/module format

\section{Iterative Spreadsheet \\ Solves for cell capacity and designs battery pack by varying: \\ 1. Cell area \\ 2. Electrode thickness \\ 3. Internal resistance}

\section{Cell Chemistry}

Measured Properties

- pulse power ASI

- sustained discharge ASI

- $\mathrm{mAh} / \mathrm{g}, \mathrm{g} / \mathrm{cm}^{3}$

- electrode porosity

- SOC window

- physical properties

ASI = area specific impedance
Calculated Battery

Properties

- volume \& mass

- specific energy, power

- materials required

Figure 3.1 Summary flow of the design model 
As noted later in the report, selecting a parallel arrangement of cells automatically assumes a cell thickness of $6 \mathrm{~mm}$ regardless of the end-use application. Additionally, the use of negative electrodes operating at potentials high above the lithium metal potential may extend the upper end of the available SOC range from 95 to $100 \%$. The lithium titanate spinel, $\mathrm{Li}_{4} \mathrm{Ti}_{5} \mathrm{O}_{12}$ (LTO), negative electrode is an example of an intercalation electrode with almost no risk of plating lithium metal during a charge pulse. On this basis, the available energy for LTO-based Li-ion cell is increased by $5 \%$ to be $75 \%$ for PHEVs and $85 \%$ for EVs. In an established factory, the fixed design parameter is most likely the electrode area for a single layer rather than a set cell thickness. To make higher capacity cells, more layers of the predetermined footprint are stacked, thus increasing the cell thickness. In our model, the plant is constructed for the sole purpose of building the battery being designed. Flexibility to produce other products is not taken into account. Most importantly, the model calculates very little difference in cost whether the cell has large-area layers that are few in number as compared to a high number of layers smaller in area. For ease of calculation, we use a set cell thickness to determine the number of layers. The area of each layer is set by the cell capacity requirement.

Accounting for capacity and power fade in the battery requires the user to design the battery with the appropriate excess energy and power at the beginning-of-life (BOL). Achieving rated end-oflife (EOL) power at a high fraction of the open-circuit voltage at BOL is one way to set the allowable power fade over the life of the battery. This is discussed in detail in the following section. Capacity or energy fade may be managed in multiple ways. The BOL SOC range for useable energy in Table 3.1 may be considered one approach to oversizing. As the battery capacity is reduced resulting from fade mechanisms, the loss in total capacity and energy is not as obvious when only cycling in the reduced SOC range. In addition, the SOC window may shift to different defined pack voltages to obtain a near constant useable energy value. Current practices by the OEMs suggest that the customer will accept some degree of capacity fade from the battery over the life of the vehicle. The Chevrolet Volt battery warranty states the capacity may fade by $10-30 \%$ over the warranty period. Certainly, the customers' previous experience with consumer electronics devices has prepared them for a reduction in battery capacity with the life of the product. However, we do not hold the same opinion on power fade. We have allotted for significant power fade by designing EOL power to be achieved at a high fraction of the open circuit voltage at BOL. The design model does not attempt to predict fade rates or even suggest an allowable fade for a specific application, other than the SOC window for useable energy. It is our view that many aspects of materials chemistry, cell design, and battery use directly affect the decay rate of the battery pack. Hence, we allow the user to make any additional accommodations for decay believed to be necessary by entering larger total energy content than what is calculated from the useable SOC windows.

\subsection{Voltage at Rated Power}

The voltage at which a cell reaches the rated power is one of the most important factors in the design of a battery. However, this specification is one of the least discussed aspects of battery design. Our design approach assumes the drivetrain will never draw a power level greater than the rated power over the entire life of the battery. The voltage at rated power is a measure of the largest polarization the cell will undergo during operation at the BOL. This initial value has a 
direct effect on round-trip battery efficiency, heat removal requirements, cold-cranking power, and allowable power fade. A basic calculation demonstrates the maximum achievable power for a battery at BOL is at $50 \%$ of the open-circuit voltage (OCV). Operating at these conditions would result in an inefficient battery and require a significant cooling system to reject heat. More importantly, the battery will never be able to reach this power level after any increase in impedance occurs. With all certainty, the impedance of a battery will rise with time and the power rating of battery will no longer be accurate.

We design the battery to achieve EOL power capabilities (rated power) at a specified fraction of the open-circuit voltage, [V/U], at BOL. This approach is unique when compared to current design practice of OEMs and cell manufacturers. However, a characteristic value of [V/U] exists for all batteries regardless of the battery design process. One may determine this value for an existing system in a straightforward manner. The voltage at rated power is measured at the end of a $10 \mathrm{~s}$ pulse at the EOL power rating and the SOC used for the power rating of a specific battery type (HEV, PHEV, EV). The designed [V/U] value is the measured potential at the end of the pulse divided by the open-circuit potential reached long after the pulse. This design point then captures the degree to which the battery has been oversized to enable long-life, cold-start, and efficient operation. The remainder of this section presents a discussion for setting the BOL voltage at rated power at no less than $80 \%$ of the open-circuit voltage, $[\mathrm{V} / \mathrm{U}]=0.8$. Defining the voltage as a fraction of the $\mathrm{OCV}$, allows for direct calculation of all the necessary battery properties (see for example Eq. 3.6 or 3.8 in the section 3.3).

The allowable increase in battery resistance over the life of the battery is a function of the designed voltage for rated power. In general, designing the battery to achieve rated power at a higher $[\mathrm{V} / \mathrm{U}]$ allows for larger resistance or impedance increases over the lifetime of the battery. Figure 3.2 created from Eq 3.1 displays how the voltage at rated power will change to meet the designed power as the internal resistance of the battery increases. Clearly, achieving BOL power at a high fraction of the OCV allows for greater degradation within the usable lifetime of a battery. $R_{1}$ is the initial resistance of the battery at BOL while $R_{2}$ is the resistance as the battery ages. If the minimum voltage is $55 \%$ of the $\mathrm{OCV}$, the allowable increase in resistance for batteries designed for BOL rated power at 70, 80, and $90 \% \mathrm{OCV}$ is 18,55 , and $175 \%$. The consequence of achieving the power at lower and lower fractions of the open-circuit voltage is that both electric current and heat generation will increase over the lifetime of the battery, Figure $3.2 \mathrm{~b}$ and Figure 3.3. The proper design of a battery will account for the changes over the entire lifetime and not just desired behavior at BOL.

The level of heat production is significantly different at BOL for batteries designed to meet rated power at differing fractions of the open-circuit voltage. We may compare the differences in designed $[\mathrm{V} / \mathrm{U}]$ by assuming the resistive heating (joule heating) is the most significant factor in determining the heat generation, Eq. 3.2. This assumption is true for moderate to high rate applications. We also reasonably assume the ASI will not change significantly in the range of current densities and electrode thicknesses we vary in the comparisons. We can analyze the difference in heat generation for different [V/U] values, Eq 3.3. 

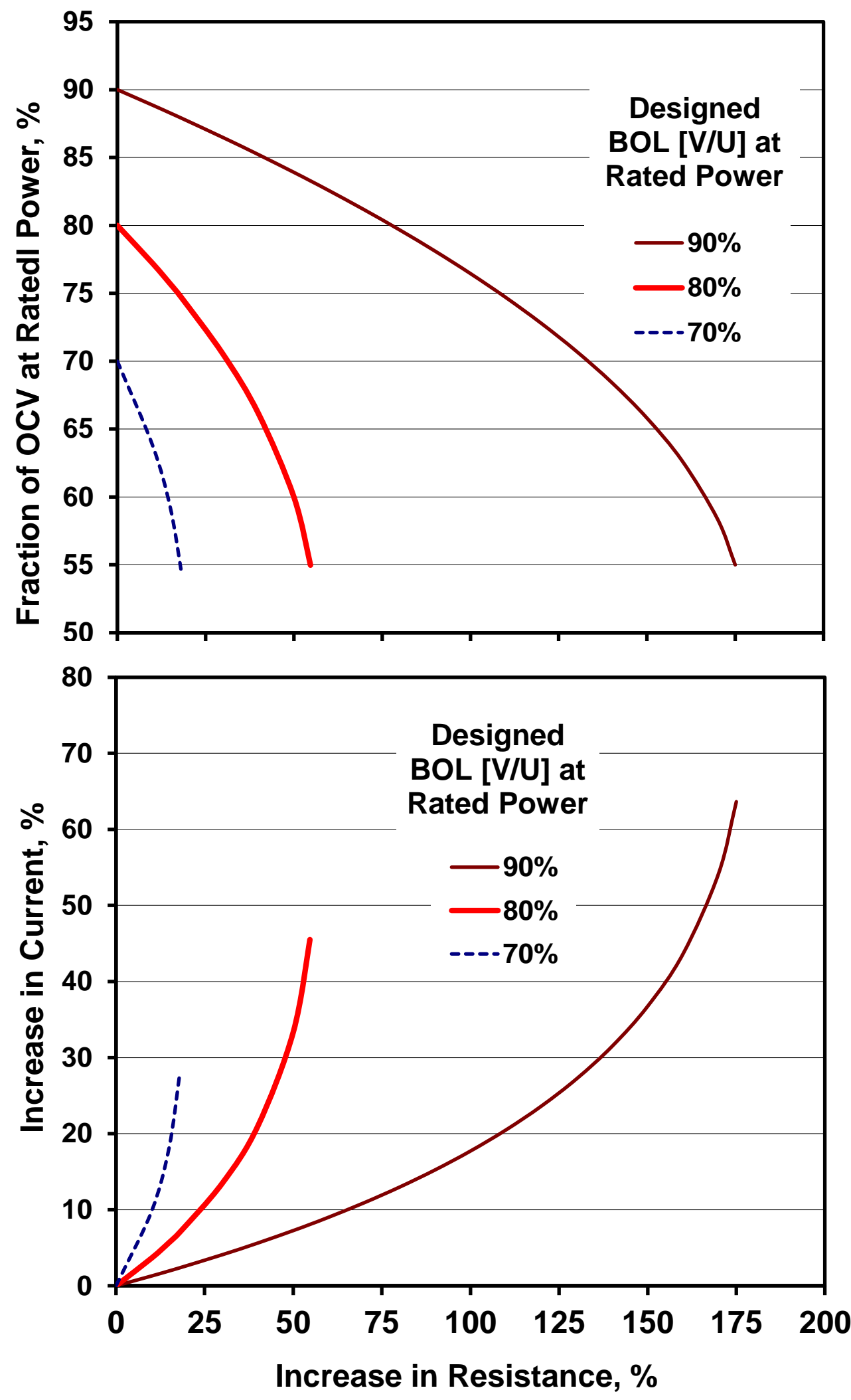

Figure 3.2 a) Required change in [V/U] to maintain rated power with increases in internal resistance over the life of the battery. b) Increase in current due to lowered [V/U]. 


$$
\begin{gathered}
{\left[\frac{V}{U}\right]_{2}=\frac{1}{2}\left\{1+\sqrt{1-4 \frac{R_{2}}{R_{1}}\left[\frac{V}{U}\right]_{1}\left(1-\left[\frac{V}{U}\right]_{1}\right)}\right\}} \\
q_{j}=\left(A_{\text {pos }} I\right)^{2} R_{j}=I_{\text {total }} U\left(1-\left[\frac{V}{U}\right]_{j}\right)=\frac{U^{2}\left(1-\left[\frac{V}{U}\right]_{j}\right)^{2}}{R_{j}} \\
\frac{q_{2}}{q_{1}}=\frac{R_{1}\left(1-\left[\frac{V}{U}\right]_{2}\right)^{2}}{R_{2}\left(1-\left[\frac{V}{U}\right]_{1}\right)^{2}}
\end{gathered}
$$

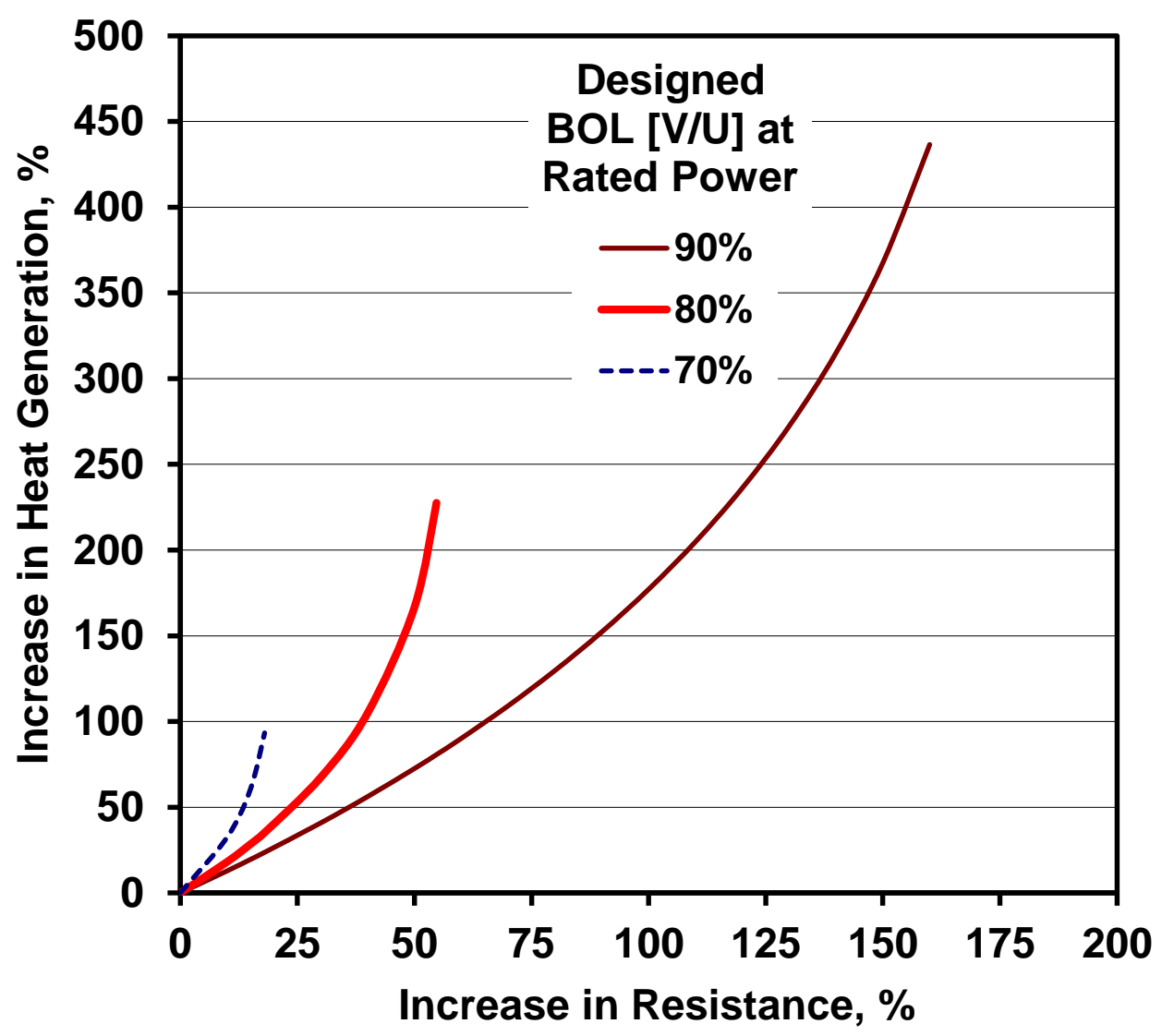

Figure 3.3 Change in heat rejection requirement from increases in resistance for batteries with different designed voltages at rated power.

The ratio of resistances may be found by equating the power for the two cases. Then the resistances, and areas if the ASIs are equivalent, are determined solely by the fraction of the open-circuit voltage at which they achieve rated power, Eq 3.4. Then substitution will give the 
ratio of heat production at rated power for the two cases, Eq. 3.5. A battery that achieves rated power at $80 \%$ of OCV will have a heat production at rated power that is 2.3 times higher than one designed at $[\mathrm{V} / \mathrm{U}]=90 \%$. A battery producing power at $70 \%$ of the OCV will have 3.9 time higher heat generation than at $[\mathrm{V} / \mathrm{U}]=90 \%$.

$$
\begin{gathered}
\frac{R_{1}}{R_{2}}=\frac{A S I_{\text {power } 1} A_{\text {pos } 2}}{A S I_{\text {power } 2} A_{\text {pos } 1}}=\frac{\left[\frac{V}{U}\right]_{1}\left(1-\left[\frac{V}{U}\right]_{1}\right)}{\left[\frac{V}{U}\right]_{2}\left(1-\left[\frac{V}{U}\right]_{2}\right)} \\
\frac{q_{2}}{q_{1}}=\frac{\left[\frac{V}{U}\right]_{1}\left(1-\left[\frac{V}{U}\right]_{2}\right)}{\left[\frac{V}{U}\right]_{2}\left(1-\left[\frac{V}{U}\right]_{1}\right)}
\end{gathered}
$$

Two different design changes would enable operating a battery at $90 \%$ of OCV compared to 80 $\%$ while maintaining the same power output. First, a second identical battery may be connected in parallel to the original battery. This will lower the resistance of the battery pack by one half but will also double the energy and cost of the battery. A more cost-effective approach is to reduce the electrode thickness by coating a larger separator area with the same amount of active material. The capacity of the cell is maintained while minimizing increases in cost from a larger separator, current collector and packaging area. This approach is feasible as long as the reduced electrode thickness is above the increase in ASI, > 20 microns as discussed in detail below.

The efficiency of a battery defines the heat rejection requirements and may be measured or calculated. Measurement of round-trip efficiency of a battery is best performed by using a calorimeter to measure the heat given off during the cycling of the battery. The calorimeter removes the requirement of knowing the exact SOC of a battery during the entire drive cycle. Calculation of the round-trip efficiency of a battery requires a detailed transient battery model within a vehicle simulation program to exercise the battery over the many acceleration and deceleration periods that occur during a drive cycle. The interesting result is that the same battery will have different power ratings depending on what level of round-trip efficiency the user is willing to accept.

Figure 3.4 shows the efficiency of a battery as a function of the designed potential at which the battery reaches rated power. The figure is created using Equations 3.1 and 3.4 above. Each line may be considered a different drive cycle, or duty load, for a battery with the same energy but different impedance (changing separator area). The straight, solid black line represents the efficiency of the battery operated only at rated power, $P / P_{\max }=1$. In example, a battery designed at $[\mathrm{V} / \mathrm{U}]=0.8$ will have $80 \%$ efficiency for a single discharge pulse at rated power. Likewise, a battery designed at 0.9 will be $90 \%$ efficient at rated power. Batteries are normally operated in the area above the line of the rated power. Therefore, the other curves represent the efficiency of discharging a battery at power levels below rated power (typical driving conditions). Consider 
two batteries each designed for a rated power of $100 \mathrm{~kW}$ although one achieves this power at a $[\mathrm{V} / \mathrm{U}]=0.9$ and the other at 0.7 . If the two batteries are discharged at $45 \mathrm{~kW}, P / P_{\max }=0.45$, the battery designed at $[\mathrm{V} / \mathrm{U}]=0.9$ will be $6.4 \%$ more efficient. This is significantly less than the 20 $\%$ efficiency improvement realized when operated at rated power. The efficiency penalty is reduced as the battery operates less and less near the rated power.

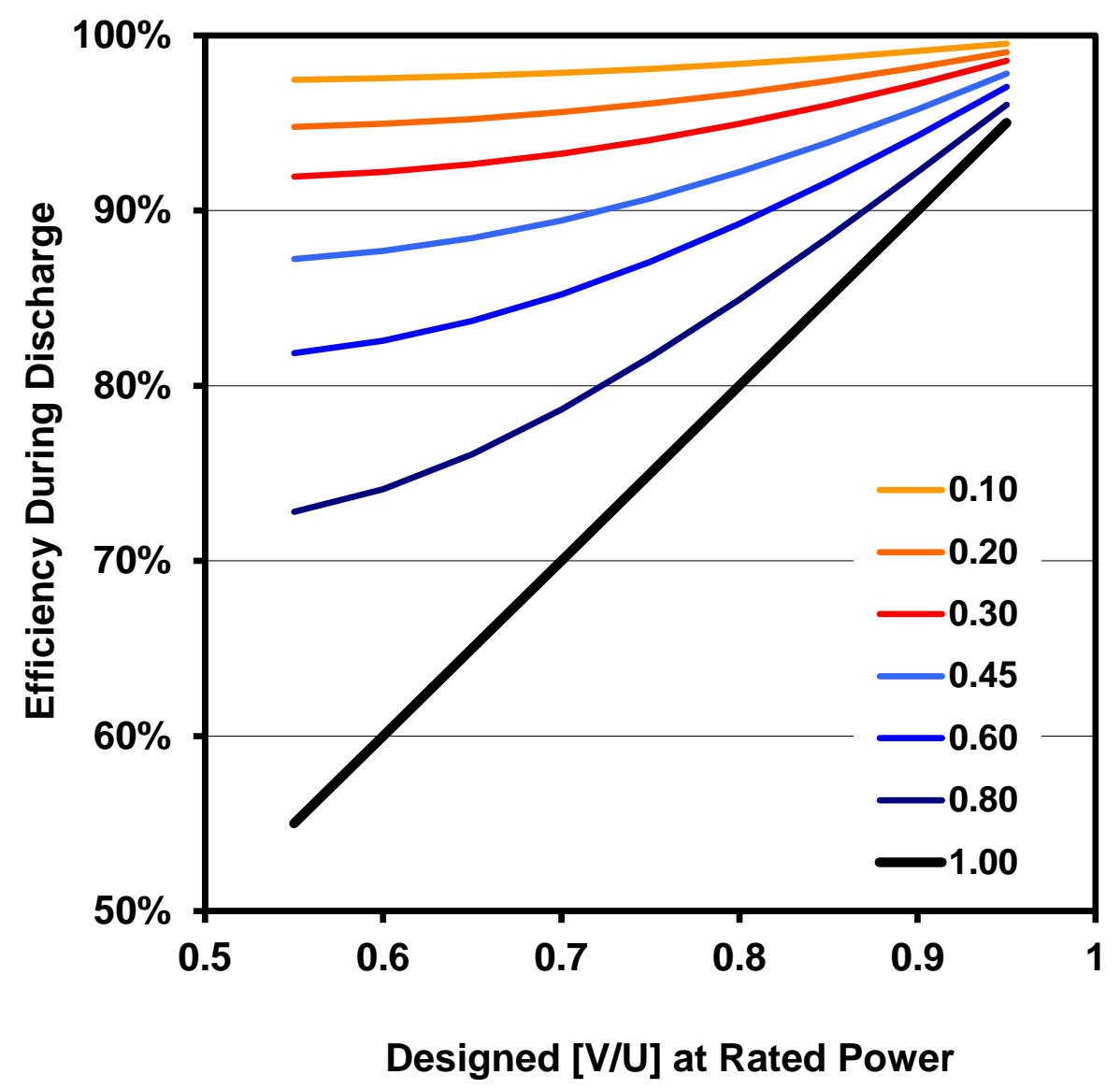

Figure 3.4 Efficiencies for batteries designed to achieve rated power at different fractions of their open-circuit voltage. Comparative efficiency lines are shown for equivalent power demands over a period of battery operation. 


\subsection{Governing Equations}

The five coupled, algebraic equations that govern the battery design are presented in this section. While these equations are perhaps the most important, many other equations are used to fully define the battery mass and volume. These other equations will be specified where necessary in the following subsections.

The user of the model specifies the required maximum rated power, $P_{\text {batt }}$, of the battery. This power is translated to a current density, $I$, in Eq 3.6 using the area of the positive electrode, $A_{\text {pos }}$, the number of cells, $N_{\text {cell }}$, the open-circuit voltage at the SOC for power, $U_{\text {ocv, }}$, and the fraction of the open-circuit voltage at which the designed power is achieved, [V/U].

$$
I=\frac{P_{b a t t}}{A_{p o s} N_{c e l l} U_{o c v, P}\left[\frac{V}{U}\right]}
$$

The relationship between capacity and battery energy is described by Equation 3.7. Formally, the energy of a battery is the product of the capacity and the average voltage at which the energy is obtained. The average cell voltage is approximated in Eq. 3.7 by subtracting the polarization from discharging the battery at a $\mathrm{C} / 3$ rate from the open-circuit voltage at the SOC for energy, $U_{\text {ocv,E}}$. The energy for all batteries designed by the model is calculated at a $\mathrm{C} / 3$ rate and the average open-circuit voltage at $50 \%$ SOC. The remaining necessary values are the capacity of the cell, $C$, ASI for energy, $A S I_{\text {energy }}$, number of cells, and area of positive electrode. Either the battery energy or capacity may be specified. The energy may alternatively be determined from a stated range, fraction of total energy available, and energy usage rate for the vehicle ( $\mathrm{Wh} / \mathrm{mile})$.

$$
E=N_{c e l l} C\left(U_{o c v, E}-\frac{C}{3} \frac{A S I_{\text {energy }}}{A_{p o s}}\right)
$$

The area of the positive electrode in Eq. 3.8 is determined largely by the area specific impedance for power, $A S I_{\text {power }}$, and resulting voltage drop. The voltage of cell at rated power, $V_{\text {cell, }, \text {, is found }}$ from the product $[\mathrm{V} / \mathrm{U}] U_{\mathrm{ocv}, \mathrm{P}}$, where $U_{o c v, P}$ is the open circuit voltage at the SOC for max power. In general, the area of the electrodes will increase if the ASI for power increases. The areas of the negative electrode and separator are determined from the area of the positive electrode. The negative electrode is taken to be $1 \mathrm{~mm}$ larger than the positive electrode in both height and width to alleviate concerns of lithium plating during charge pulses. The separator area is slightly larger than the negative electrode to prevent the electrical shorting of the two electrodes.

$$
A_{\text {pos }}=\frac{A S I_{\text {power }} P_{\text {batt }}}{N_{c e l l}\left(U_{o c v, P}\right)^{2}\left[\frac{V}{U}\right]\left(1-\left[\frac{V}{U}\right]\right)}
$$

The positive electrode thickness, $L_{\mathrm{pos}}$, in Eq. 3.9 is determined from the capacity of the cell, $C$, specific capacity of the electrode material, $Q$, volume fraction of active material, $\varepsilon_{\text {act }}$, bulk 
density of the active material, $\rho$, and the positive electrode area. The negative electrode thickness is determined by its specific reversible-capacity and the designed excess-capacity to prevent lithium plating during charging. We have chosen a ratio of 1.25 negative to positive reversiblecapacity (N/P ratio) for the default value for the cells with graphite negative electrodes. LTO negative electrode based cells are designed at a $1.1 \mathrm{~N} / \mathrm{P}$ ratio because of the previously mentioned minimal possibility of lithium deposition. The maximum allowable electrode thickness is a user defined value. The calculation for the electrode area changes when the designed thickness is greater than the maximum allowed (Section 3.6.1).

$$
L_{p o s}=\frac{C}{Q \rho \varepsilon_{a c t} A_{p o s}}
$$

Finally, the ASI for power (and for energy to a lesser extent) is calculated using an expression that is based on the electrode thicknesses, the current density, and the C-rate. The exact expression will be discussed in the next session. The ASI in Eq 3.10 shows the basic dependencies with $\alpha$ and $\beta$ being constant valued parameters.

$$
\mathrm{ASI}=\frac{\alpha+f(I)}{L_{p o s}}+\beta
$$

\subsection{Calculation of the ASI}

In most battery design scenarios, the ASI and [V/U] directly determine the electrode thickness and area to meet a specified power-to-energy $(\mathrm{P} / \mathrm{E})$ ratio and capacity requirement. Clearly, the ASI plays a significant role in the design of a battery and particularly in the case of the P/E ratios required by automotive applications. However, the ASI is not an inherent constant of a specific battery chemistry or cell design. The measured value of the ASI is a complex combination of resistances within the battery resulting from the physical processes occurring at different length and time scales. Consequently, the measured value is a function of many factors (state of charge, pulse length, current density, C-rate, particle size, transport and kinetic parameters, etc). The calculation used for the ASI in this battery design model has been discussed in detail and validated against experiments elsewhere. ${ }^{20}$ The physical meaning of the equation will be discussed but those interested in the derivation are directed to the separate publication. We note that the ASI described here is slightly different than the one addressed in the paper. The thermodynamic component is removed that originated from the change in open-circuit potential with concentration for the intercalation materials. Equation 3.11 contains the definition of the ASI used in this document. $I_{\mathrm{t} 1}$ is a positive valued current density for a discharge pulse. $I_{\mathrm{t} 2}$ is equal to zero as it is during the relaxation period after the pulse. The subscripts are as follows: time $0, t 0$, is the time just before a current pulse begins, time $1, t 1$, is the time just before the current pulse ends, and time $2, t 2$, is the time long after the current pulse when the cell is at opencircuit and the concentration gradients have relaxed. Therefore, this ASI measurement is not troubled by accounting for a change in open-circuit voltage with the passage of current. In general, the ASI measured with this definition is similar, although smaller, in value to those produced using the more standard definition used elsewhere. 


$$
A S I=\frac{V_{t 2}-V_{t 1}}{I_{t 1}-I_{t 2}}
$$

The ASI for the electrochemical charge and discharge process is referred here-in as $A S I_{\text {echem }}$. Our calculation approach for both the ASI for power and for energy involves adding three components together to reach the $A S I_{\text {echem }}$, Eq. 3.12. The first two factors include impedance that arises from the interfacial charge transfer and transport. The third factor is a lumped parameter used to capture the remaining impedance.

$$
A S I_{\text {echem }}=A S I_{\text {intf }}^{\text {pos }}+A S I_{\text {intf }}^{\text {neg }}+A S I_{\text {const }}
$$

The interfacial impedance for positive and negative electrodes both contain the charge transfer resistance component $\bar{R} T /\left(i_{o} a L F\right)$ as shown in Eq. 3.13 and 3.14. Here, $i_{o}$ is the exchange current density related to the interfacial area and $a$ is the ratio of interfacial area to electrode volume. An approximation often used for $a$ relates the parameter to the volume fraction of the active material and the particle radius, $a=3 \varepsilon_{\mathrm{act}} / \mathrm{r}_{\mathrm{p}}$. The variables $i_{o}$ and $a$ should be specified to relate to the same area as they are often not independently determined. $\bar{R}$ and $T$ correspond to the universal gas constant and absolute temperature respectively. $F$ is Faraday's constant. The influence of the interfacial impedance is that the $A S I_{\text {echem }}$ increases as the electrode thickness is reduced. This behavior is typically observed at electrode thicknesses less than 30 microns for common Li-ion battery materials.

$$
\begin{gathered}
A S I_{\text {intf }}^{\mathrm{neg}}=\frac{\bar{R} T}{i_{o} a L_{n e g} F} \\
A S I_{\mathrm{intf}}^{\mathrm{pos}}=\frac{\bar{R} T}{i_{o} a L_{\text {pos }} F}\left\{\left(1-\frac{I}{I_{\text {lim }}^{\text {ionic }}}\right)\left[1-\left(\frac{r_{C}}{r_{C, \mathrm{lim}}}\right)^{2}\right]\right\}^{-0.5}
\end{gathered}
$$

The positive electrode interfacial impedance also includes two factors that account for the physical limitations that occur from depleting the concentration of the reactants within the porous electrode. The $I_{\lim }^{\text {ionic }}$ term is the limiting ionic current for lithium cation transport through the porous separator. The $r_{C, \text { lim }}$ term is the limiting $\mathrm{C}$-rate for solid state diffusion of lithium in the active materials. The C-rate may be related to the current density with Eq. 3.15. Here, the specific capacity, $Q$, the active material density, $\rho$, active material volume fraction, $\varepsilon_{a c t}$, and the electrode thickness, $L$, are used. If either the limiting C-rate or limiting ionic current are approached, the ASI will begin to approach an infinite value. This approach assumes the cell and material design is such that the transport limitations all occur on the positive electrode. The parameters required for the ASI expression are fit to experimental measurements. The ASI values are corrected for the interfacial contributions present during measurement so that the correct ASI may be determined at different electrode thicknesses. This is termed "ASI correction factor" on the System Selection worksheet of the spreadsheet model. 


$$
I=r_{C} Q \rho \varepsilon_{a c t} L_{p o s}
$$

The cell ASI for energy, $A S I_{\text {energy }}$, and power, $A S I_{\text {power }}$, are determined by adding the $A S I_{\text {echem }}$ to that of the current collectors, $A S I_{c c}$, as discussed in the next subsection. The difference between $A S I_{\text {energy }}$ and $A S I_{\text {power }}$ is that the limiting currents are not important during the $\mathrm{C} / 3$ discharge for energy and the $A S I_{\text {const }}$ is a different value for two cases. $A S I_{\text {energy }}$ will always be higher than $A S I_{\text {power }}$ if a battery is operated far from the limiting current. The higher impedance is due to the formation of significant concentration polarizations during the longer time scale of the energy discharge. A reasonable rule-of-thumb is that the $A S I_{\text {const }}$ for energy is 2.2 times the value for power in layered oxide materials such as $\mathrm{LiNi}_{0.80} \mathrm{Co}_{0.15} \mathrm{Al}_{0.05} \mathrm{O}_{2}$.

\subsubsection{Current Collection Resistance}

The resistance from the conductors used to collect the current must be accounted for as they can contribute significant ohmic drop to the battery. The ASI used to calculate the required cell separator area, $A S I_{\text {power }}$, is larger than the ASI for the electrochemical charge and discharge processes, $A S I_{\text {echem, },}$, as shown in Equation 3.16. The $A S I_{\text {echem }}$ value is typically measured from experiments and must be added to the external resistances that arise from the materials used to conduct the electric current. These resistances come from current collection in the cell and also those on the module and battery pack level.

$$
A S I_{\text {power }}=A S I_{\text {echem }, P}+A S I_{c c}+A S I_{\text {term }}^{\text {cell }}+\frac{R_{c n c t} A_{\text {pos }}}{N_{\text {cells }}}
$$

The current collector foil impedance, $A S I_{c c}$, is determined from an analytical expression, Eq. 3.17, which accounts for the coated and uncoated region of the foil, labeled $a c t$ for active and $t a b$ respectively. The resistance factor, $R_{f}$, and the resistance of the current collector foils, $R_{c c}$, are also shown for clarity in Eq 3.18 and 3.19. The factor of 2 in the $R_{f}$ term is due to assuming half of the foil thickness carries the current produced on one side of the foil. While all of the current passes through the tab region, the magnitude of the current varies along the height of the coated foil as the reaction area continually contributes current to the foil. An equivalent length for the resistance calculation may be determined so that multiplication by the total current for a cell will give the correct ohmic drop. This equivalent length is $\mathrm{H} / 3$ if the current density is relatively constant over the entire area. The derivation of this equivalent length as well as an in-depth discussion of the voltage and current distribution in the foils may be found in subsection 3.4.2. Also in the later subsection, the assumption of constant current density is verified with numerical modeling.

$$
\begin{gathered}
A S I_{c c}=H_{a c t} W_{a c t} R_{c c}=R_{f}\left(\frac{\left(H_{a c t}\right)^{2}}{3}+H_{a c t} H_{t a b}\right) \\
R_{f}=\left(\frac{2}{\sigma_{\text {foil,neg }} L_{\text {foil,neg }}}+\frac{2}{\sigma_{\text {foil, pos }} L_{\text {foil }, p o s}}\right)
\end{gathered}
$$




$$
R_{c c}=R_{f}\left(\frac{H_{a c t}}{3 W_{a c t}}+\frac{H_{t a b}}{W}\right)
$$

The cell terminals are ultrasonically welded to the ends of the current collector foil tabs. While the welding removes this contact resistance, the ASI of the terminal must be included in the total cell resistance. The ASI of the cell terminals, $A S I_{\text {term }}^{\text {cell }}$, is the summation of the positive and negative cell terminals as shown in Eq 3.20. The dimensions for these terminals are set by the calculated width of the cell and the user defined terminal thickness and height.

$$
A S I_{\text {term }}^{\text {cell }}=\left(\frac{1}{\sigma_{\text {term,neg }}}+\frac{1}{\sigma_{\text {term, pos }}}\right) \frac{H_{\text {term }}}{W_{\text {term }} L_{\text {term }}} A_{\text {pos }}
$$

The ASI for connection losses is the last term in the ASI summation stated in Eq. 3.16. This ASI value is calculated by multiplying the ratio of cell positive electrode area to number of cells by the summation of the resistances, $R_{\text {cnct }}$, for cell terminals, module terminals, module interconnects, and batteries terminals. In this way, each cell shares in the burden of overcoming the system losses from carrying the electric current. The calculation of $R_{\text {cnct }}$ is detailed in Eq. 3.21 with the individual sources of connection losses shown. The voltage drop resulting from cell-to-cell contact resistance, $R_{\text {cntct }}^{\text {cell }}$, is taken to be $10^{-4} U_{\mathrm{ocv}, \mathrm{E}}$ in Eq. 3.22, a small fraction of the open-circuit voltage. A battery manufacturer would only tolerate a minimal voltage drop from cell-to-cell contact. One connection method is to physically press the two cell terminals together. This resistance could be lowered by increasing the physical pressure and contact area, or by laser welding the terminals together. Regardless, the value used in the model is left to the choice of the user to leave as is or to change to a different value.

$$
\begin{gathered}
R_{\text {cnct }}=N_{\text {cell }} R_{\text {cntct }}^{\text {cell }}+N_{\text {mod }} R_{\text {term }}^{\mathrm{mod}}+\left(N_{\mathrm{mod}}-1\right) R_{\text {incnt }}^{\mathrm{mod}}+R_{\text {term }}^{\text {batt }} \\
R_{\text {cnct }}^{\text {cell }}=10^{-4} \frac{N_{\text {cell }} U_{\text {ocv }, E}}{I A_{\text {pos }}}
\end{gathered}
$$

The module terminal resistance, $R_{\text {term }}^{\mathrm{mod}}$, calculation in Eq. 3.23 is shown as an example of how the terminal and interconnect resistances are calculated for the module and battery pack. The size of the terminals and thus their resistance are determined from a calculation based on a predetermined allowable rate of temperature rise for the conductor. This approach is explained in more detail in subsection 3.4.3.

$$
R_{\mathrm{term}}^{\mathrm{mod}}=\frac{H_{\text {term }}}{\sigma_{\text {term }} \pi\left(r_{\text {term }}\right)^{2}} N_{\text {term }}^{\mathrm{mod}}
$$




\subsubsection{Potential and Current Distribution in the Current Collection Foils}

The designed current collection system was evaluated using a numerical simulation package. Equations 3.24-3.26 were solved for a steady state, isothermal, and 1-D simulation. Here, the conductivity, $\sigma_{\mathrm{j}}$, is the effective conductivity of $1 / 2$ of the foil (the other half carries the current from the opposite side). The bulk conductivity value, $\sigma_{\mathrm{j}}^{0}$, is multiplied by the thickness of the conductor, $L_{\mathrm{j}} / 2$, to lower the dimension of transport.

$$
\begin{gathered}
I_{n}=\frac{U_{o c v}-\left(\Phi_{1, p o s}(x)-\Phi_{1, \text { eeg }}(x)\right)}{A S I_{\text {echem }}} \\
\nabla \cdot\left(\sigma_{p o s} \nabla \Phi_{1, p o s}\right)=-I_{n} \\
\nabla \cdot\left(\sigma_{\text {neg }} \nabla \Phi_{1, \text { neg }}\right)=I_{n}
\end{gathered}
$$

The boundary conditions were set for both ends of each foil. The tab ends of the foils were set to a specified voltage and the opposite ends of the foils were restricted to a no flux condition. The simulation was performed using the foils defined in our battery design: 12 micron thick copper

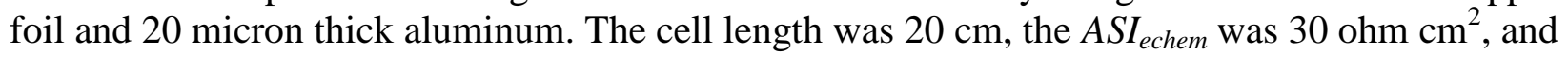
the $U_{o c v}$ and $V_{\text {cell }}$ were set to 3.72 and $3.57 \mathrm{~V}$ respectively. Figure 3.5 shows the current and potential distribution in the foils and in the cell resulting from the simulation. The cell potential along the length of the foil varies only by $1.5 \mathrm{mV}$ from maximum to minimum difference. The $0.04 \%$ variation in voltage results in a $0.9 \%$ variation in current density. This verifies the current density is uniform along the length of the foil. This is also obvious from the linear relationship of current with foil height in Fig. 3.5. The assumption of constant current density was tested in cell heights up to $100 \mathrm{~cm}$ and found to be satisfactory. The assumption should be reasonable as long as the $A S I_{\text {echem }}$ is at least twice the value of $A S I_{c c}$. The simulated resistance of the foils is found to raise the $A S I_{\text {echem }}$ by 0.7 for an $A S I_{\text {power }}$ of $30.7 \mathrm{ohm} \mathrm{cm}{ }^{2}$. Additionally, the numerical result verified that $\mathrm{H} / 3$ is the correct equivalent length to represent the $A S I_{c c}$ for the cell. This may also be found analytically, Eq. 3.27-3.29, if you assume an even current distribution. We have shown that to be a reasonable assumption.

$$
\begin{gathered}
\Phi_{1, \text { pos }}=V_{\text {cell }}+\frac{I_{n}}{2 \sigma_{\text {pos }}}\left(H^{2}-x^{2}\right) \\
\Phi_{1, \text { neg }}=\frac{I_{n}}{\sigma_{\text {neg }}}\left(\frac{x^{2}}{2}-x L\right) \\
A S I_{\text {echem }}+A S I_{c c}=\frac{1}{H} \int_{0}^{H} \frac{\Phi_{1, \text { pos }}-\Phi_{1, \text { neg }}}{I_{n}} d x=\frac{V_{\text {cell }}}{I}+\frac{H^{2}}{3}\left(\frac{1}{\sigma_{\text {pos }}}+\frac{1}{\sigma_{\text {neg }}}\right)
\end{gathered}
$$




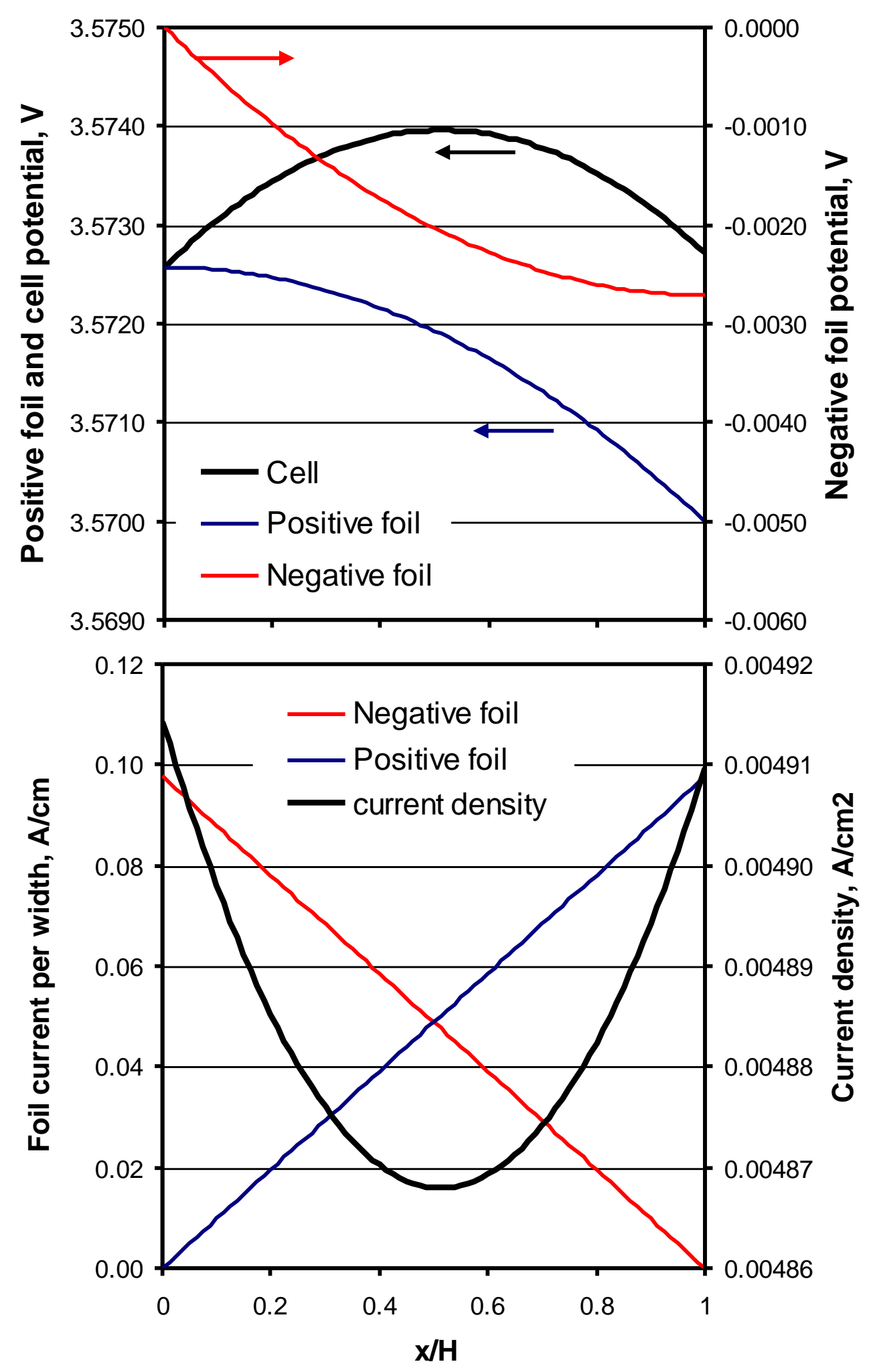

Figure 3.5 The change in current and potential within the positive and negative foils. The current collection design results in a uniform current distribution along the length of the foil. 
An analogous problem has been solved by Euler and Nonnemacher and then communicated repeatedly by Newman et al. ${ }^{24,25}$ The analytical solution they presented may be used after a slight alteration to dimensionalize the current density to the geometry of our concern, Eq. 3.30 and 3.31. This solution was reached assuming linear polarization behavior and is valid for cases where the current density varies along the height of the current collector foil. Thus, this approach is a more general solution than the one we use in the design model.

$$
\begin{gathered}
\mathrm{ASI}_{\text {echem }}+\mathrm{ASI}_{c c}=\frac{U_{o c v}-\left(\Phi_{1, p o s}-\Phi_{1, \text { neg }}\right)}{I}=\frac{H^{2}}{\sigma_{n e g}+\sigma_{p o s}}\left[1+\frac{2+\left(\frac{\sigma_{n e g}}{\sigma_{p o s}}+\frac{\sigma_{p o s}}{\sigma_{n e g}}\right) \cosh v}{v \sinh v}\right] \\
v^{2}=\frac{H^{2}}{A S I_{\text {echem }}}\left(\frac{1}{\sigma_{\text {pos }}}+\frac{1}{\sigma_{\text {neg }}}\right)
\end{gathered}
$$

\subsubsection{Determination of Module Terminal, Battery Terminal, and Module Inter-connect Size}

An important factor for setting the resistances of a module terminal, battery terminal, or module interconnect is the allowable rate of temperature rise in the conductor at full power. We set the acceptable rate of temperature rise, $\mathrm{dT} / \mathrm{dt}$, at $0.2{ }^{\circ} \mathrm{C} / \mathrm{sec}$ or a $2{ }^{\circ} \mathrm{C}$ rise for a $10-\mathrm{sec}$ power burst under adiabatic conditions. The heating rate, $q$, is then used to determine the mass, $m$, of the terminal required for the designed battery in Eq. 3.32. Since the heating rate may also be determined by Eq. 3.33, we may determine the cylindrical terminal radius and mass by assuming a length, $H_{\text {term. }}$. In this way, the size of the module terminal is redesigned during each simulation to meet the specified power requirements and allowable temperature rise, Eq. 3.34. The mass of the conductor is found to be inversely proportional to the allowable temperature rise.

$$
\begin{gathered}
q=m C_{p} \frac{d T}{d t} \\
q=\frac{H_{\text {term }}}{A_{\text {term }} \sigma_{\text {term }}}\left(I A_{\text {pos }}\right)^{2} \\
A_{\text {term }}=I A_{\text {pos }}\left[\rho_{\text {term }} \sigma_{\text {term }} C_{p} \frac{d T}{d t}\right]^{-1 / 2}
\end{gathered}
$$

A copper busbar must also be sized for batteries using a single row of modules. We have somewhat arbitrarily assumed a $\Delta V_{b b}=30 \mathrm{mV}$ drop across the busbar to be allowable at maximum current. This value maybe easily changed by the user. Equation 3.35 is used to calculate the mass of the busbar, $m_{b b}$. The complicated expression for the volume of the busbar is 
derived from the voltage drop, conductivity, busbar width, $w_{b b}$, and required busbar crosssectional area.

$$
m_{b b}=\rho_{b b} \frac{I_{t o t}\left(w_{b b}\right)^{2}}{\Delta V_{b b} \kappa_{b b}}
$$

\subsection{Calculation of Battery Dimensions}

The goal of the model is to quantify how the various components of a specific battery design sum to make the mass and volume of the battery pack. In this way, a true energy and power density can be calculated as well as the exact materials requirement to meet this design. Summing the mass of the components is relatively straight forward. Determining the total volume that contains the components and required free volume is not as obvious. The exact calculations used in the design model are detailed below for the cell, module, and battery pack.

\subsubsection{Cell Dimensions}

The number of layers in each cell is approximated in Eq. 3.36 by accounting for the compression factor, $X_{\text {comp }}$, and the individual thicknesses of the current collector foils, $L_{\text {foil }}$, electrodes, $L_{p o s}$ and $L_{n e g}$, separator, $L_{\text {sep }}$, and container, $L_{\text {cont }} . X_{\text {comp }}$ is usually taken to be 0.97 . The Li-ion battery chemistries this model was designed for are assumed to undergo negligible volume change on the cell level. Slight volume changes can be accommodated as mentioned in Section 2.3.

$$
N_{\text {layers }}=X_{\text {comp }} \frac{L_{c e l l}-2 L_{\text {cont }}+L_{\text {foil }}^{\text {neg }}}{L_{\text {foil }}^{\text {neg }}+L_{\text {foil }}^{\text {pos }}+2\left(L_{\text {sep }}+L_{\text {neg }}+L_{\text {pos }}\right)}
$$

The $N_{\text {layers }}$ approximation is necessary as the cell thickness is a user defined parameter. The aspect ratio of the cell is also user defined; therefore, solving for the width also determines the height of the cell as seen in Eq. 3.37. The width is calculated from the number of layers and the aspect ratio, $H / W$. The factor of 2 enters the denominator as both sides of the foil are assumed to be coated.

$$
W_{p o s}=\sqrt{\frac{A_{p o s}}{2 \frac{H}{W} N_{\text {layers }}}}
$$

Having determined the width and height of the electrode, the rest of the cell dimensions are relatively straightforward, Eq. 3.38 and 3.39. The width of the cell, $W_{\text {cell }}$, is $2 \mathrm{~mm}$ wider than the positive electrode to allow for the larger separator area and pouch seals. The thickness of the folded edge, $L_{e}$, is also included in the width dimension. The pouch seals are folded up, pressing along the inside wall of the module casing. The height of the cell, $H_{\text {cell }}$, is the height of the positive electrode in addition to the distance for the terminals and connections to the foil tab, $L_{\text {term,cnt }}$. Our assumed design requires $15 \mathrm{~mm}$ for this distance at each end of the cell for a total of $30 \mathrm{~mm}$. The volume of the cell is the product of the three dimensions. 


$$
\begin{gathered}
W_{\text {cell }}=W_{p o s}+2+2 L_{e} \\
H_{\text {cell }}=H_{p o s}+2 L_{t e r m, c n t}
\end{gathered}
$$

\subsubsection{Module Dimensions}

The module dimensions are defined by Eq. 3.40-3.42. The height and length of the module are both just $2 \mathrm{~mm}$ wider than the cell dimension. The width of the module is related to the total thickness from all of the cells with allowance for a SOC controller at one end.

$$
\begin{gathered}
H_{\mathrm{mod}}=W_{\text {cell }}+2 \\
L_{\mathrm{mod}}=H_{\text {cell }}+2 \\
W_{\mathrm{mod}}=L_{\text {cell }}\left(N_{\text {cell } / \mathrm{mod}}+1\right)+1
\end{gathered}
$$

\subsubsection{Battery Pack Dimensions}

The battery pack volume includes all of the modules, spacing for connections between modules, channel for the cooling air to flow, $H_{\text {air }}$, thickness of the module compression plates, $L_{\text {comp }}$, and the battery pack jacket, $L_{j a c k}$ (Eq. 3.43-3.45). $L_{j a c k}$ includes a $10 \mathrm{~mm}$ thick insulation layer sandwiched between two aluminum walls for the container. The thickness of the aluminum wall increases from 1 to 1.5 to $2 \mathrm{~mm}$ as the battery volume increases from $<20 \mathrm{~L}$ to $<40 \mathrm{~L}$ to larger dimensions. The layout of the modules, number per row, $N_{\text {mod/row }}$, and number of rows, $N_{\text {row }}$, is also included. The final volume of the battery is the product of the three dimensions. The space left for connections between modules, $L_{g a p}$, is a function of the number of rows of modules. $L_{g a p}$ is equal to 8,10 , or 20 depending if there is one, two, or four rows of modules. Three rows of modules are not allowed as the positive and negative terminal for the battery would be on opposite ends and thus not very practical. A number greater than four rows of modules is deemed unnecessary.

$$
\begin{gathered}
H_{\text {batt }}=H_{\text {mod }}+2 H_{\text {air }}+2 L_{\text {jack }} \\
L_{b a t t}=N_{\text {mod } / \text { row }} W_{\text {mod }}+H_{\text {air }}+2 L_{\text {comp }}+2 L_{j a c k} \\
W_{\text {batt }}=N_{\text {row }} L_{\text {mod }}+L_{\text {gap }}+2 L_{\text {jack }}
\end{gathered}
$$

\subsection{Additional Considerations}

A few situations may arise that require a change in the calculation method. These situations are addressed in the subsections below. The inclusions of these calculations into the model allow for a more realistic depiction of limitations often encountered by cell manufactures. 


\subsubsection{Maximum Electrode Thickness}

A practical limitation exists for the maximum achievable electrode thickness. This limitation may be set by manufacturing capabilities, ionic and electronic current transport within the porous electrode, susceptibility to plating lithium on the negative electrode, or aging characteristics related to adhesion to the current collector. Some of these challenges are discussed in great detail in the following subsection. When the maximum electrode thickness, $L_{\max }$, has been reached on either the positive or negative electrode, the electrode area equation is modified as shown in Eq 3.46. The electrode thickness, $L_{t g t}$, is the largest electrode thickness, negative or positive, calculated at the targeted fraction of the OCV $[\mathrm{V} / \mathrm{U}]$.

$$
A_{p o s}^{L \max }=\frac{L_{t g t}}{L_{\max }} A_{p o s}
$$

The area of the electrode is now determined by the cell capacity requirement to meet the battery energy demands and not the target voltage at rated power. As a consequence, the battery pack will operate at a higher $[\mathrm{V} / \mathrm{U}]$ than originally selected by the battery designer. The new $[\mathrm{V} / \mathrm{U}]$ may then be calculated from Eq. 3.47 which is the solution to the quadratic found in Eq. 3.48.

$$
\begin{gathered}
{\left[\frac{V}{U}\right]=\frac{1}{2 U_{\text {cell }}}\left[U_{\text {cell }}+\sqrt{\left(U_{\text {cell }}\right)^{2}-4 \frac{P_{\text {batt }} A S I_{\text {power }}}{N_{\text {cells }} A_{\text {pos }}}}\right]} \\
V_{\text {cell }}=U_{\text {cell }}-\frac{P_{\text {batt }} A S I_{\text {power }}}{V_{\text {cell }} N_{\text {cells }} A_{\text {pos }}}
\end{gathered}
$$

The maximum electrode thickness may have a large impact on the energy density and cost of cells designed for high energy and range. Nelson et al. demonstrated this concept in 2009 assuming a 100 micron maximum electrode thickness. ${ }^{12,19}$ In 2010, Santini et al. relaxed this assumption to 300 micons; although, the thickest electrode discussed in the paper was a 225 micron graphite electrode in the LMO-Gr EV with 100 mile range. ${ }^{13}$ In conversations with manufactures, 100 microns appears to be the general electrode thickness used for EV type cells at the present time. However, Santini et al. has shown substantial increases in energy density and decreases in cost if larger electrode thicknesses may be utilized. The challenges to achieving thick electrodes, in addition to those already mentioned, relate to fast charging while avoiding lithium metal deposition, utilizing all of the materials reversible capacity, removing gases formed during formation cycling, wetting the full porosity of the electrode, achieving defect free coatings, and drying the thick electrode at high rates. Our opinion is that the successful cell manufacturers will engineer ways to overcome these challenges to increase energy density and lower cost.

\subsubsection{Challenges of Large Electrode Thicknesses}

Dependent upon the battery chemistry and designed P/E ratio, the maximum achievable electrode thickness (loading) may have a significant effect on the end cost and energy density of a battery pack. For batteries designed at low P/E ratios or for cell chemistries with low 
volumetric capacities, the designed electrode thickness based on the target efficiency is often larger than what is feasible during operation in a transportation environment. This subsection explores some of the challenges that arise in the electrochemistry when larger electrode thicknesses are utilized.

Argonne gained a wealth of experience in the NCA-Gr in 1.2 $\mathrm{M} \mathrm{LiPF}_{6}$ 3:7 EC:EMC cell during the Advanced Technology Development program sponsored by the US Department of Energy (DOE). Dees and coworkers developed a world-leading parameter set for a numerical model through exhaustive electrochemical measurements, ex-situ characterization techniques, and multi-scale modeling activities. ${ }^{26-35}$ The resulting phenomenological cell model founded on the methodology originating from John Newman (UC Berkeley) will be used to evaluate the electrochemical behavior of cells using thick electrodes. ${ }^{36}$ The coupled, non-linear partial differential equations are solved with the finite element method using FlexPDE.

Simulated discharge capacity for the $\mathrm{C} / 1$ and $\mathrm{C} / 3$ discharge rate is shown in Figure 3.6 as a function of electrode thickness. For reference, the target positive electrode thicknesses for this cell operating at a $5 \mathrm{C}$-rate and a $[\mathrm{V} / \mathrm{U}]=0.8$ is 142 microns. The line of $100 \%$ capacity utilization is also shown as a means to judge the deviation from theoretical capacity. As expected, the $\mathrm{C} / 1$ rate deviates more strongly than the $\mathrm{C} / 3$ rate with increasing electrode thickness. The loss in capacity is a result of the cell hitting the discharge voltage cut-off, $3.3 \mathrm{~V}$, before all of the lithium has been transported from the negative to the positive electrode.

Figure 3.7 displays the normalized concentration profile of the electrolyte salt, $\mathrm{LiPF}_{6}$, at the end of a $\mathrm{C} / 1$ and $\mathrm{C} / 3$ discharge for an electrode thickness of 245 microns. The $\mathrm{C} / 1$ discharge results in a positive electrode starved of electrolyte salt. This transport limitation results in the cell prematurely reaching the voltage cutoff. In order to overcome this limitation, the electrode would need to be engineered with significantly reduced tortuosity ${ }^{37}$ or utilize an electrolyte with better mass transfer characteristics. This behavior is exacerbated by lower temperatures, such as those experienced during winter driving conditions. The fraction of theoretical discharge capacity begins to lower significantly at thicknesses greater than 100 microns, $3.4 \mathrm{mAh} / \mathrm{cm}^{2}$, at the $\mathrm{C} / 1$ rate and 175 microns, $6.4 \mathrm{mAh} / \mathrm{cm}^{2}$, at the $\mathrm{C} / 3$ rate. The electronic transport properties of the cathode material also play an important role in determining the current distribution within the electrode. While the NCA material has a reasonably high conductivity, other cathode materials have lower valued electronic conductivities and, depending on the conductive additive properties, may have different current distributions and limitations within the electrode. 


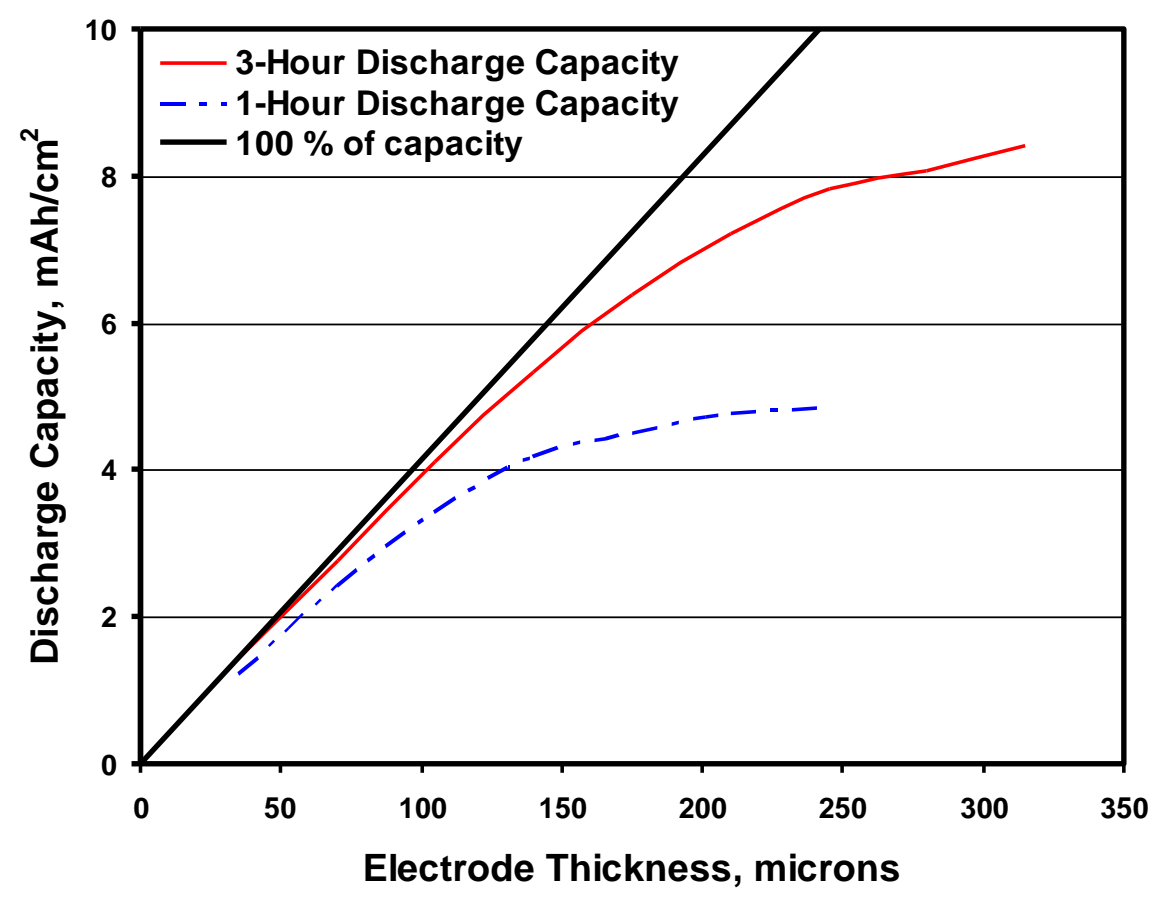

Figure 3.6 Cell capacity simulated at the $\mathrm{C} / 1$ and $\mathrm{C} / 3$ rate as a function of electrode thickness (loading) for NCA-Gr.

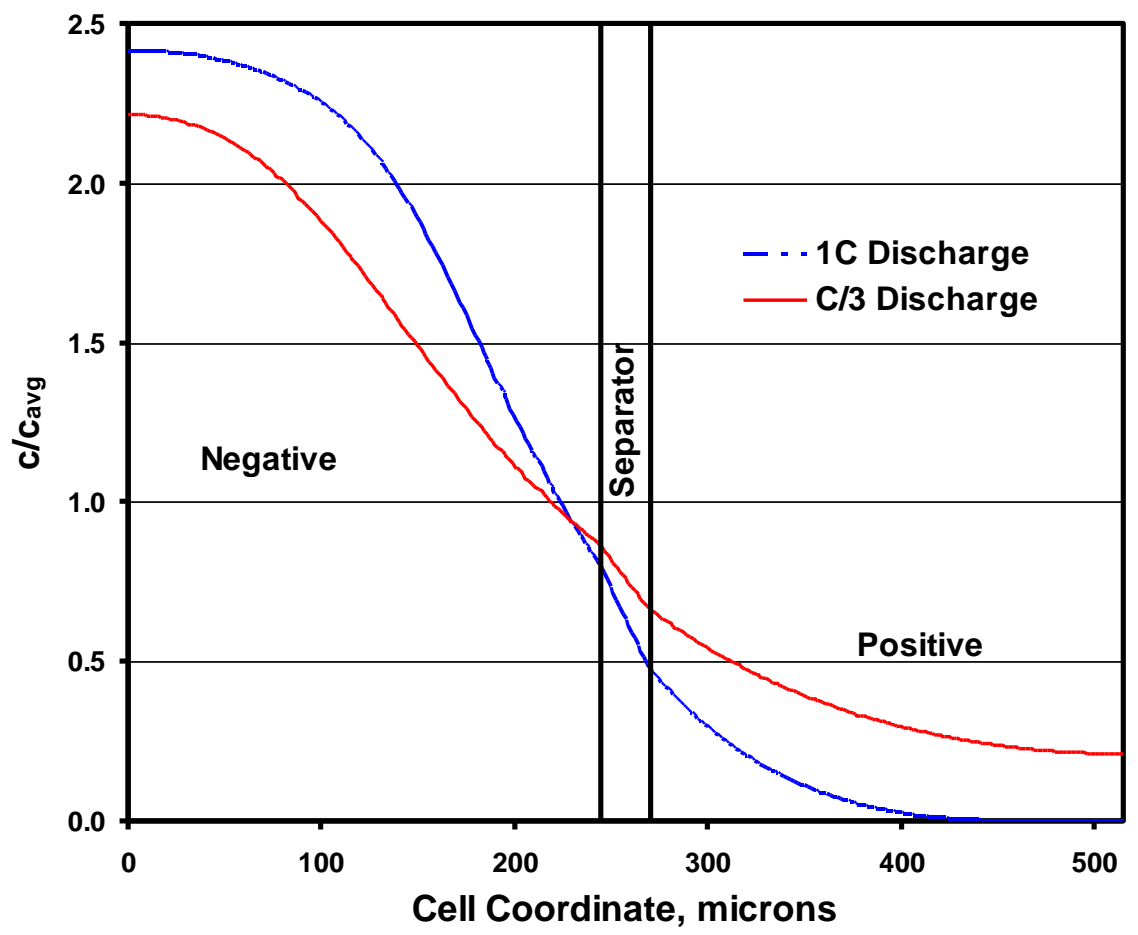

Figure 3.7 Normalized electrolyte salt concentration at the end of discharge at the $C / 1$ and $C / 3$ discharge rates. The second half of the positive electrode next to the current collector is starved of the $\mathrm{LiPF}_{6}$ salt resulting in a lower utilization of the inherent cell capacity. 
The simulated ASI for a 5C, 10-s discharge pulse at $60 \%$ SOC is shown in Figure 3.8 as a function of electrode thickness. The initial decrease in the ASI is a mathematical result of diminishing significance of the interfacial impedance as more current is passed in the same geometric area. The ASI then remains constant from 75 microns to nearly 400 microns. The constant ASI results from ohmic losses that behavior linearly with applied current. The dramatic increase in the ASI at the largest electrode thicknesses results from limitations in electrolyte transport within the porosity of the positive electrode. This is similar to what is displayed in Fig 3.7 above during the constant discharge at the $\mathrm{C} / 1$ rate for an electrode thickness of 245 microns.

The most significant issue for pulse power operation with thick electrodes occurs on the negative electrode during a charge or regen pulse, Figure 3.9. The potential of the negative electrode may drop below that of a hypothetical lithium reference electrode during a charge pulse, inferring an undesirable side reaction of lithium plating on graphite. ${ }^{38}$ This behavior is exacerbated by increasing electrode thickness. Operation at higher SOC and lower temperatures will also increase the probability of lithium plating. The lithium reference electrode is taken to be in the center of the separator layer. The two times shown in the graph, 1-s and 10-s, represent different polarization measurements for the electrode. The 1-s value includes all of the interfacial impedance and minor contributions from concentration polarization. The longer time value includes additional changes in potential due to the concentration gradient in the electrolyte. The 1 -s time is the more accurate valuation of the tendency of the electrode to plate lithium.

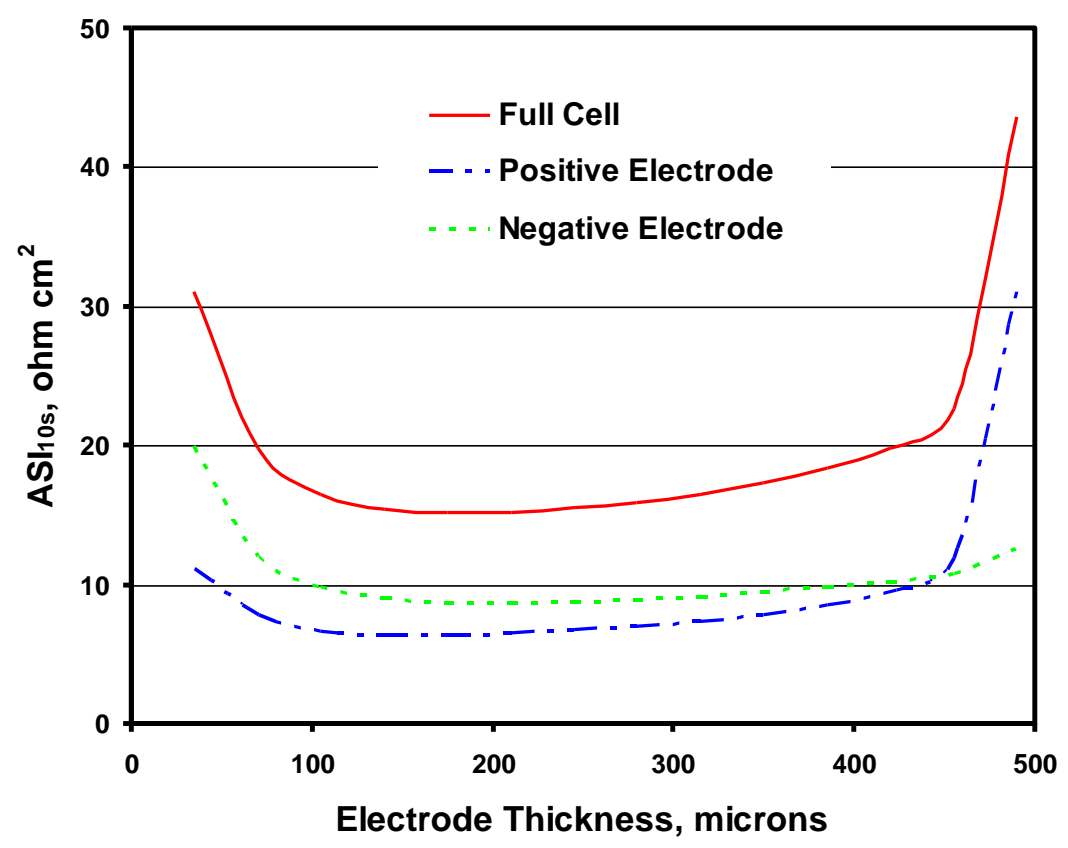

Figure 3.8 Calculated ASI from a simulated 10-s, 5C discharge pulse for the NCA-Gr cell couple at $60 \%$ SOC. Positive and negative electrode thicknesses are similar in value for this cell design. Transport within the electrolyte is not limiting until the electrode thickness approaches 450 microns for these simulation conditions. 


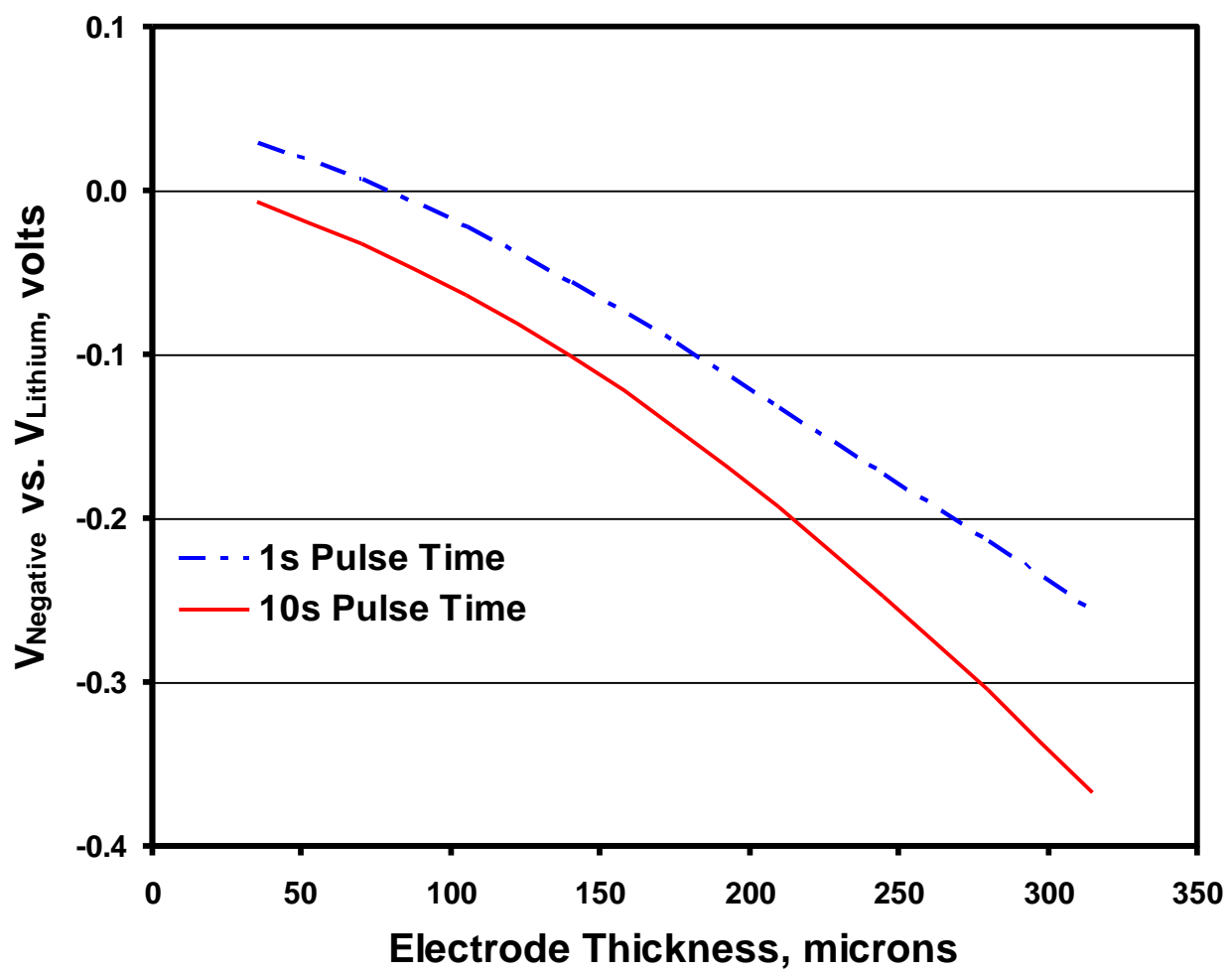

Figure 3.9 The potential of the negative electrode versus a hypothetical lithium reference electrode located in the center of separator during a $5 \mathrm{C}$ charge pulse for the NCA-Gr couple.

The tendency for lithium plating appears to be significant at electrode loadings greater than 3.4 $\mathrm{mAh} / \mathrm{cm}^{2}$ under these specific conditions. Lower continuous and pulse charge rates are most likely necessary to ensure the safe operation and long life of this battery. Fast charging of PHEV and EV batteries is an oft discussed value-added characteristic necessary to increase the attractiveness of electric vehicles to the consumer. However, this fast charge requirement may require a lower loading design to prevent lithium plating from occurring. This would not be true for batteries based on LTO negative electrodes, or possibly even non-graphitic carbon electrodes (e.g. hard carbon). The consequence of a lower loading design is that higher quantities of inactive materials are used resulting in a more expensive and less energy dense battery.

A limit of 100 microns has been chosen for the default maximum electrode thickness. This thickness represents a graphite electrode balanced to a positive loading of $3.5 \mathrm{mAh} / \mathrm{cm}^{2}$ and is the largest thickness that ASI measurements have been validated at Argonne. However, a low volumetric capacity electrode, such as LMO, will result in a lower area-specific capacity as the limit will be determined by the positive electrode thickness. One domestic OEM has suggested that at the time of this publication, state of the art electrode loadings for PHEV applications are less than $2 \mathrm{mAh} / \mathrm{cm}^{2}$. This low loading level was selected based on cold-start performance, life testing, and rate capability studies. We note that different electrolytes will likely have the most significant effect on the transport limitations and result in different optimum electrode loadings. Gel-based electrolytes or standard carbonate electrolytes mixed with low molecular weight polymers are often utilized in pouch cell based batteries. While the ionic conductivity of these systems may approach standard carbonate electrolytes used, diffusion of the salt is restricted. 
This decrease in mass transport will result in large increases in impedance during longer discharges (constant speed highway driving). Hence, companies using an electrolyte with sluggish mass transport will require thinner electrodes than what the model would normally calculate based on pulse power applications. Greater electrode thicknesses may be achievable in the future as manufacturers expend significant engineering efforts to minimize the inactive material that lowers energy density and raises cost. The concerns over lithium plating may remain unless new, less susceptible negative electrodes are developed that still enable high energy density.

Table 3.2 displays a calculated sensitivity analysis for designing the battery at different target electrode loadings to achieve $17 \mathrm{kWh}$ of total energy for the NCA-Gr cell couple for two power levels, $110 \mathrm{~kW}$ and $60 \mathrm{~kW}$ of power. The consequence of varying electrode loading at constant power and energy is to change the fraction of open circuit voltage at which rated power is achieved at BOL. This quantitative comparison of electrode thickness with $[\mathrm{V} / \mathrm{U}]$ is only valid for the specific battery and cell chemistry designed in the table, while the qualitative results would hold for all systems. An alternate but equivalent way to create Table 3.2 is to maintain a constant value of $[\mathrm{V} / \mathrm{U}]$, but vary the designed power level. As mentioned previously, private communications suggest that current electrode thicknesses used in PHEV applications are near 50 microns or $2 \mathrm{mAh} / \mathrm{cm}^{2}$; however, the exact details of that cell configuration are unknown and thus direct comparison should be conducted with caution. For the cell chemistry shown in the table, a loading of $2 \mathrm{mAh} / \mathrm{cm}^{2}$ with $110 \mathrm{~kW}$ of power correlates to achieving the rated power at $\mathrm{BOL}$ at $[\mathrm{V} / \mathrm{U}]=0.84$. Our default suggestion of using $80 \%$ of open-circuit voltage results in a moderately less expensive battery, albeit similar in value. If a battery of lower $\mathrm{P} / \mathrm{E}$ ratio were designed, then the electrode thickness (loading) would be much larger for the same designed fraction of open-circuit voltage. The sensitivity to $[\mathrm{V} / \mathrm{U}]$ decreases with lower $[\mathrm{V} / \mathrm{U}]$ values owing to the inverse proportionality of electrode loading to the P/E ratio. The calculated designed electrode loadings for lower P/E ratios will differ the most significantly from those used in industrial practice today. This is in part the motivation to limit electrode thicknesses to 100 microns as well as the transport limitations discussed earlier. While the standard practices of today are important, the goal of the calculations is to evaluate the potential cost of Li-ion batteries in the future years after improvements have been made resulting from the competitive marketplace. Therefore, calculating a range of values will be the most instructive approach to determining where future battery costs may fall. Additional variation studies may be found in Appendix A.

Table 3.2 The effect of electrode loading on the price of a $17 \mathrm{kWh}$ NCA-Gr PHEV40 battery with 96 cells

\begin{tabular}{|c|c|c|c|c|c|c|}
\hline $17 \mathrm{kWh}$ & \multicolumn{3}{|c|}{$110 \mathrm{~kW}$} & \multicolumn{3}{c|}{$60 \mathrm{~kW}$} \\
\hline$[\mathrm{V} / \mathrm{U}]$ & $\mathrm{mAh} / \mathrm{cm} 2$ & microns & Price, $\$$ & $\mathrm{mAh} / \mathrm{cm} 2$ & microns & Price, $\$$ \\
\hline 68 & 3.74 & 96 & 4305 & 7.38 & 188 & 3954 \\
\hline 72 & 3.45 & 88 & 4358 & 6.80 & 174 & 3977 \\
\hline 76 & 3.09 & 79 & 4442 & 6.11 & 156 & 4014 \\
\hline 80 & 2.67 & 68 & 4572 & 5.30 & 135 & 4091 \\
\hline 84 & 2.19 & 56 & 4780 & 4.38 & 112 & 4188 \\
\hline 88 & 1.65 & 42 & 5163 & 3.36 & 86 & 4364 \\
\hline 92 & 1.04 & 27 & 6045 & 2.22 & 57 & 4749 \\
\hline
\end{tabular}




\subsubsection{Accounting for Parallel Cell Arrangements}

The user of the design model may wish to use a parallel arrangement of cells within the larger series arrangement of the battery pack. Several motivations exist for a parallel cell arrangement. For example, a battery supplier may wish to only produce cells of a specific capacity. The manufacturer may only have the equipment to produce a certain size cell or they may encounter engineering design problems for very large cells ( $>60 \mathrm{Ah}$ ). Thus, a cell group composed of parallel connected cells may be necessary to meet the energy requirements while staying within battery pack voltage and current requirements.

When the user chooses to have cells connected in parallel, the design model calculation includes the appropriate factors necessary to account for changes in the resistance, volume, and mass of the battery. The end result is a lower energy density for the battery from including the cell group interconnects and additional inactive material for each cell. Furthermore, the thickness of the cells is reduced to $6 \mathrm{~mm}$ to better suit the smaller cell format.

\subsubsection{Accounting for Parallel Module Arrangements}

Designing a battery composed of modules in parallel cannot be explicitly simulated in the model. However, one may approximate this scenario by simply doubling the number of modules, and thus battery pack voltage. The simulated battery pack is nearly the same as if constructed of parallel packs. A simple wiring change would lower the pack voltage with a proportional increase in capacity. The overall energy and power will be the same. Subtle errors will exist in the size of the module terminals and conductors as the calculated total current will be less in the series arrangement than that in a parallel configuration. 


\section{Thermal Management}

The power and life of lithium-ion batteries are more dramatically affected by the battery temperature than they are for most other batteries including those based on lead-acid, nickelcadmium, and nickel-metal hydride systems. It is important that the temperature of a lithium-ion battery be controlled at all times, even when the battery is at rest. Thermal variation within the individual cells must also be minimized to prevent uneven aging characteristics. Poor performance from a weakened cell will reduce the capability of the entire pack. Developing schemes for effectively controlling the pack temperature at minimum cost will certainly be important in the success of this technology. The most difficult problem is the removal of heat generated within the battery, principally by ohmic heating. Avoiding excessive temperature rise during idle periods in hot ambient conditions is also a problem. Either of these conditions might raise the temperature to well above $40^{\circ} \mathrm{C}$, which enhances degradation reactions and shortens the battery life. Thus, maintaining the battery temperature as near the minimum temperature for adequate power will prolong battery life. Because the battery has poor power at low temperatures, heating the battery from a very cold condition is necessary and especially difficult for large EV battery packs for which no assistance is available from the engine. For electric-drive vehicles to be competitive in the market with conventional vehicles, these thermal control problems must be solved at moderate costs and by means that do not compromise the safety of the vehicle or battery system.

The BatPaC model has a separate worksheet for estimating the thermal parameters and requirements for lithium batteries and for designing the thermal management system. The results are transferred to the Battery Design worksheet to calculate the mass, volume and materials requirements for the battery pack.

\subsection{Heat Generation Rates in the Battery Pack during Driving}

During driving, the heat generation rate depends on the driving cycle and the power of the battery relative to the demands of the cycle for the vehicle being driven. As discussed below, the thermal mass of the battery pack smooths out fluctuations in the heat generation rate. The rate that the cooling system must handle is the average rate for the most difficult driving conditions to which the battery pack will be subjected.

The best way to determine the maximum cooling rate requirement for the battery pack is by vehicle simulation studies. These studies require a battery impedance algorithm that makes possible accurate estimates of internal heating and the use of vigorous driving cycles and highspeed driving patterns. The results of vehicle simulation studies of battery heating can be entered on line 19 in the Thermal worksheet to override the estimated default values. However, pertinent results are not always accessible and therefore we have provided some initial, although dramatically simplified, estimations for heat generation.

For microHEV and HEV-HP battery packs, heat generation is intermittent and substantial periods of little or no heat generation exist in the load profile. The model estimates the heat generation rate for $25-\mathrm{kW}$ micro-HEV batteries at $100 \mathrm{~W}$. For the HEV-HP battery packs, the maximum average battery power is derived from the energy requirement, default of $\dot{E}=300$ 
Wh/mile, entered on the Battery Design worksheet (line 157). The energy use requirement for $\mathrm{HEV}$-HP batteries is estimated to take place at an average driving speed of $40 \mathrm{mph}$ and involve the battery $50 \%$ of the time. These assumptions calculate an average estimated battery power level of $6.0 \mathrm{~kW}$. For a $50-\mathrm{kW}$ battery pack, the heat generation is estimated as $5 \%$ of the average battery power. The heat generation for a HEV-HP battery of different maximum power is estimated to be inversely proportional to the battery pack rating as shown in Equation 4.1.

$$
q_{\mathrm{HEV}-\mathrm{HP}}=\dot{E} * 40 * 0.5 * 0.05 * \frac{50}{P_{\text {batt }}}
$$

For PHEV battery packs, the maximum heating condition is deemed to occur during the charge depleting period when essentially all of the vehicle power is supplied by the battery. Thus, the factors controlling heating during operation of PHEVs and EVs are similar and may be treated in the same way. The highest rate of continuous heat generation will occur on a very vigorous driving cycle or when driving at sustained high speed. Continuous discharge of the battery at constant power results in increasing impedance and increasing heat generation rate because of solid-state diffusion overvoltage. The area-specific impedance (ASI) will reach 2-3 times the 10second ASI in about five minutes accompanied by a similar increase in the internal heat generation rate. Whether or not steady high speed driving will result in greater internal heat generation than a vigorous driving cycle will depend on many factors including vehicle speed, battery power, and electrode thickness. The energy usage requirement, default of $\dot{E}=300$ $\mathrm{Wh} / \mathrm{mile}$, is assumed to occur at a steady discharge of $60 \mathrm{mph}$ in PHEVs and EVs. The vehicle speed and energy usage assumptions provide an estimate of the maximum long-term discharge rate. The heat generation is calculated from this power requirement and ASI for energy. Finally, the maximum heat generation rate is assumed to be 1.3 times the value at $60 \mathrm{mph}$. The heat generated in the battery pack for these conditions is inversely related to the pack power.

\subsection{Heating under Adiabatic Conditions}

A factor to be considered in thermal management is the substantial thermal mass of the battery pack. This smoothes out temperature fluctuations resulting from power bursts so that the heat dissipation system need only handle the average heat generation rate for the most extreme driving profiles the battery is likely to encounter. For large PHEV and EV batteries the thermal mass of the battery will limit the temperature rise of the centerline of the cells by distributing the heat throughout the battery until steady state is reached. For a large EV battery with power of $120 \mathrm{~kW}$ and energy of $50 \mathrm{kWh}$, the temperature rise under adiabatic conditions may be only $15^{\circ} \mathrm{C}$ or less for a complete discharge and certainly less with a cooling system even if it is only moderately effective. For HEV batteries, which have high power-to-energy ratios, the main effect of the thermal mass will be to smooth out temperature fluctuations.

\subsection{Active Cooling Systems}

There are several choices of coolant that have been considered for cooling battery packs including air from the cabin, which may be heated or cooled, water-ethylene glycol solutions and dielectric liquids such as transformer coolants. Air is the least expensive, but it is less effective than the liquids because of its poor conductivity, the need for large flow passages and high 
pumping power. Dielectric liquids are expensive, but have the advantage of being compatible with terminals and other parts at electrical potential. Water-50\% glycol solution is inexpensive and has good conductivity; we have selected it as the coolant for this study.

We selected a general cell and battery design that can be adapted to all of the electric-drive batteries from micro-HEVs packs to EV packs (section 2). This design incorporates a hermetically sealed module closure. Unfortunately, the enclosure does not have sufficient surface area to be cooled effectively by air. This design can be effectively cooled by liquids and requires that only the module terminals and connectors be protected from contact with a conducting coolant, thus accommodating water-glycol coolant. In contrast, cooling individual cells would require flow passages between the cells, which would add to the pack volume. That design feature would permit air cooling for microHEV and HEV-HP batteries. For larger batteries requiring liquid cooling, flow passages between the cells would probably require the use of a dielectric coolant because of the difficulty of protecting so many cell terminals from a conducting coolant. Alternatively, elaborate flow channels with engineered seals may be used to contain an aqueous based heat transfer fluid.

\subsubsection{Heat Transfer from Cell to Module Wall}

As described in section 2, the cells transfer heat to the cooled walls of a hermetically sealed module with the aid of an aluminum heat conduction channel. Some of the heat is transferred through the sides of the cell to the channel and from there to the module wall. The remainder is transferred directly through the seal edge of the cell to the conduction channel flange which is in contact with the module wall. Calculation of heat transfer in this two-dimensional array through several materials is complex requiring a numerical model. The spreadsheet iterates several hundred times in reaching a solution, each resulting in a slightly different cell design. Thus, it would be impractical to imbed a numerical model directly, which may increase the total calculation time to many minutes. Instead, a software program based on the finite element method, FlexPDE 6.15 by PDE Solutions Inc., was employed to calculate heat transfer rates for 70 cell configurations. The resulting simulations were empirically correlated so that simple equations occupying a few cells in the spreadsheet could rapidly calculate the heat transfer rate with only a small error.

An important requirement for calculating heat transfer rates within the cell is to estimate the composite conductivities of the cell layers both parallel to the layers and across the layers. The resulting conductivities vary considerably with the relative thicknesses of the layers as shown in Table 4.1, for which the results are consistent with the literature. ${ }^{39-43}$ These values for conductivities and a range of cell dimensional parameters (Table 4.2) were employed in selected arrangements for calculating heat transfer rates with the FlexPDE model for 70 representative cells that covered a broader range of variables than is needed for practical cells. For each of these cells, the FlexPDE model calculated the temperature difference between the cell center and the module housing per unit of heat generation, $\Delta \mathrm{T} / \mathrm{q}\left({ }^{\circ} \mathrm{C} / \mathrm{W}\right)$, and the fraction of the total heat that was transferred through the edge of the cell, $\mathrm{q}_{\mathrm{e}} / \mathrm{q}$. The balance was transferred through the side of the cell to the aluminum conductor, $\mathrm{q}_{\mathrm{s}}$. The division of the heat transfer into two routes is represented by the equation: 


$$
q / \Delta T=q_{e} / \Delta T+q_{s} / \Delta T
$$

Estimated values for $q_{e} / \Delta T$ and $q_{s} \delta \Delta T$ were determined by empirical correlation of the results obtained for the calculation of the 70 cells by the FlexPDE model with the result shown in Fig. 4.1. Empirical values of these estimated values resulted in the equations:

$$
\begin{gathered}
q_{e} / \Delta T=3.917 k_{y}{ }^{0.58} k_{x}^{-0.19} L_{c e l l}{ }^{1.2} W^{0.75} \\
q_{S} / \Delta T=1628 k_{y}{ }^{0.55} k_{x}{ }^{0.58} L_{c e l l}{ }^{-0.21} W^{0.7} L_{A l}{ }^{0.72}
\end{gathered}
$$

Table 4.1 Sample calculations of composite thermal conductivities of cell structures across layer and parallel to layers

\begin{tabular}{|c|c|c|c|c|}
\hline & \multicolumn{4}{|c|}{ Parameter Levels Evaluated } \\
\hline & 1 & 2 & 3 & 4 \\
\hline Conductivities, W/cm-K & & & & \\
\hline Across layers, $\mathrm{k}_{\mathrm{x}}$ & 0.00689 & 0.00689 & 0.01045 & 0.0 .01112 \\
\hline $\begin{array}{l}\text { Parallel to layers, } \mathrm{k}_{\mathrm{y}} \\
\text { Cell edge, } \mathrm{k}_{\mathrm{e}}\end{array}$ & $\begin{array}{c}0.4127 \\
0.10\end{array}$ & 0.4127 & 0.1228 & 0.0892 \\
\hline Cell Dimensions, $\mathrm{cm}$ & & & & \\
\hline Cell thickness, $\mathrm{L}_{\text {cell }}$ & 0.6 & 1.0 & 1.4 & \\
\hline Cell width, W & 8 & 12 & 18 & \\
\hline Cell edge thickness, $\mathrm{L}_{\mathrm{e}}$ & 0.1 & & & \\
\hline Aluminum conductor thickness, $\mathrm{L}_{\mathrm{Al}}{ }^{(\mathrm{b})}$ & 0.03 & 0.06 & 0.10 & \\
\hline
\end{tabular}

\begin{tabular}{|l|c|c|c|c|}
\hline & Cell 1 & Cell 2 & Cell 3 & Cell 4 \\
\hline Layer Thicknesses, microns & & & & \\
Positive foil & 20 & 20 & 20 & 20 \\
Negative foil & 12 & 12 & 12 & 12 \\
Positive coating & 30 & 75 & 150 & 220 \\
Negative coating & 40 & 100 & 200 & 300 \\
Separator & 20 & 20 & 20 & 20 \\
Total bicell structure & 212 & 422 & 772 & 1112 \\
& & & & \\
Thermal Conductivities, W/cm-K & & & & \\
Aluminum & 2.0 & 0.2 .0 & 0.2 .0 & 0.2 .0 \\
Copper & 3.8 & 3.8 & 3.8 & 3.8 \\
Positive coating & 0.013 & 0.13 & 0.13 & 0.13 \\
Negative coating & 0.013 & 0.13 & 0.13 & 0.13 \\
Separator & 0.0020 & 0.0020 & 0.0020 & 0.0020 \\
Across layers, $\mathrm{k}_{\mathrm{x}}$ & 0.00689 & 0.00689 & 0.01045 & 0.0 .01112 \\
Parallel to layers, $\mathrm{k}_{\mathrm{y}}$ & 0.4127 & 0.4127 & 0.1228 & 0.0892 \\
\hline
\end{tabular}

Table 4.2 Range of parameter values for calculating heat transfer rates in FlexPDE model

${ }^{(a)} T h e \mathrm{k}_{\mathrm{x}}$ and $\mathrm{k}_{\mathrm{y}}$ values are calculated as in Table 4.1 and were, thus, paired together in the Flex PDE model calculations.

${ }^{\text {(b) }}$ The total conductor thickness consists of the conductor thickness itself plus twice the thickness of the aluminum layer within the pouch material. 


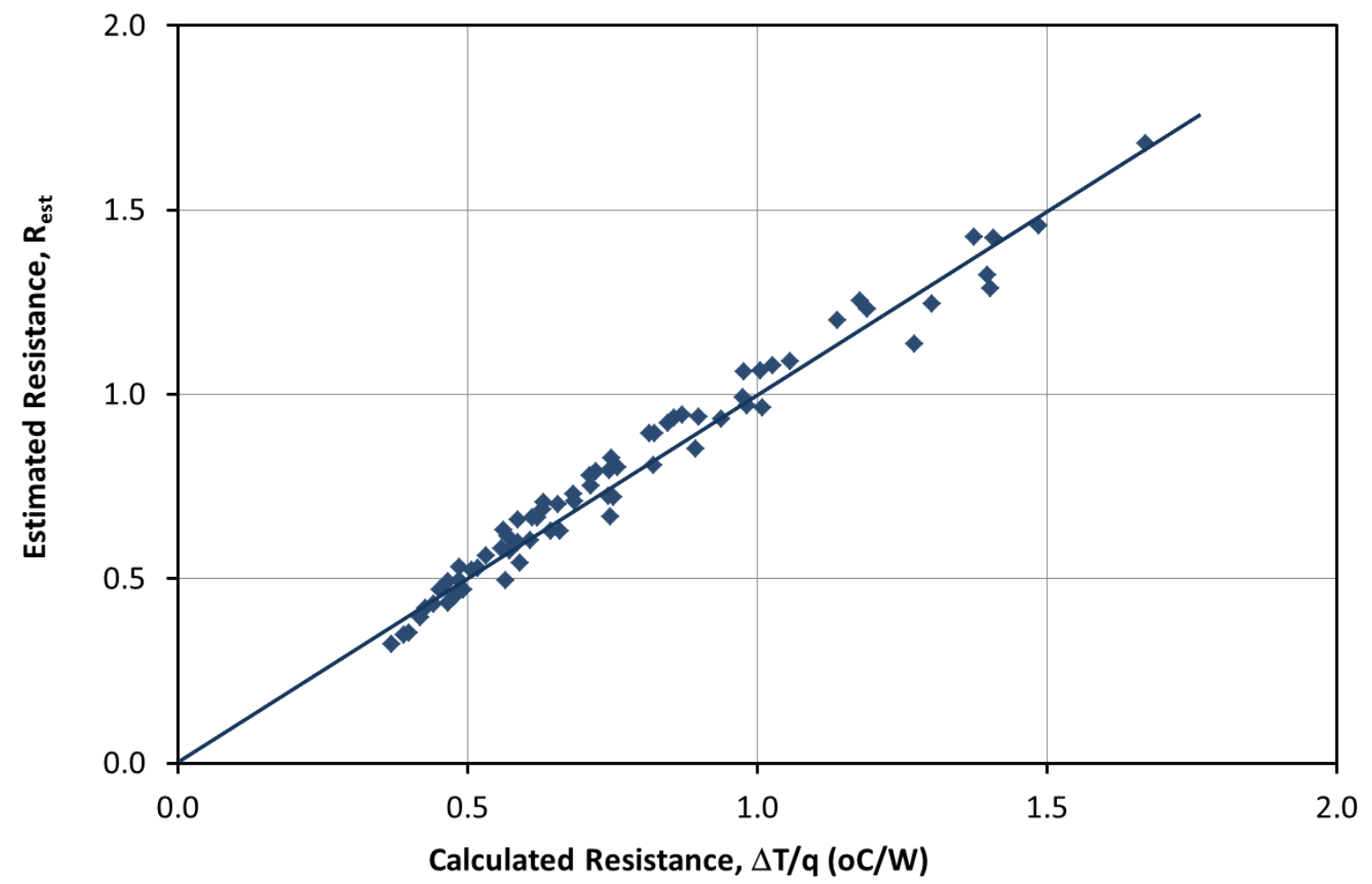

Figure 4.1 Plot comparing the estimated resistance to heat transfer from the cell center to the cooled surface of the module to that calculated by the FlexPDE model.

The average error in the estimated $\Delta T / q$ compared to the values calculated by the FlexPDE model for the 70 cases studied was $6.0 \%$ and the maximum error was $13.0 \%$. This accuracy was deemed to be satisfactory in that for all practical battery designs, the error will be only a fraction of a degree Celsius.

\subsubsection{Heat Transfer from Module Wall to Flowing Coolant}

Heat may be transferred to and from the modules by flowing fluid directly across the module casing. For ease of communication, the focus of this discussion will be on cooling of the module rather than heating for cold-climate operation. In theory, both liquid and air may be used as the heat transfer fluid. However, the stacked cell design we have selected has minimal exposed area relative to the overall volume of the cells. Our calculations have shown that liquid cooling is the only feasible option for this particular module design. The superior heat transfer of liquids (density and heat capacity) allows for implementation of this compact design without exposure of the individual cells to the heat transfer fluid. A design of this kind should result in a lower cost and higher energy density battery than a different design that cools individual cells. 
The model directly calculates the temperature drop between the module wall and the heat transfer fluid for a set pressure drop, fluid (coolant) temperature rise, and fluid physical properties. A 50/50 ethylene glycol, deionized water $\left(\mathrm{EG} / \mathrm{H}_{2} \mathrm{O}\right)$ mixture was selected based on the low cost and contemporary use in coolant systems. The default pressure drop was taken to be 10 millibar, but may be changed by the user if desired. The gap in which fluid flows is sized to maintain the target pressure drop without going below a minimum gap height of $3 \mathrm{~mm}$. A coolant temperature rise of $1{ }^{\circ} \mathrm{C}$ was selected to establish a mass flow rate, but also may be changed by the user.

Calculation of the heat transfer coefficient allowed for determination of the temperature difference between the module and average coolant temperature. A schematic of the flow passageway and change in temperature profile with distance is shown below in Figure 4.2. The outer wall of the flow passage is assumed to be perfectly insulated. The inner wall (module casing) is assumed to have a constant heat flux perpendicular to the wall. Laminar flow was assumed to simplify the calculation of the velocity profile (parabolic).

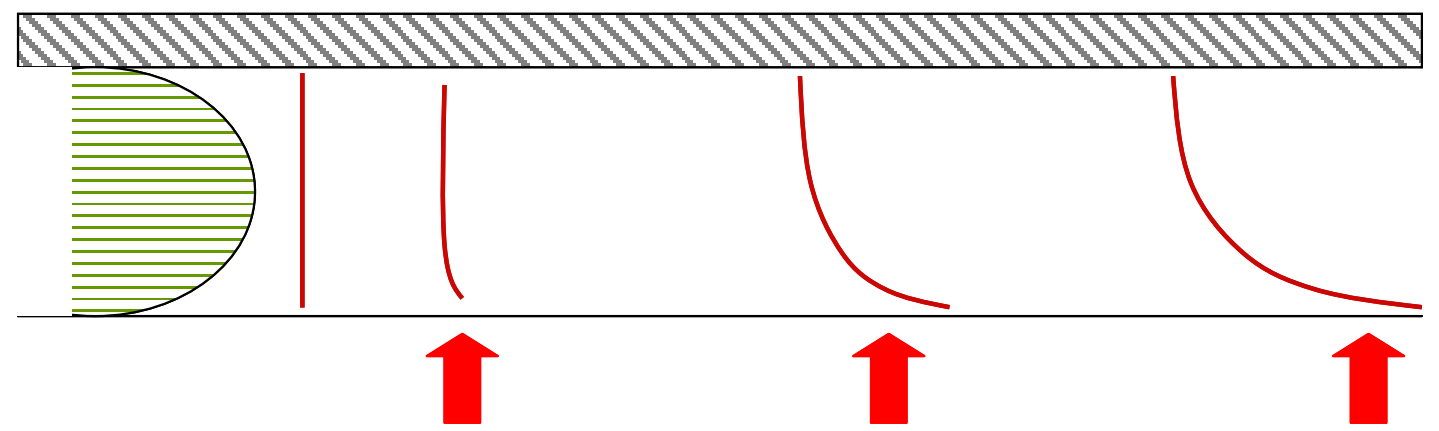

Figure 4.2 Heat transfer from the module wall to the laminar flow heat transfer fluid. The temperature profile of the fluid is shown at different lengths down the path.

Frequent use of dimensionless numbers was necessary to adequately correlate the numerical results into a generally useable form. We define the Reynolds, Prandlt, Graetzl, and Nusselt numbers here for completeness. ${ }^{44}$ The Reynolds number, Re, is the ratio of inertial to viscous forces. The Reynolds numbers were always less than 1000 confirming laminar flow. The Prandlt number, $\mathrm{Pr}$, is the ratio of the momentum diffusivity to thermal diffusivity. The Prandlt number for the $\mathrm{EG} / \mathrm{H}_{2} \mathrm{O}$ mixture is approximately 38 . The Graetz number, $\mathrm{Gz}$, is directly proportional to the product of the Reynolds and the Prandlt numbers. Moreover, the $\mathrm{Gz}$ value is inversely proportional to the distance down the fluid flow path, $l$, resulting in higher values near the start of the flow path. Finally, the Nusselt number, $\mathrm{Nu}$, is the ratio of the convective to conductive heat transfer. Here $u_{\text {ave }}$ is the average fluid velocity, $d_{H}$ is the hydraulic radius (twice the flow gap), and $\mu$ is the viscosity. The heat capacity, $c_{p}$, thermal conductivity, $k$, and heat transfer coefficient, $h$, are the critical heat transfer values. The mass flow rate, $G$, and the width of the channel, $W$, are the remaining parameters.

$$
\begin{gathered}
\operatorname{Re}=\frac{\rho u_{\text {ave }} d_{H}}{\mu} \\
\operatorname{Pr}=\frac{c_{p} \mu}{k}
\end{gathered}
$$




$$
\begin{gathered}
\mathrm{Gz}=2 \frac{G c_{p} d_{H}}{k W l}=2 \frac{d_{H}}{l} \operatorname{Re} \operatorname{Pr} \\
\mathrm{Nu}=\frac{h d_{H}}{k}
\end{gathered}
$$

Coupled momentum and heat transfer has been solved previously, by determining a number of the eigenvalues of an analytical series solution, for a vast number of various geometrical configurations related to pipe, duct, and parallel plate flow. ${ }^{45,46}$ We have chosen to reach the solution numerically and then fit a correlation between the Graetz number and the mean Nusselt number. The empirical form provided by Nickolay and Martin provides an accurate means of correlating the results over many orders of magnitude. ${ }^{47}$ The correlation, shown in Equation 4.9, relates the Graetz number and the limiting solution, $\mathrm{Nu}_{\infty}=5.385$, to the mean Nusselt number. Then the mean heat transfer coefficient may then be directly calculated from Nu. Here $n$ and $C_{1}$ are fitting parameters.

$$
\mathrm{Nu}=\left[\left(\mathrm{Nu}_{\infty}\right)^{n}+\left(\mathrm{C}_{1} \mathrm{Gz}^{1 / 3}\right)^{n}\right]^{1}
$$

The numerical model was solved with the finite element method using FlexPDE software. We note that the bulk or "cup mixing" fluid temperature in Equation 4.10, the average temperature of the fluid normalized by the fluid velocity profile, was necessary to reach the proper values.

$$
T_{\text {avg }}=\frac{1}{2 u_{\text {avg }}} \int T(y) u(y) \partial y
$$

The following important assumptions were used to reach a solution.

1. Flow of incompressible heat transfer fluid is laminar

2. Thermal diffusion is allowed up and down stream of the heat transfer (for convergence)

3. Boundary conditions: $\mathrm{dT} / \mathrm{dy}=0$ at insulation; $\mathrm{q}=$ constant at module casing

4. Negligible radiative energy transfer

5. Steady state conditions reached

Figure 4.3 displays the temperature profile between the module casing and the insulated wall for various distances along the flow channel. The average temperature of the fluid has risen $1{ }^{\circ} \mathrm{C}$ at the end of the flow path even though the maximum and minimum temperature is separated by nearly $5{ }^{\circ} \mathrm{C}$. The simulated change in average temperature down the length of the flow channel allows the calculation of the average heat transfer coefficient and thus Nusselt number. The correlation, Eq 4.9, determined from various simulations conditions is shown in Figure 4.4. An excellent fit is obtained allowing for implementation of the correlation into the design and cost model. This correlation now enables efficient and accurate calculations of the heat transfer coefficient to be made in the spreadsheet informing the user of the effectiveness of the thermal management in the design. 


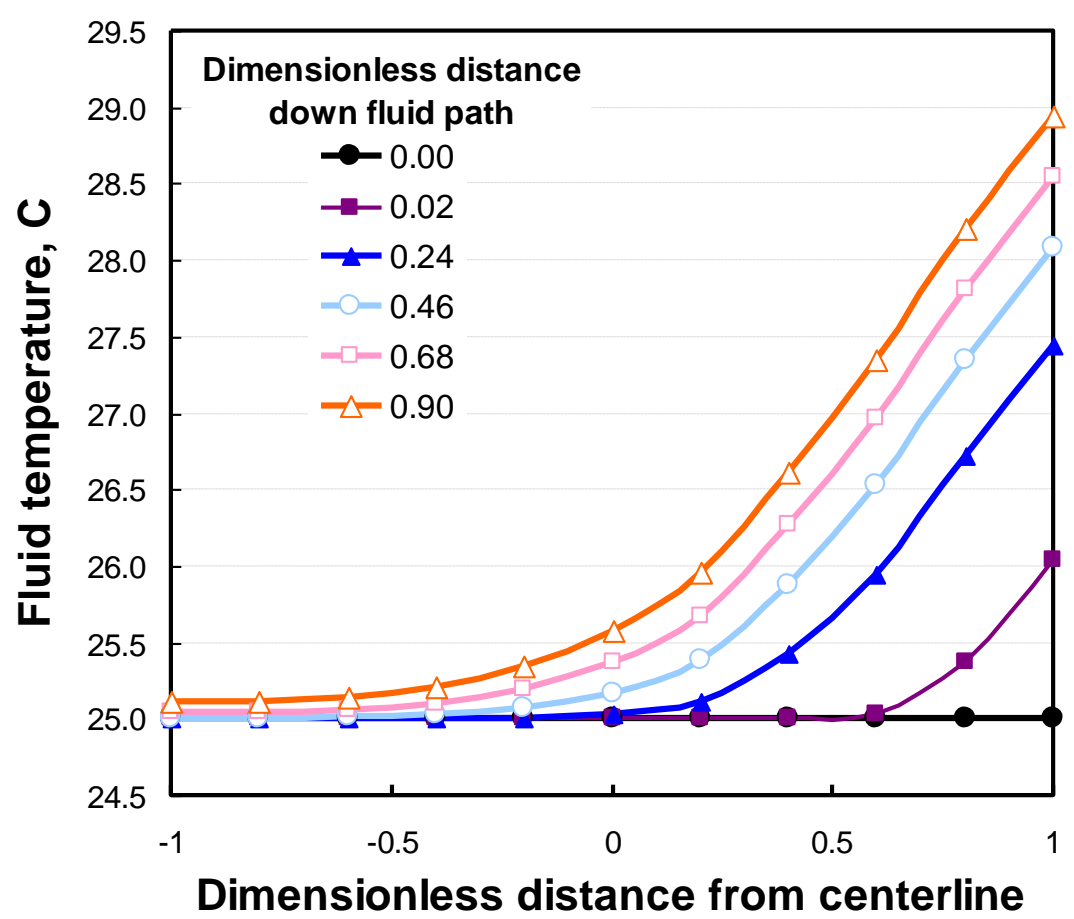

Figure 4.3 Temperature profile in the heat transfer fluid for various fractions of the dimensionless path length.

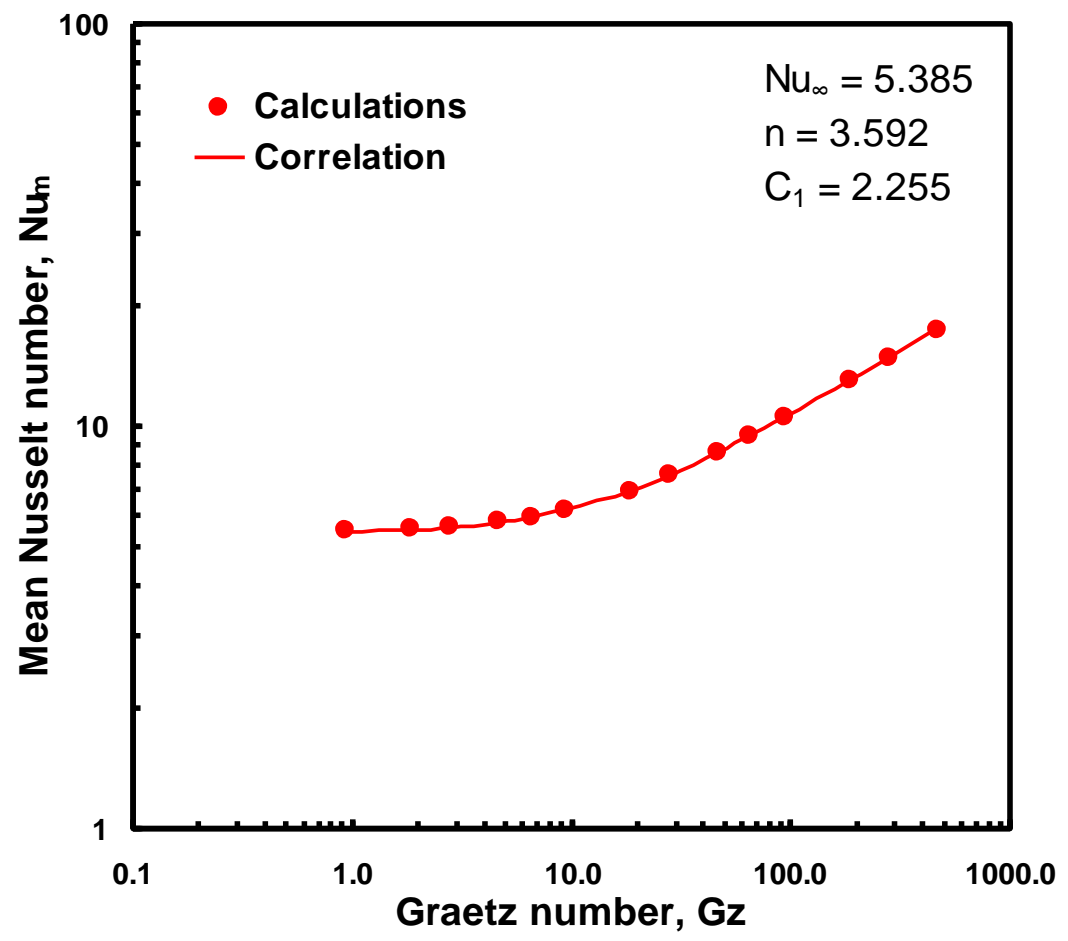

Figure 4.4 Correlation of model simulation results relating the Graetz number and mean Nusselt number for laminar flow between an insulated surface and the module casing. 
In general, the heat transfer from the module is improved by increasing the contact area and increasing the fluid flow rate. The contact area may be increased by using cells with a higher aspect ratio. This also results in a smaller temperature gradient within the cell as discussed previously in section 4.3.1. Increasing the fluid flow rate is accomplished by using a lower temperature rise and/or a larger target pressure drop. The gap height may prevent a change in a single parameter from having a significant affect on the temperature drop. Physical limitations of implementing a cooling system should be considered when moving to higher flow rates and pressure drops. The user should note that raising both of these parameters will increase the cost of the battery design in ways that the model does not consider (e.g. more expensive pump, increasing structural integrity, etc).

For high speed driving or very aggressive driving cycles, the temperature difference between the surface of the cooled module surface and the bulk of the coolant may become fairly large $\left(>10^{\circ} \mathrm{C}\right)$. This coupled with the temperature rise within the cells could result in too high cell centerline temperatures. This result can be avoided by controlling the inlet coolant temperature as a variable that is adjusted in a classic cascade automatic control system to control the module wall temperature at the desired value. Thus, the temperature rise at the center of the cells will be essentially held to that resulting from conduction within the cell and will not be greatly influenced by the temperature rise in the coolant.

\subsection{Cooling and Heating Required to Maintain Pack Temperature}

When parked in the sun for several hours, the internal vehicle temperature and, thus, that of the battery may become so hot that the life of the battery is reduced. To avoid this, the vehicle air conditioning system may be actuated intermittently to cool the battery. By allowing the temperature of the battery to fluctuate by several degrees, it is only necessary to actuate the cooling system about once per hour for a few minutes. For a set of target temperatures with a difference of $25^{\circ} \mathrm{C}$ and with the default insulation thickness $(10 \mathrm{~mm})$ and default thermal conductivity $(0.00027 \mathrm{~W} / \mathrm{cm}-\mathrm{K})$, BatPaC calculates the average cooling requirement to be about $60 \mathrm{~W}$ for PHEV-40 batteries. The performance coefficient of the vehicle air-conditioning system might reduce the actual energy draw to less than half that, but heating of the system outside of the battery during the hour-long downtime periods would be a counter-acting factor. The BatPaC model calculates the energy required for cooling of all types of electric-drive vehicle batteries. However, most HEVs may not have electrically driven air-conditioning units and some other method might be needed to avoid very high battery temperatures during parking such as thicker insulation and fan cooling.

If the battery is to deliver full power at startup, it must be at a temperature of at least $5^{\circ} \mathrm{C}$. This minimum temperature can be maintained by heaters and circulation of the glycol solution. $\mathrm{BatPaC}$ calculates the amount of power required to maintain the battery temperature for any set of battery and ambient temperatures. PHEV-40 batteries would require about $50 \mathrm{~W}$ of heat to maintain the battery temperature at $20^{\circ} \mathrm{C}$ above that of the ambient under steady-state conditions. During recharging this heating could be easily accomplished for 20 hours at a cost of $\$ 0.10$, assuming an energy cost of $\$ 0.10$ per $\mathrm{kWh}$. If the vehicle is not at a source of power for recharging, limited energy (say 1-2 kWh) can be drawn from the battery (if not blocked by a 
switch actuated by the driver) and then automatically shut off after maintaining the battery temperature for one to three days, depending on the ambient temperature.

\subsection{Heat-up from Cold Ambient Conditions}

All of the batteries for the various types of electric-drive vehicles will occasionally be exposed to very cold temperatures, which will require special heat-up procedures. All but the EV batteries can be heated with the aid of the engine. This can be done with electric heaters operated from power taken from the generator or from glycol solution from the engine cooling system. If the latter, it might be prudent to isolate the engine coolant from the battery coolant by means of a plastic heat exchanger.

Another method of heating the battery is by means of the electric heaters that should be available for maintaining the battery temperature (section 4.4). BatPaC calculates the amount of heat needed and the time required with suitable heater power. For PHEV-40 batteries, about 15 minutes is required with $2-\mathrm{kW}$ heaters. This method of heating will be slower than with the engine coolant and even the latter would result in some delay before the battery is capable of full power.

To avoid delay in starting vehicles from a cold startup, the driver could initiate heating by means of a remote device, which in the future may be a telephone. By this means, heating could be initiated either from heat drawn from the engine or electric heaters. Remote initiation of heat-up would be especially important for an EV away from a charging station in that no engine is available to assist heating and the large size of the battery would result in a long heating period with electric heaters. The BatPaC model estimates the time under these conditions. 


\section{Modeling of Battery Pack Manufacturing Cost}

\subsection{Approach}

The manufactured cost of a battery pack is calculated with input from the design information generated in modeling the cell and battery pack performance. The design modeling determines the annual materials and purchased items requirements. The manufacturing cost is then added to these materials costs, along with a warranty cost, to reach the unit cost of a single battery pack. The manufacturing costs for the designed battery are scaled from a baseline plant. The baseline plant was designed for a battery of intermediate size and production scale so as to establish a center-point for other designs. The baseline plant accounts for the size, speed, number of units, direct labor, and depreciation of the capital cost for each processing step. These costs are adjusted to meet the requirements for a plant producing the battery under study. The process expenses are summed with the additional costs of operating the manufacturing facility. These costs include launch costs, working capital, variable overhead, general, sales, administration (GSA), research and development, depreciation, and profit. Additionally, the costs for the thermal management, battery management system, and disconnects have been estimated to provide the total cost to the OEM for the integrated battery pack.

In this analysis, all costs are evaluated for 2020 when large battery manufacturing plants are built. All dollar values are brought back to 2010 with allowance for inflation. In other words, all costs and prices are in 2010 dollars. Some materials and battery manufacturing costs are lower than recent values, where we judged that processing improvements for high volume production of materials would reduce costs.

The baseline manufacturing plant was calculated for an annual production rate of 100,000 batteries. The cost model accounts for different scales of manufacture by recalculating the costs of each individual step in the manufacturing process. The changes in capital and operating costs will change the calculated unit cost of the battery pack. The parameters were determined to provide reasonable estimates for manufacturing rates of 20-500 \% of the baseline rate. Thus, for a plant that is far different in size from the baseline plant, for instance a pilot plant having an annual production of only 5,000 battery packs per year, the estimate from this study would be expected to be less accurate than if determined in a study dedicated to that purpose.

To simplify the cost calculations, it was assumed that all hardware items for the cells, modules and battery will be purchased from a vendor specializing in similar products. The costs for these items were estimated to be a fixed value plus an additional value proportional to the weight of the item, which is calculated during the battery design. In mature manufacturing plants in 2020, toward which this study is directed, some items which are assumed to be purchased in this study might actually be internally manufactured from raw materials. This would increase the number of processing steps needed in our manufacturing simulation and thus complicate the cost calculations. Assuming that some parts would be purchased if they would actually be produced from raw materials would tend to underestimate capital and labor costs and overestimate purchased items expenses. However, the net effect would be a very small change to the overall unit cost of the battery pack. 


\subsection{Materials Costs, Purchased Items, and Pack Integration}

The end battery pack cost depends significantly on the cost of both the active and inactive materials that compose the design. In this subsection, the assumed material costs and the rationale behind them are presented. We provide for means to scale the materials cost with production volume using the same method used for processing rates as discussed in section 5.4. In general, the materials costs will be largely insensitive to production volume since we have assumed a high volume market already exists. Only the negative and positive electrode active materials are assumed to have a minor benefit for larger scales of production. While we state suggested materials costs and sensitivity to production scale, the users of the cost model may enter any value that they desire.

\subsubsection{Battery Specific Materials Cost}

The largest contributions to the materials cost of the battery are from the following components: positive and negative electrode active material, separator, electrolyte, and current collector foils. The choice of the materials often defines the size and performance of the battery as well as the cost. Many different variations of materials are possible in the Li-ion family of chemistries. However, we have chosen to focus on the different available positive electrode materials with less attention on the negative electrode. This reflects the current research and manufacturing activities. The separator and the electrolyte are also both active areas of development. However, the following battery designs are based on a single electrolyte and separator combination. Including the cost and effect of additives and enhanced separators is beyond the scope of this work. The user is always able to modify the dimensions, cost, and ASI that may be required to account for changes in these materials.

The price of specific battery materials is of some debate. The values presented in Table 5.1 compare our suggested costs to those reported recently in the open literature. Our values, as well as the others in the table, are derived from conversations with material, cell, and original equipment manufacturers. The sources are commonly anonymous and the accuracy of the values is generally unknown. We present the comparison of published values so that the user of the cost model may appreciate the accepted range of values for commonly used materials.

\subsubsection{Positive Electrode Active Materials}

The cost of positive electrode materials is driven to a large extent by the cost of the raw materials from which it is made. The archetype Li-ion positive electrode material, lithium cobalt oxide (LCO), was the original material commercialized in Li-ion batteries for consumer electronics. LCO has many excellent characteristics but is not considered a viable choice for use in Li-ion batteries for automotive applications. One of the largest drawbacks of LCO, other than safety concerns, is the high and volatile cost of the cobalt. While tolerable in the consumer electronics market, the cost is too high for use in an automobile battery. Many other materials are in a commercially viable state of development and are currently utilized in Li-ion batteries produced today (Table 5.1) such as lithium manganese spinel oxide (LMO) and lithium nickel manganese cobalt oxide (NMC). ${ }^{3,6}$ The relative advantages and disadvantages of each material will not be discussed here. 


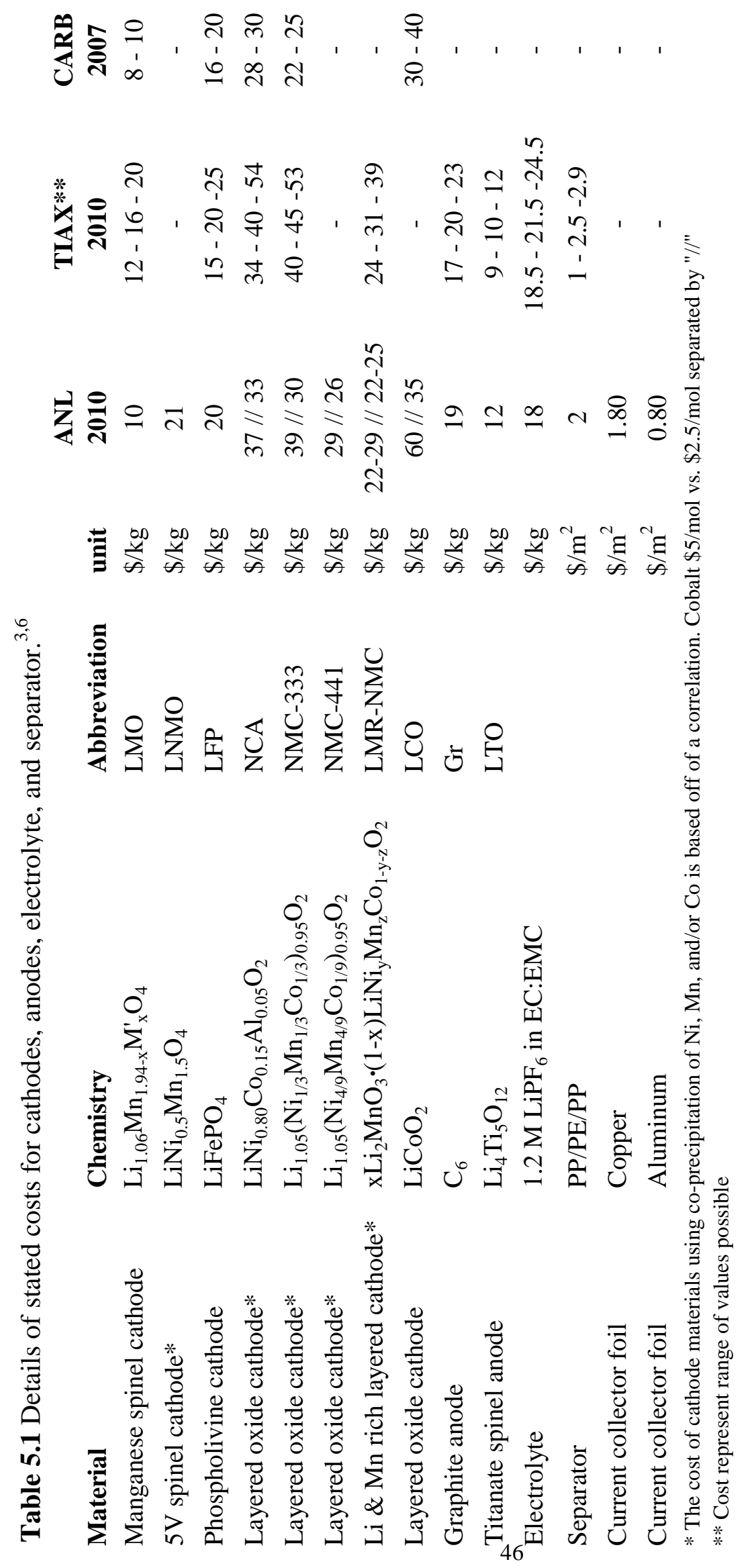


The amount of cobalt and nickel, as well as ease of manufacture, controls the end price for a positive electrode material. For example, the NMC-441 is less expensive than the NMC-333 as the cobalt quantity is significantly reduced. The market prices for cobalt and nickel metals vary dramatically from year to year. Reducing the quantities of these materials in the positive electrode will reduce the total price and price volatility. Researchers at TIAX LLC have treated this variation and shown the significant effect on end battery cost. ${ }^{10}$ The average traded metal prices for the last 20 years is $48 \$ / \mathrm{kg}$ and $15 \$ / \mathrm{kg}$ for cobalt and nickel respectively. These numbers are based on historical prices for the metals as collected by the United States Geological Survey (USGS). ${ }^{48}$ The metal prices are indicators for how the intercalation material cost will relate when compared to one another. The fact these materials are not earth abundant means they will not benefit as much as other materials from increased scales of production.

We employ the relationship in Equation 5.1 to systematically calculate the cost of the transition metal based spinel and layered compounds. The final cost, $C$, of the lithiated oxide depends on the baseline cost, $C_{0}$, and the contributions of the lithium and transition metal raw materials, $C_{i}$. The molar stoichiometry, $x_{i}$, is transformed to a mass basis with the molecular weight of the raw material, $M W_{\mathrm{i}}$, and the final product, $M W$. The baseline cost is the sum of the cost for processing, additional raw materials, and profit margin associated with the manufacture of the materials. We assume a baseline cost of $\$ 7 / \mathrm{kg}$ for single metal containing oxides (LMO and LCO) and $\$ 16 / \mathrm{kg}$ for the co-precipitated metal oxides such as NMC-333 and NMC-441. NCA is known to have a slightly lower yield and requires additional raw materials resulting in an assumed $C_{0}=\$ 20 / \mathrm{kg}$. The costs for $\mathrm{Li}, \mathrm{Ni}, \mathrm{Mn}$, and $\mathrm{Co}$ are taken to be $0.22,0.85,0.15$, and $5.00 \$ / \mathrm{mol}$ respectively. Aluminum is assumed to be similar in cost to manganese for these calculations. One may directly translate these numbers to raw materials costs resulting in $\$ 6 / \mathrm{kg}$ for $\mathrm{Li}_{2} \mathrm{CO}_{3}, \$ 5.5 / \mathrm{kg}$ for $\mathrm{NiSO}_{4}$, $\$ 32 / \mathrm{kg}$ for $\mathrm{CoSO}_{4}$, and $\$ 1 / \mathrm{kg}$ for $\mathrm{MnSO}_{4}$. Calculations are also shown in Table 5.1 using $\$ 2.5 / \mathrm{mol}$ for cobalt as a simple demonstration of the effect of cobalt on the end material cost.

$$
C\left(\frac{\$}{k g}\right)=C_{0}+\frac{1}{M W} \sum_{i} x_{i} C_{i} M W_{i}
$$

In general, earth abundant elements should be the dominate transition metals used if a low cost positive electrode is desired. Both iron and manganese are abundant and inexpensive transition metals for intercalation materials. Comparison of the iron phosphate, LFP, to manganese spinel, LMO, reveals how processing costs contribute to the end price of a material. LMO is relatively easy to manufacture. In contrast, LFP requires a reducing atmosphere and a carbon coating step to reach the end product. The increased complexity in the manufacturing process is realized in the price. However, one could argue that the manufacturing cost will decrease with increased knowledge from larger scales of production.

\subsubsection{Negative Electrode Active Materials}

While several negative electrode materials exist for Li-ion batteries, carbon materials in the form of graphite and/or hard carbon are still used in the vast majority of commercial cells. Graphite offers the greatest energy density while hard carbon is said to enable high rate capability with decreased risk of lithium plating (an undesired side reaction) during high charge rates. We have chosen synthetic graphite as a generic carbon electrode in our model. The price of graphite is 
much better understood than that of most of the positive electrode materials. However, significant differences in cost and performance will exist between synthetic, natural, and coatednatural graphite. The method of production and necessary heat-treatment will control the end cost. Graphite, although in different purity grades or microstructure forms, is used in many industries. This is in stark contrast to the positive electrode materials.

The lithium titanate electrode, LTO, offers an interesting option compared to graphite. Unlike graphite, LTO operates within the stability window of the electrolyte. The higher electrode potential, $1.5 \mathrm{~V}$ vs $\mathrm{Li}$, dramatically reduces or eliminates the formation of the solid electrolyte interphase (SEI). As a result, nanoparticle-based LTO may be implemented without concerns of increased side reactions with the electrolyte. The reduced nanoparticle dimensions increase the available surface area for reaction while simultaneously shortening the diffusion length. Both of these factors combined with the lack of SEI dramatically reduce the impedance of the electrode.

\subsubsection{Electrolyte and Separator}

The electrolyte used in this model is based on a lithium hexafluorophosphate salt, $\mathrm{LiPF}_{6}$, dissolved in a carbonate based solvent system. The carbonate solvent system is a blend of ethylene carbonate, EC, and a linear carbonate such as ethyl methyl carbonate, EMC, or dimethyl carbonate, DMC. Other chemical additives may be used to limit the capacity and power fade of the battery over time. Polymers may be added to the electrolyte as either a minor or major component. This is not discussed in any further detail in this work. The price of $18 \$ / \mathrm{kg}$, about $22 \$ / \mathrm{L}$, is only for the base electrolyte (i.e. no additional additives).

The separator is typically a porous membrane based on polypropylene (PP) and sometimes includes a polyethylene (PE) middle layer. PP and PE are very inexpensive raw materials and thus the suggested cost of $\$ 2 / \mathrm{m}^{2}$ is in large part due to the manufacturing process required to form the porous network in the membrane. As competition and scale of manufacture increase, the prices of the separator may fall closer to $\$ 1 / \mathrm{m}^{2}$. However, the cost of improved technology may offset some of this cost reduction, so we have retained our cost estimate of $\$ 2 / \mathrm{m}^{2}$.

As safety is a major concern for Li-ion batteries, the separator plays a key role in isolating the oxidant from the fuel. If the two charged electrodes contact each other (short), then a run-away reaction is possible. Separators have been designed to "shut-down" or melt at key temperatures. The middle PE layer is the shut-down feature in our proposed separator. Ceramic coatings have also been used to ensure structural integrity. Many other approaches are being developed to increase the safety of Li-ion batteries. The user of the cost model should account for the specific separator technology in the price and dimensions (thickness and porosity) of the separator as needed.

\subsubsection{Current Collector Foils}

The current collector foils are based on copper metal for the negative electrode and aluminum for the positive electrode. However, the LTO anode material, because of its high voltage relative to lithium, enables the use of aluminum as the negative electrode current collector. The price of these foils is based on raw materials and manufacturing costs. The aluminum foil is produced by 
rolling of thicker stock foils into thinner and thinner sheets. On the other hand, copper foil is more likely to be produced through an electrodeposition process. The foils are 12 microns and 20 microns thick for the copper and aluminum current collectors respectively. The foils used in batteries have additional requirements beyond the cheapest product available. Surface treatments are often necessary to promote adhesion of the composite electrode to the foil surface. In addition, alloying of the foil may be necessary to achieve the required material properties for long life.

The raw material contributions to the foil price will vary with the volatility of the market price for the metals. Figure 5.1 displays the metal ingot price contribution on a $\$ / \mathrm{m}^{2}$ basis. These numbers are based on historical prices for the metals as collected by the USGS. ${ }^{48}$

The values for both aluminum and copper tend to vary significantly over the time period examined. The price for copper is more volatile and always more expensive than aluminum. Analysis of Figure 5.1 reminds the user of the cost model that cost quotes are only valid for a short period. As the market price for raw materials changes, so will the price for the finished product.

Conversations with manufacturers and suppliers lead us to take a price of 1.80 and $0.80 \$ / \mathrm{m}^{2}$ for battery grade copper and aluminum foil respectively. We point out that the current metal ingot price is only a small contribution to the end foil price being about $16 \%$ of the aluminum foil price and $23 \%$ of the copper foil price. Thus, a doubling of the ingot prices would only moderately increase the foil prices.

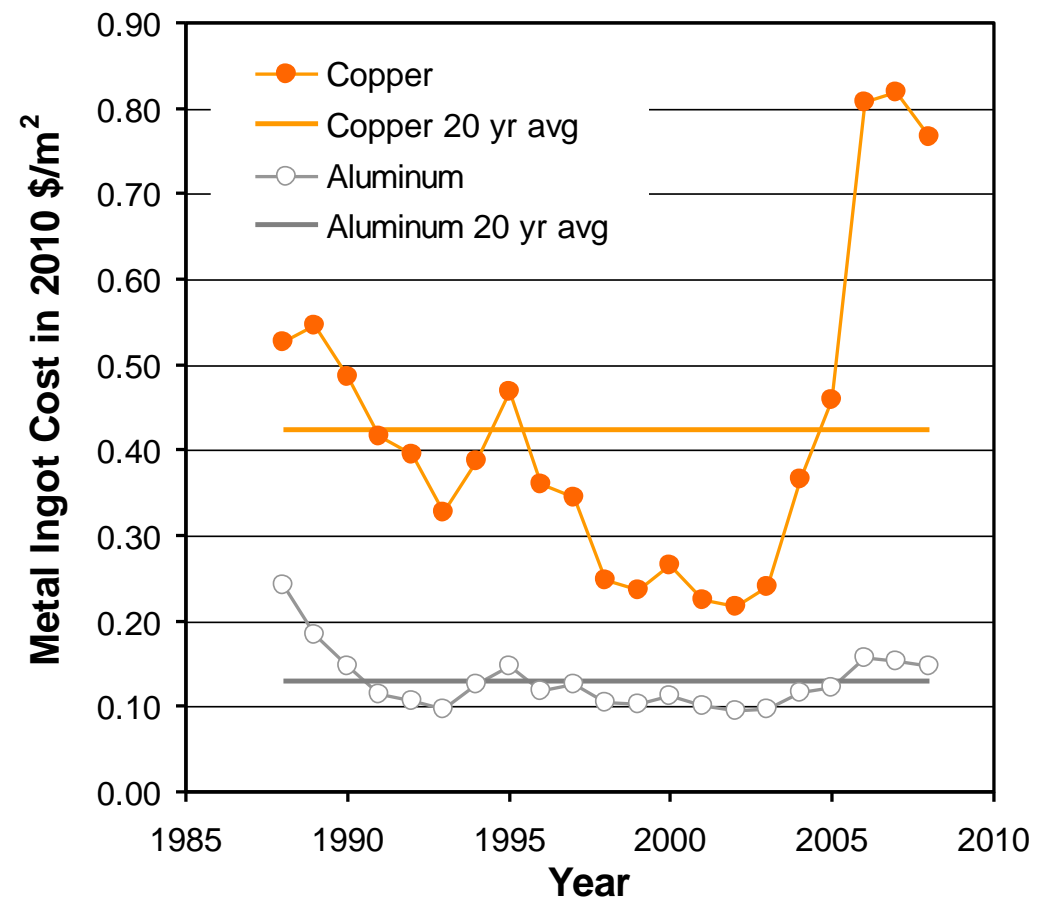

Figure 5.1 Metal ingot cost contribution to the current collector foils over a 20 year period. The average for that period is also shown. All costs are in 2010 US\$. 


\subsubsection{Additional Electrode Components}

The binder and conductive additive in the positive and negative electrodes add a small but real cost to the battery. The conductive additive, more common for the positive electrode, was priced at $6.80 \$ / \mathrm{kg}$ for a high purity and moderate surface area carbon black material. The binder, perhaps PVDF or CMC based, is assumed to be $10 \$ / \mathrm{kg}$. The $N$-Methyl-2-pyrrolidone (NMP) solvent for the PVDF binder is estimated to be $3.20 \$ / \mathrm{kg}$. Most of the NMP is recovered after evaporation and recycled as discussed in section 5.3.3. Only the small amount lost in processing need be replaced. No cost is assumed for water used in the electrode slurry processing.

\subsubsection{Purchased Items Cost}

Table 5.2 lists the purchased items for the cell module and battery jacket. The cost of a SOC controller for each cell, or group of parallel cells, is $\$ 2.50$ plus a small factor for the cell capacity (Ah), which allows for higher cell balancing currents for larger cells. The other component costs include a fixed amount plus an additional factor, which is proportional to their mass, $m_{i}$. The cell negative terminal and parallel cell group connection are both made from nickel plated copper sheet and thus have the same cost equation. The costs shown for the terminals include an allotment for isolation tape that is necessary to protect the electrical connection. The bus bar is a fixed cost and is only charged if a single row of modules is used. A single row of modules requires a bus bar in order to locate the positive and negative terminals at the same end of the battery.

Table 5.2 Cost equations for purchased items

\begin{tabular}{|l|l|l|}
\hline Component, $\boldsymbol{i}$ & Cost Equation, $\$ \mathbf{u n i t}$ & Cost per unit \\
\hline SOC controller & $2.50+0.01 C$ & cell or parallel cell group \\
\hline Cell positive terminal & $0.25+4 m_{i}$ & cell \\
\hline Cell negative terminal & $0.25+6 m_{i}$ & cell \\
\hline Cell container & $0.20+3 m_{i}$ & cell \\
\hline Aluminum heat conductor & $0.10+4 m_{i}$ & cell \\
\hline Parallel cell group connection & $0.25+6 m_{i}$ & parallel cell group \\
\hline Module terminals & $0.75+5 m_{i}$ & module \\
\hline Balance of module (casing) & $1.00+3 m_{i}$ & module \\
\hline Module interconnect & $1.00+5 m_{i}$ & module \\
\hline Battery terminals & $15.00+0.02 I_{\text {total }}$ & battery pack \\
\hline Bus bar for one module row & 20.00 & battery pack \\
\hline Battery jacket & $30.00+7 m_{i}$ & battery pack \\
\hline
\end{tabular}

\subsubsection{Pack Integration Cost}

Various additional components and thus cost are necessary to integrate the battery into the electric drive system, which adds cost. While it is not clear what should and should not constitute the cost of the "battery pack," we present these additional items in Table 5.3 in an attempt to be complete. The model treats these values as a cost to the OEM for integrating the battery into the vehicle. After all, the price of the entire system is of interest to the final consumer of the product. 
The general conclusion is that the pack integration costs have the largest consequence for the smallest batteries. The worst case is perhaps that of a small PHEV10 battery. The integration costs of a PHEV10 battery carry the burden of charging from the grid, but provide only a modest electric drive benefit. The fixed cost of pack integration may amount to $25 \%$ of the battery pack total even without considering the costs of additional powertrain components. Clearly, understanding the entire cost of the electric drive system is of importance to evaluating the true value of the electrified vehicle to a consumer.

Table 5.3 Costs to integrate battery pack into vehicle drivetrain. $\$ / \mathrm{kW}$ numbers reflect maximum $\mathrm{kW}$ of cooling or heating required.

$\begin{array}{cccc}\text { Battery Management System } & \text { MicroHEV } & \text { HEV-HP } & \text { PHEV \& EV } \\ \quad \begin{array}{c}\text { Current and voltage sensing, \$ } \\ \quad \text { Module controls, \$/module }\end{array} & 40 & 70 & 100 \\ \begin{array}{c}\text { Disconnect Units } \\ \text { Auto. disconnect, \$ }\end{array} & 10 & 10 & 20 \\ \quad \text { Manual disconnect, \$ } & 15 & 70 & 200 \\ \text { Thermal Management System } & & 15 & 15 \\ \quad \text { Baseline thermal system, \$ } & 30 & 80 & 120 \\ \quad \begin{array}{l}\text { Additions to AC system, \$/kW } \\ \text { Heating system, \$/kW }\end{array} & 40 & 40 & 40 \\ & 20 & 20 & 20\end{array}$

\subsubsection{Battery Management System}

The battery management system (BMS), in our assumed battery design, integrates the modules and battery into the overall electric drive system. The BMS includes measurement and control features such as the following:

- Measurement of battery pack current and voltage

- Balancing of the module voltages (cell balancing done within module)

- Estimation of battery pack state-of-charge (SOC) and state-of-health (SOH)

- Estimation of module SOC and SOH

- Monitoring and signaling of battery thermal management

The cost of the BMS will scale with magnitude of battery current and with the need to charge from the electrical grid. Therefore the PHEV and EV batteries will have a higher burden from the BMS. The micro-HEV is assumed to have less complicated management and thus less cost than the HEV-HP.

\subsubsection{Manual and Automatic Disconnects}

The manual and automatic disconnects integrate a high-level of safety and electrical management into the electric drive system. The manual disconnect breaks the current flow pathway from the high-voltage terminals to the outer system allowing for the safe service of the vehicle and battery pack. This disconnect is designed to be operated when the electrical system is de-energized. The automatic disconnect is much more complex. This unit contains the connections for the highvoltage system to the rest of the vehicle's electrical system: drivetrain, grid charging (if applicable) and accessories (high and low voltage). Fuses are present as a hard-wired safety 
device to prevent unusually large current spikes from damaging the battery or drivetrain. Multiple contactors are used to appropriately channel electrical current depending upon normal operation or grid-charging. Engaging the contactors requires that multiple safety interlocks are established including isolation of the high voltage bus from the vehicle chassis and an inertia based sensor (crash protection). Finally, a small circuit is provided to prevent arcing of the current across the high-voltage contactor when the high-voltage circuit is closed.

The relative cost of the automatic disconnect amongst the various battery designs is driven by the pack voltage, maximum battery current, and the need for charging from the grid. The voltage of the pack has a significant effect if a $42 \mathrm{~V}$ micro-HEV pack is considered. For this system, electrical safety regulations allow a less complicated system to be used. Requiring higher battery currents generally increases the cost of electronics and conductors. The additional complications arising from grid-charging adds a significant additional cost to the PHEV and EV systems. It is unclear to the authors at this time what other factors may enable a lower burden of external safety controls. These additional costs in the automatic disconnect unit have the most pronounced effect on the cost of smaller batteries, as the burden amounts to a significant fraction of the total cost.

\subsubsection{Balance of Thermal Management System}

The thermal management of the battery is crucial to meeting the life and safety requirements of transportation applications. The complexity of this system must be minimized to reduce the cost and size burden on the vehicle. Our assumed design format uses liquid thermal management for all vehicle battery types. In practice, current microHEVs and HEV-HPs are more likely to be cooled by blowing air. Air-cooling is generally less expensive than liquid cooling, but is less effective, requires larger system volume, and may result in substantial background noise. Furthermore, directly cooling the pouch cells with air increases the magnitude of oxygen and water permeation through the seals resulting in a shortened lifespan for the battery. Air cooling is not feasible with our current assumed battery format (stacked cells sealed within module). The cells would need to be separated to allow air to flow past at least one side to achieve sufficient heat transfer as earlier versions of this model had used. ${ }^{16}$ Future versions of the model may include an option to select either air or liquid cooled. However, the main goal of this model is to explore the effect of battery performance and materials chemistry on the price of the battery to the OEM.

A single refrigerant compressor is used for both the cabin air and the battery cooling applications. Likewise, the same radiator and fan as the cabin cooling will also be used for the battery cooling refrigerant. Most OEMs appear to use an electric compressor for all full-HEVs (HEV-HP) and PHEVs/EVs that are liquid cooled. The incremental cost for an electric compressor at high volume in year 2020 will likely be $\$ 200-300$ more than the commonly used $\$ 100$ belt driven compressor. We do not include this incremental cost in our thermal management system cost; however, we state it here for completeness. The additional cost to the compressor for the battery cooling capacity is insignificant compared to burden of transitioning to the electric compressor. Experts in the field have informed us that the electric motor and highvoltage invertor are the largest contribution to the incremental cost of the electric compressor. 
An expansion valve on the refrigerant line and a heat exchanger (chiller) transfers the thermal energy from the heat transfer fluid to the refrigerant loop. A 50/50 DI-water/ethylene-glycol solution is selected as the heat transfer fluid. The assumed battery design has the heat transfer fluid pumped over the module casing to transfer heat from and to the cells. The battery may be heated by either a positive thermal coefficient (PTC) or flexible mat heater. The PTC heater would directly raise the temperature of the heat transfer fluid in a reservoir while the matt heater would be placed under the battery jacket insulation.

The PHEV and EV batteries will likely have both active and passive thermal management modes requiring some additional monitoring and an electrically actuated valve. We have assumed decreasing cooling costs for the HEV-HP and microHEV systems without explicitly dictating where the savings originate. In general, one would expect smaller batteries to have a less complicated control system, lower flow rates and possibly even direct cooling of the cells with the evaporator.

\subsection{Baseline Manufacturing Plant}

The model's baseline plant is designed to produce 100,000 NCA-Gr baseline battery packs per year. The baseline battery pack produced by the plant has sixty, 40-Ah capacity cells, providing a total pack power of $50 \mathrm{~kW}$ and total energy of $8.7 \mathrm{kWh}$. The battery will power 20 miles of vehicle travel at $70 \%$ of the pack energy and $300 \mathrm{Wh} / \mathrm{mile}$. The schematic diagram of the plant (Fig. 5.2) is designed to illustrate the flow of materials through the plant and the relative floor areas for the processing steps rather than representing a realistic plant layout. The overall manufacturing rate of 100,000 battery packs per year is achieved by operating for three shifts at the equivalent of 300 days per year of fully effective production. There will be more than 300 days of operation, but some days will have less than $100 \%$ effectiveness. The exceptions to three-shift operation are the Receiving and Shipping sections, which are active for only two shifts per day. The cost factors for the individual manufacturing steps in the baseline plant are summarized in Table 5.4 and discussed in detail in the sections that follow. Most of the operations are carried out with normal factory atmosphere, but the cell assembly process steps are completed in a dry room atmosphere. 


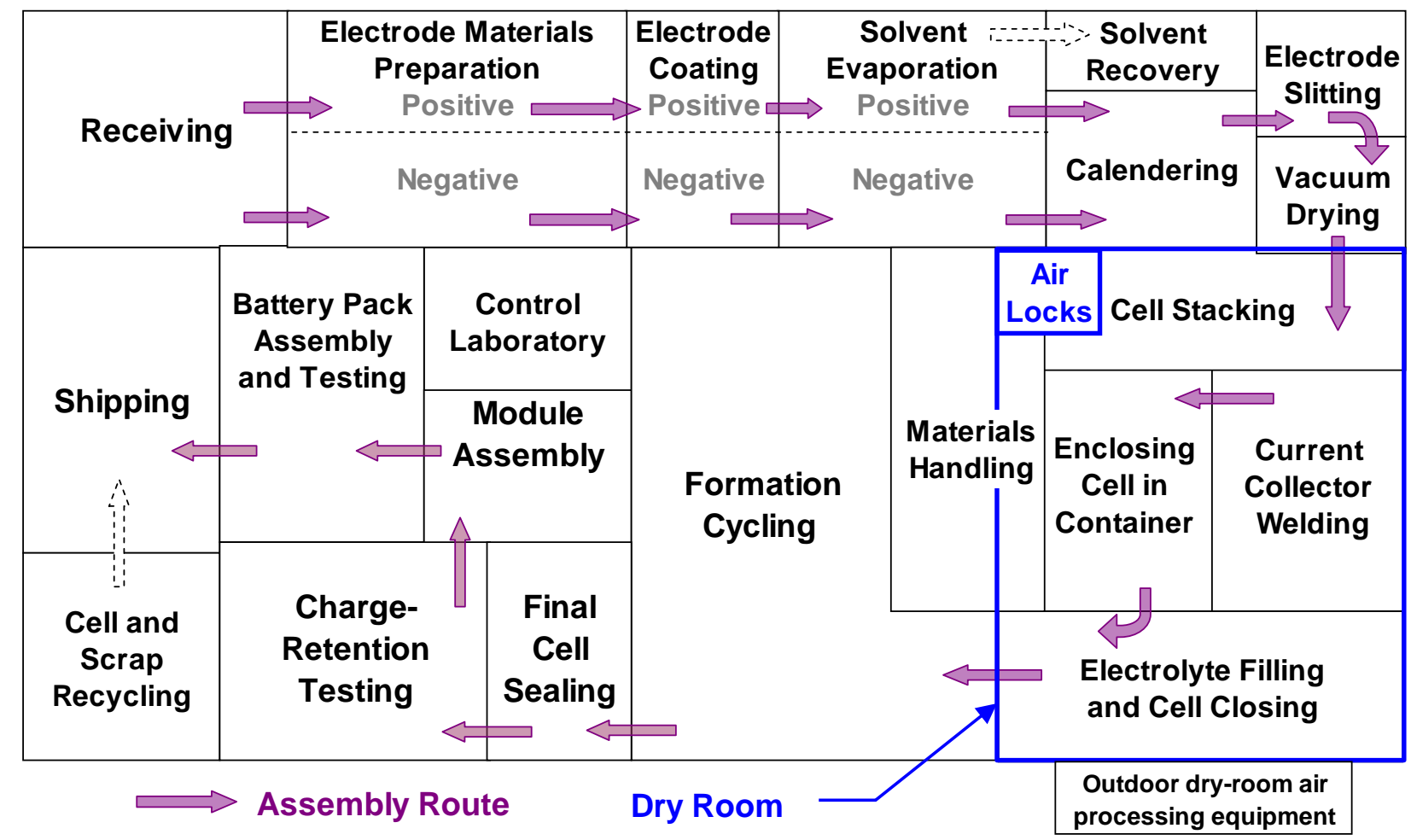

The areas in this diagram for each processing step are approximately proportional to the estimated plant areas in the baseline plant.

Figure 5.2 Baseline lithium-ion battery manufacturing plant schematic diagram. Manufacturing rate: 100,000 NCA-Gr battery packs per year, 50-kW pack power, 40-Ah capacity, 60 cells per battery. Operating year: 300 days with three 8-h shifts (two shifts for receiving and shipping)

\subsubsection{Receiving and Shipping}

These operations incorporate the moving equipment and storage facilities common to any such factory facilities. The Receiving section handles slightly less than $6,000,000 \mathrm{~kg}$ of materials per year and also has facilities to handle and store some of the electrode materials in a dry atmosphere. The Shipping section is required to enclose the battery packs in crates, which requires some automated equipment and more labor than is required for Receiving. Shipping also handles about 400,000 kg of scrap each year, which is broken down and prepared for shipping in the Rejected Cell and Scrap Recycle section. The estimated resources needed for the Receiving and Shipping sections are shown in the table below.

\begin{tabular}{|l|c|c|c|c|}
\hline & Rate Factor & Direct Labor & Capital Equip.* & Plant Area, $^{2}$ \\
\hline Receiving & $870,000 \mathrm{kWh} / \mathrm{y}$ & 3 per shift & $3.60 \mathrm{mil} \$$ total & 900 \\
Off-loading & & & 0.60 & \\
Moving & & & 1.20 & \\
Storage & & & 1.80 & \\
\hline Shipping & $870,000 \mathrm{kWh} / \mathrm{y}$ & 6 per shift & $5.0 \mathrm{mil} \$$ total & 900 \\
\hline
\end{tabular}

*Total cost including installation 


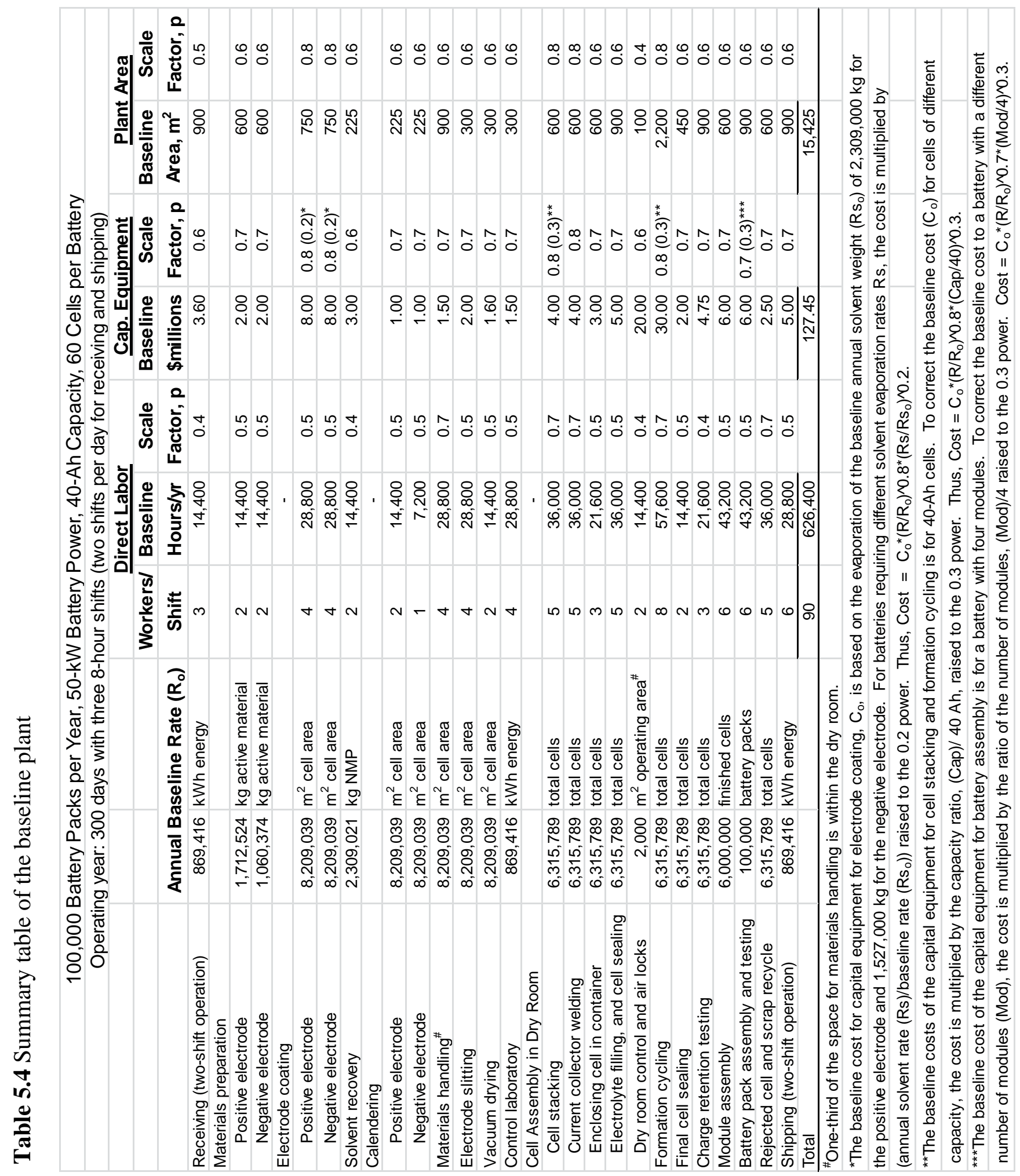




\subsubsection{Electrode Materials Preparation and Delivery to Coating}

The electrode materials, which consist of active material, carbon (if necessary), binder and binder solvent, are well mixed in small batches in portable tanks. At the design production rate in the baseline plant, each shift requires three tanks each holding about 1000 liters of positive electrode material mix and three tanks each holding about 900 liters of negative electrode material mix. The section must be capable of exceeding this design rate of production by at least 25\% to catch up in case of unscheduled downtime in Materials Preparation or in some of the section immediately following that section. The tanks of prepared materials are moved to the Coating section and pressurized to push the coating paste into the coating mechanism. The estimated resources needed are the following:

\begin{tabular}{|l|c|c|c|c|}
\hline Materials Prep. & Rate Factor & Direct Labor & Capital Equip.* & Plant Area, $\mathbf{~ m}^{2}$ \\
\hline Positive & $1,710,000 \mathrm{~kg} / \mathrm{y}$ & 2 per shift & 2.0 mil\$ total & 600 \\
Materials & active material & & & \\
\multicolumn{1}{|c|}{ Storage tanks } & & & $1.00 \mathrm{mil} \$$ & \\
\multicolumn{1}{l|}{ Mixing tanks } & & & 0.50 & \\
\hline Moving equip. & & & 0.50 & \\
\hline Negative & $1,210,000 \mathrm{~kg} / \mathrm{y}$ & 2 per shift & 2.0 mil $\$$ total & 600 \\
Materials & active material & & & \\
\hline
\end{tabular}

*Total cost including installation

\subsubsection{Electrode Coating on Current-Collector Foil}

The positive and negative electrode structures are formed by coating both sides of the current collector foil. In the baseline plant, the coating lines are 1.5 meter wide continuous roll-to-roll coating processes carried out at a line speed of $10 \mathrm{~m} / \mathrm{min}$. The first set of coating and drying stations coats one side of the current collector foil, drives off the solvent in a heated oven, and turns the foil over while transferring it to a second set of stations. The second set of coating and drying stations applies and dries the remaining coating before the coated foil is wound into a large roll at the end of the line. An advanced alternative would be to run the foil directly into the calendering process. The negative and positive coating lines are very similar. However, some of the negative material is coated only on one side to provide the electrodes at the end of the cell stacks. For the baseline plant, a total of $8,170,000 \mathrm{~m}^{2} / \mathrm{y}$ of coating (annual cell area) is required for the positive electrode (slightly more for the negative electrode), which allows for the $5 \%$ loss of cells expected to fail testing and inspection. A larger area of foil than the coated area must be fed to the coaters to allow for the part of the foil that is not coated so as to provide tabs for welding to the terminals (about 10\%) and to allow for trimming losses during electrode slitting $(8 \%)$. Also, about $30 \%$ excess coating capacity must be provided to allow for unscheduled downtime. Only one coating line is needed for each electrode type to meet these needs. If one coating line breaks down, the other coating line may change over temporarily to coat the other electrode material.

The oven sections of the coating line are designed to dry coatings about 100 microns thick at the coating speed of $10 \mathrm{~m} / \mathrm{min}$. A thicker coating will require longer ovens at additional capital cost which is provided in the adjustment of costs discussed in section 5.4. For the same annual area 
throughput, a coating line that coats both sides with a 300 -micron coating would cost $\$ 9,500,000$ rather than the $\$ 8,000,000$ cost for the 100 -micron coater. The binder solvent for the positive electrode in the baseline plant is NMP, which must be recovered by condensation and recycled. About $0.5 \%$ of the binder solvent is combusted with a thermal oxidizer and must be replaced. For the negative electrode the binder is water, which need not be recovered. The estimated resources to meet these needs are the following:

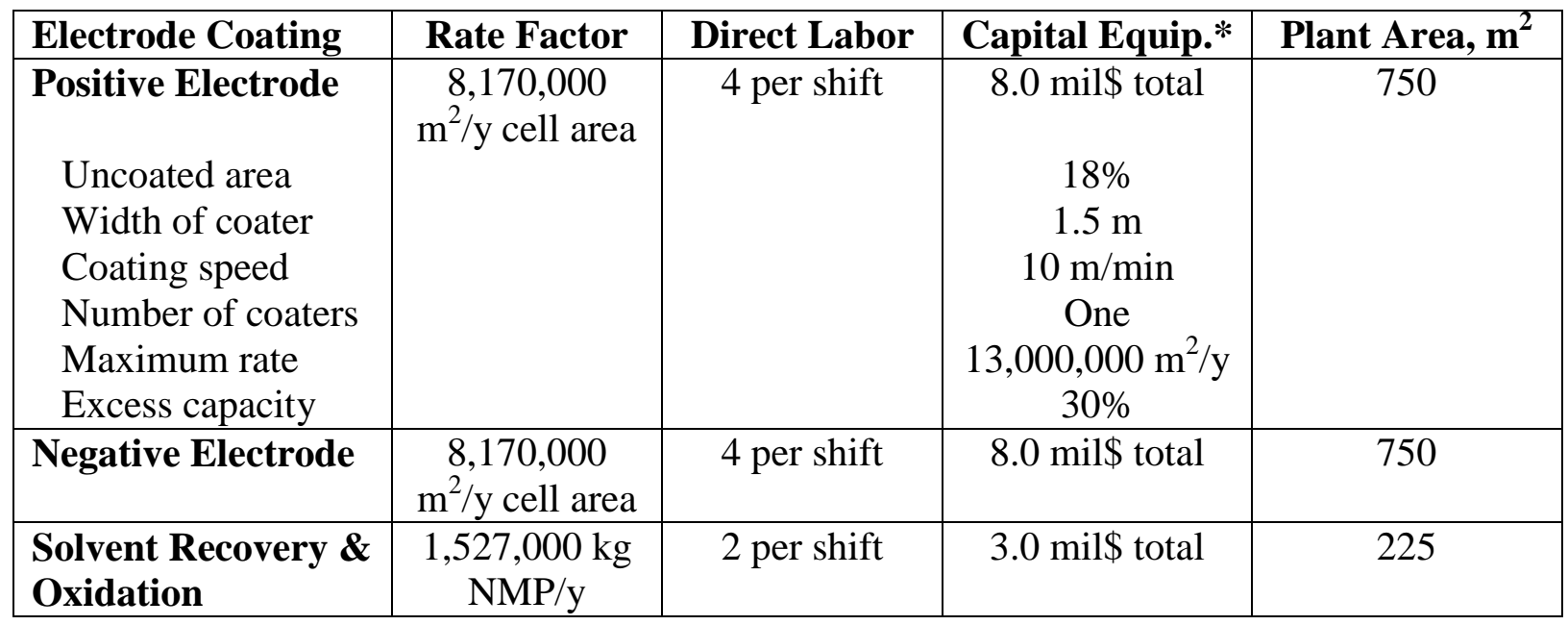

*Total cost including installation

\subsubsection{Calendering}

The materials leaving the coating lines may be stored on large rolls (see next section). However, typically the materials leaving the coaters would go directly to the calendering process in which the coatings are compressed by rolling to meet the specified void volume fraction, which will later be filled with electrolyte. The calendering equipment must match the output of the coating equipment producing $8,170,000 \mathrm{~m}^{2} / \mathrm{y}$ of cell area with a maximum rate of $13,000,000 \mathrm{~m}^{2}$ of foil per year to meet contingencies as in coating. We estimate three workers are necessary to collectively operate the two pieces of equipment. The estimated resources to meet these needs are the following:

\begin{tabular}{|l|c|c|c|c|}
\hline Calendering & Rate Factor & Direct Labor & Capital Equip.* & Plant Area, $\mathbf{~ m}^{\mathbf{2}}$ \\
\hline Positive Electrode & $\begin{array}{c}8,170,000 \\
\mathrm{~m}^{2} / \mathrm{y} \text { cell area }\end{array}$ & 2 per shift & 1.0 mil\$ total & 225 \\
\hline Negative Electrode & $\begin{array}{c}8,170,000 \\
\mathrm{~m}^{2} / \mathrm{y} \text { cell area }\end{array}$ & 1 per shift & 1.0 mil\$ total & 225 \\
\hline
\end{tabular}

*Total cost including installation

\subsubsection{Inter-Process Materials Handling}

For all processes (Fig. 5.2), work in progress must be transported and occasionally stored to permit nearly-continuous operation of the equipment. Storage areas must be provided both inside and outside of the dry room. Raw materials must also be moved to the processing sites, which for those in the dry room means through a separate air lock for materials transfer. One-third of the 
total space for Inter-Process Materials Handling is within the dry-room for the baseline plant and also for all other plants. The estimated resources to meet these needs are the following:

\begin{tabular}{|c|c|c|c|c|}
\hline Materials Handling & Rate Factor & Direct Labor & Capital Equip.* & Plant Area, $\mathbf{~ m}^{\mathbf{2}}$ \\
\hline & $\begin{array}{c}8,170,000 \\
\mathrm{~m}^{2} / \mathrm{y} \text { cell area }\end{array}$ & 4 per shift & 1.5 mil\$ total & 900 \\
\hline
\end{tabular}

*Total cost including installation

\subsubsection{Electrode Slitting}

The coated electrode foils are slit into strips between the coated sections and then into individual electrodes as shown in Fig. 2.3. The estimated scrap loss of foil for this process is about $8 \%$. The estimated resources to meet these needs are the following:

\begin{tabular}{|l|c|c|c|c|}
\hline Electrode Slitting & Rate Factor & Direct Labor & Capital Equip.* $^{*}$ & Plant Area, $^{2}$ \\
\hline & $\begin{array}{c}8,170,000 \\
\mathrm{~m}^{2} / \mathrm{y} \text { cell area }\end{array}$ & 4 per shift & 2.0 mil\$ total & 300 \\
\hline
\end{tabular}

*Total cost including installation

\subsubsection{Final Electrode Drying}

In the absence of electrolyte, no harm is done by exposing the electrodes to normal factory air; however, the electrodes must be dried by heating under vacuum prior to cell assembly. Maintaining extremely low moisture conditions during cell assembly is believed to be very important in achieving long battery life. The final drying step coupled with dry room conditions ensures minimal moisture content in the final product. The pertinent processing rate in determining the resources necessary for drying is the total amount of active materials processed per year (other electrode materials are approximately proportional), which for the baseline plant is $2,950,000 \mathrm{~kg} / \mathrm{y}$ or $3,275 \mathrm{~kg} / \mathrm{shift}$. The individual electrodes exiting from the electrode slitting process are separated into stacks by polarity, loaded into vacuum drying ovens, dried for several hours, and unloaded directly into the dry room. The estimated resources to meet these needs are the following:

\begin{tabular}{|l|c|c|c|c|}
\hline Electrode Drying & Rate Factor & Direct Labor & Capital Equip.* & Plant Area, m$^{2}$ \\
\hline & $\begin{array}{r}2,950,000 \mathrm{~kg} / \mathrm{y} \\
\text { active material }\end{array}$ & 2 per shift & $1.6 \mathrm{mil} \$$ total & 300 \\
$\begin{array}{l}\text { Dryer capacity } \\
\text { Number of dryers }\end{array}$ & & & $600 \mathrm{~kg} / \mathrm{shift}$ & \\
Maximum rate & & & 8 & \\
\hline
\end{tabular}

*Total cost including installation

\subsubsection{Control Laboratory}

The purpose of the control laboratory is to ensure that the raw materials and the electrodes being fabricated meet specifications. Laboratory personnel collect or supervise collection of samples and carry out analyses. The estimated resources to meet these needs are the following: 


\begin{tabular}{|l|c|c|c|c|}
\hline & Rate Factor & Direct Labor & Capital Equip.* $^{*}$ & Plant Area, $^{2}$ \\
\hline Control Lab & $869,000 \mathrm{kWh} / \mathrm{y}$ & 4 per shift & 1.5 mil\$ total & 300 \\
\hline
\end{tabular}

*Total cost including installation

\subsubsection{Cell Stacking}

The cells are assembled in four steps, which are carried out in a dry room. The first of these steps is cell stacking. The primary rate factor that determines the cost for all steps in cell assembly is the number of cells assembled per year. For cell stacking an additional cost factor is the capacity of the cells; large cells usually require more electrodes of larger area and thus a more capable, faster cell stacking machine. The method used to determine the extra costs of stacking equipment is detailed in Table 5.4. The capacity of the cells is deemed to have only a minor effect on the other steps in cell assembly and is not taken into account for those steps. The electrodes are inserted in a folded separator sheet, the positive electrodes tabs protrude on one side and the negative electrodes tabs on the other. As in other parts of the plant, excess capacity is provided to allow catching up after unscheduled downtime. The estimated resources to meet these needs for the baseline plant are the following:

\begin{tabular}{|l|c|c|c|c|}
\hline Cell Stacking & Rate Factor & Direct Labor & Capital Equip. $*$ & Plant Area, $\mathbf{m}^{\mathbf{2}}$ \\
\hline & $6,320,000$ cells/y & 5 per shift & 4.0 mil\$ total & 600 \\
Stacking rate & & & 5 cells/min & \\
Number of units & & & 4 \\
Maximum rate & & & $8,640,000$ cells/y & \\
\hline
\end{tabular}

*Total cost including installation

\subsubsection{Current Collector Welding}

The current collector tabs for the negative and positive electrodes are welded to their respective terminals by ultrasonic welding. This procedure achieves a connection of near-zero resistance and avoids overheating the electrodes during the welding process. The estimated resources to meet these needs are the following:

\begin{tabular}{|l|c|c|c|c|}
\hline Tab Welding & Rate Factor & Direct Labor & Capital Equip.* & Plant Area, $\mathbf{m}^{\mathbf{2}}$ \\
\hline & $6,320,000$ cells/y & 5 per shift & 4.0 mil $\$$ total & 600 \\
Cell rate & & & 5 cells/min & \\
Number of units & & & 4 \\
Maximum rate & & & $8,640,000$ cells/y & \\
\hline
\end{tabular}

*Total cost including installation

\subsubsection{Enclosing Cell in Container}

The aluminum foil layer in the pouch container is sufficiently thick (100 microns default thickness) to permit the use of stiff, pre-shaped pouch halves. The pouches are assumed to be purchased as finished parts. Each cell is enclosed in these containers, which are then partially 
sealed prior to injecting electrolyte. The estimated resources to meet these needs are the following:

\begin{tabular}{|l|c|c|c|c|}
\hline Enclosing cells & Rate Factor & Direct Labor & Capital Equip.* & Plant Area, $\mathbf{~ m}^{\mathbf{2}}$ \\
\hline & $6,320,000$ cells/y & 3 per shift & 3.0 mil\$ total & 600 \\
Cell rate & & 5 cells/min & \\
Number of units & & & 4 & \\
Maximum rate & & & $8,640,000$ cells/y & \\
\hline
\end{tabular}

*Total cost including installation

\subsubsection{Electrolyte Filling and Cell Sealing}

At this station, the cells are evacuated, filled with electrolyte and temporarily sealed. The estimated resources to meet these needs are the following:

\begin{tabular}{|c|c|c|c|c|}
\hline Filling \& $1^{\text {st }}$ Seal & Rate Factor & Direct Labor & Capital Equip.* & Plant Area, $\mathbf{m}^{2}$ \\
\hline $\begin{array}{l}\text { Cell rate } \\
\text { Number of units } \\
\text { Maximum rate }\end{array}$ & $6,320,000$ cells/y & 5 per shift & $\begin{array}{c}5.0 \mathrm{mil} \$ \text { total } \\
5 \text { cells } / \mathrm{min} \\
4 \\
8,640,000 \text { cells } / y\end{array}$ & 900 \\
\hline
\end{tabular}

*Total cost including installation

\subsubsection{Dry Room Management}

Excellent dry-room atmosphere is required for lithium-ion cell assembly. A maximum dew point temperature of $-40{ }^{\circ} \mathrm{C}$ is maintained in the room. The load on the dry-room drying apparatus is determined by diffusion of water vapor through the walls, entry of air through the air locks, the number of workers in the room, and the need to admit some fresh air to limit the build up of contaminants such as electrolyte solvent vapor. These load factors are approximately a function of the room area. Because of the importance of the proper functioning of the dry room, two workers are on duty at all times to monitor its performance. The equipment for circulation and purification of the dry air will be located outside of the plant building, adjacent to the dry room. The estimated resources to meet these needs are the following:

\begin{tabular}{|l|c|c|c|c|}
\hline & $\begin{array}{c}\text { Operating } \\
\text { Area }\end{array}$ & Direct Labor & Capital Equip.* & Air Locks, $\mathbf{m}^{\mathbf{2}}$ \\
\hline Dry Room & $3,000 \mathrm{~m}^{2}$ & 2 per shift & 20.0 mil\$ total & 100 \\
\hline
\end{tabular}

*Total cost including installation

\subsubsection{Formation Cycling, Final Cell Sealing and Charge Retention Testing}

Formation cycling is expensive because it takes considerable time and each cell must be monitored separately. For plants to be operated in 2020, we expect some improvements from present day operations because of the urgency to improve and thus save cost. We project that the entire formation cycling and testing can be done in two shifts. These operations consist of 
charging the cell, discharging to full depth to measure capacity and impedance, followed by fully recharging the cells. These tests will be carried out in large temperature controlled cycling units that test 500 cells simultaneously, monitor each cell and automatically identify failed cells. The capital cost of the cycling equipment is primarily a function of the annual number of cells to be tested, but to a lesser extent on the capacity of the cells.

The short-term testing described above does not detect cells that have self-discharge rates that are slightly above normal, which could lead to catastrophic failures later. To detect such defects, the cell charge is topped off and the cells are stored for two weeks and then checked for loss of charge. Most of the test period is spent in large racks in compact arrays, without electronic monitoring. Incidentally, the two-week long self-discharge testing requires less floor space than for formation cycling, which lasts only two shifts.

The final cell sealing occurs between the formation cycling and charge-retention storage test. Gas generated during formation cycling may accumulate in the reservoir space that was created during the temporary sealing step. This gas is removed by creating the final seal below the reservoir and trimming off the unwanted portion.

The estimated resources to meet these needs are the following:

\begin{tabular}{|c|c|c|c|c|}
\hline & Rate Factor & $\begin{array}{l}\text { Direct } \\
\text { Labor }\end{array}$ & Capital Equip.* & $\underset{\mathbf{m}^{2}}{\text { Plant Area, }}$ \\
\hline $\begin{array}{l}\text { Formation Cycling } \\
\text { Cell capacity } \\
\text { Number of cyclers } \\
\text { Cells per cycler } \\
\text { Length of test } \\
\text { Testing capacity }\end{array}$ & $6,320,000$ cells/y & 8 per shift & $\begin{array}{c}30.0 \text { mil\$ total } \\
40 \mathrm{Ah} \\
35 \\
500 \\
2 \mathrm{shifts} \\
7,875,000 \text { cells } / y\end{array}$ & 2200 \\
\hline Final Cell Sealing & $6,320,000$ cells/y & 2 per shift & 2.0 mil $\$$ total & 450 \\
\hline $\begin{array}{l}\text { Charge Retention } \\
\text { Testing rack capacity } \\
\text { Racks per stack } \\
\text { Number of racks } \\
\text { Length of test } \\
\text { Testing capacity }\end{array}$ & $6,320,000$ cells/y & 3 per shift & $\begin{array}{c}4.75 \text { mil } \$ \text { total } \\
500 \text { cells } \\
5 \\
750 \\
14 \text { days } \\
8,040,000\end{array}$ & 900 \\
\hline
\end{tabular}

*Total cost including installation

\subsubsection{Module and Battery Assembly}

Approximately 5\% of the cells are expected to fail the formation cycling and charge-retention tests and these are sent to the Rejected Cell and Scrap Recycle section. The accepted cells $(6,000,000$ finished cells per year) are assembled into modules by attaching the terminals through laser welding or mechanical joining with spring loaded devices. Electronic circuit packs are attached that occupy about the same volume as a cell. An aluminum heat conductor is placed around every cell. These operations are carried out at four automated stations each capable of 
handling about 280 cells per hour. For the module design being cost estimated in this model, the module is enclosed in an air-tight aluminum container by double seaming. The processing rate that determines the cost of module assembly is the number of finished cells that must be handled per year.

The finished modules are assembled into battery packs with the aid of automated stations. The total cost of these stations is dependant mainly on the number of battery packs to be assembled per year $(100,000$ for the baseline plant), but to a lesser extent on the number of modules per pack. After assembly, the packs are moved to testing stations where they are discharged as a final check of impedance and to lower the state of charge to a level suitable for shipping. The estimated resources to meet these needs are the following:

\begin{tabular}{|l|c|c|c|c|}
\hline & Rate Factor & $\begin{array}{c}\text { Direct } \\
\text { Labor }\end{array}$ & $\begin{array}{c}\text { Capital Equip.* } \\
\text { Plant Area, } \\
\mathbf{m}^{\mathbf{2}}\end{array}$ \\
\hline $\begin{array}{l}\text { Module Assembly } \\
\text { Number of stations }\end{array}$ & $6,000,000$ cells/y & 6 per shift & 6.0 mil\$ total & 600 \\
Cells/h/station & & 4 & 280 \\
Capacity & & & $8,060,000$ cells/y & \\
\hline Battery Pack Assembly & 100,000 packs/y & 3 per shift & 3.0 mil\$ total & 450 \\
Modules/pack & & & 4 & \\
Number of stations & & & 6 & \\
Packs/h/station & & & 130,000 packs & \\
Capacity & & & 3.0 mil\$ total & 450 \\
\hline Battery Pack Testing & 100,000 packs/y & 3 per shift & & \\
\hline
\end{tabular}

\subsubsection{Rejected Cell and Scrap Recycle}

Scrap is generated in preparing the electrodes and by the rejection of $5 \%$ of the cells that go through formation cycling and charge-retention tests. This scrap is gathered and packaged for shipment for recycling of the materials having value. No credit is taken for the value of the scrap in this model except that the costs of gathering, sorting, packaging and shipping are understated by about that value. The main factor in determining the cost of scrap recycle is the number of cells rejected, which have to be disassembled to recover the scrap, a labor intensive process. The yields of materials in the various processing steps are shown in Table 5.5.

Table 5.5 Materials yields during electrode and cell fabrication

\begin{tabular}{|l|c|c|c|c|c|c|}
\hline \multicolumn{1}{|c|}{ Material } & $\begin{array}{c}\text { Material } \\
\text { Mixing }\end{array}$ & Coating & $\begin{array}{c}\text { Electrode } \\
\text { Slitting }\end{array}$ & $\begin{array}{c}\text { Cell } \\
\text { Stacking }\end{array}$ & $\begin{array}{c}\text { Electrolyte } \\
\text { Filling }\end{array}$ & Total \\
\hline Positive Electrode & 99 & 95 & 99 & 99 & & 92.2 \\
\hline Negative Electrode & 99 & 95 & 99 & 99 & & 92.2 \\
\hline Positive Current Coll. & & 99 & 92 & 99 & & 90.2 \\
\hline Negative Current Coll. & & 99 & 92 & 99 & & 90.2 \\
\hline Separator & & & & 98 & & 98.0 \\
\hline Electrolyte & & & & & 94 & 94.0 \\
\hline
\end{tabular}


The estimated resources needed for scrap recycle are the following:

\begin{tabular}{|l|c|c|c|c|}
\hline & Rate Factor & $\begin{array}{c}\text { Direct } \\
\text { Labor }\end{array}$ & Capital Equip.* & ${\text { Plant Area, } \mathbf{m}^{2}}$ \\
\hline $\begin{array}{c}\text { Scrap Recycle } \\
\text { Scrap rate }\end{array}$ & $6,320,000$ cells/y & 5 per shift & $\begin{array}{c}2.5 \mathrm{mil} \$ \text { total } \\
441 \mathrm{~kg} / \mathrm{shift}\end{array}$ & 600 \\
\hline
\end{tabular}

\subsubsection{Baseline Plant Summary}

The processing rates and the primary cost factors for the baseline plant are summarized in Table 5.4. The main processing rate for each step is shown in the second column. The requirements for direct labor, capital equipment and plant area, which are shown in detail in the subsections above, are summarized in the table. It is seen that the plant requires a total of 90 workers per shift, $\$ 127,450,000$ worth of capital equipment, and 15,425 square meters of plant area to manufacture the baseline battery at a rate of 100,000 battery packs per year.

\subsection{Adjustment of Costs for Varying Production Volumes}

Production volume may affect the end price of the battery in two distinct ways. First, the user of the model may change the annual production volume and every processing step will be affected. Somewhat differently, as the performance requirement and thus design is changed, the production of individual steps will change in non-uniform ways. As noted in Table 5.4, there are many processing rates that must be considered in addition to the overall number of battery packs manufactured per year. Each of these rates affects the costs of one or more steps in the process and may have no effect upon the costs of other steps in the process. For instance, when the user of the model increases the power of the battery packs without increasing the number of cells or their capacity, the model increases the area of the cells and decreases the electrode coating thicknesses. Such changes would result in an increase in the cost of the coating equipment, the floor area occupied by the equipment, and in the direct labor for that step in the process. It would have no effect on the cost of mixing the materials to be coated because the amounts of these materials per battery back are unchanged under the assumed conditions.

The general approach to cost estimation of multiplying a known cost by the ratio of processing rates raised to a power has also been applied to the capital cost of individual items of equipment. ${ }^{49}$

$$
C=C_{\mathrm{o}}\left(R / R_{\mathrm{o}}\right)^{p}
$$

Here, $C_{\mathrm{o}}$ is the capital cost of an installed equipment item designed for the baseline processing rate, $R_{\mathrm{o}}$. The power factor, $p$, relates the capital investment cost and the processing rate for the manufacturing step.

If the value of $p$ were 1.0, it would imply that the cost of the equipment item, or the equipment items if there are several in parallel, would be directly proportional to the processing rate. However, the value of $p$ for the cost of equipment is frequently about 0.6 to 0.7 for many 
manufacturing process steps because the equipment is larger for the higher processing rates and its cost is less than if it were directly proportional to the processing rate. For process steps requiring the addition of many identical pieces of equipment for scale up, such as may be true for formation cycling of battery cells, the value of $p$ may be as high as 0.9 . The value of $p$ is unlikely to reach 1.0 because the equipment cost includes installation, for which there is some savings even in installing multiple units of the same processing capacity. The relationships between cost and processing rate for two-fold and three-fold rate changes are illustrated in Table 5.6.

Table 5.6 The effect of processing rate $(R)$ on cost for various scale factors

\begin{tabular}{|c|c|c|}
\hline \multicolumn{3}{|c|}{$C / C_{o}=\left(R / R_{\mathrm{o}}\right)^{p}$} \\
\hline & \multicolumn{2}{|c|}{ Cost Ratio, $C / C_{\mathrm{o}}$} \\
\hline Scale Factor, $p$ & $R / R_{\mathrm{o}}=2$ & $R / R_{\mathrm{o}}=3$ \\
\hline 0.25 & 1.19 & 1.32 \\
\hline 0.3 & 1.23 & 1.39 \\
\hline 0.4 & 1.32 & 1.55 \\
\hline 0.5 & 1.41 & 1.73 \\
\hline 0.6 & 1.52 & 1.93 \\
\hline 0.7 & 1.62 & 2.16 \\
\hline 0.8 & 1.74 & 2.41 \\
\hline 0.95 & 1.93 & 2.84 \\
\hline 1.0 & 2.00 & 3.00 \\
\hline
\end{tabular}

Similar equations have been applied for determining the effect of processing rate on the annual hours of labor and the plant area required for a manufacturing step. In general, the value of $p$ is low for the labor equation, usually only 0.4 to 0.5 , because only a relatively small addition to the labor crew permits operation of larger equipment or of operating several more units of the same processing capacity. ${ }^{24}$ The value of $p$ for the plant area required for a processing step is slightly less than that for equipment. The floor area required for larger equipment or for more equipment items of the same size is proportionately less than the increase in the processing rate because of the more efficient use of the space occupied by the equipment and the savings in aisle area.

The value of the scale factors (i.e. $p$ factors) for labor, capital equipment, and floor area were estimated for each of the processing steps (Table 5.4). The scale factors selected for the direct labor requirement are usually only 0.4 to 0.5 , which indicates considerable unit cost reduction for increasing the plant throughput.

For most processing steps, increasing the processing rate beyond that in the baseline plant would result in a decision to increase automation or use faster equipment to mitigate the costs of higher levels of throughput. Decreasing the processing rate would have the opposite effect. Some steps in the process such as cell stacking, welding of current collectors, and formation cycling do not appear to be easily automated beyond the level intended in the baseline plant and, thus require a higher value for the scale factor of 0.8. This higher scale factor results in achieving fewer reductions in the cost per battery pack with increasing production volume. Additionally, a higher 
$p$ factor results in a less severe penalty for lower production scale for an individual step in the process.

There are five steps for which the cost of the capital equipment is affected by factors other than the main processing rate for the process step. These are discussed in the footnotes at the bottom of Table 5.4. For these steps, the costs that have been adjusted for the changes in the processing rate from the baseline rate are further adjusted to take into account the other cost factors. The cost of the coating equipment is adjusted for the amount of solvent to be driven off the positive and negative electrodes; thicker coatings need longer, more expensive ovens to drive off the additional binder solvent or the coater most be operated at lower speeds. The costs of the cell stacking equipment and the formation cycling equipment, for which the main cost factor in both cases is the number of cells to be fabricated annually, are also adjusted for the capacity of the cells; larger cells require more expensive equipment. The cost of the capital equipment for battery assembly is primarily a function of the number of cells in the battery, but it is also a function of the number of modules that must be interconnected. This dependence is accounted for in the model with an additional multiplying factor.

A breakdown of the baseline plant capital equipment costs listed in Table 5.4 is illustrated in Fig. 5.3. The largest costs for capital equipment are for formation cycling and testing, cell assembly (in the dry room) and electrode coating. These capital costs are likely to be dominant in any lithium-ion battery plant in the near future.

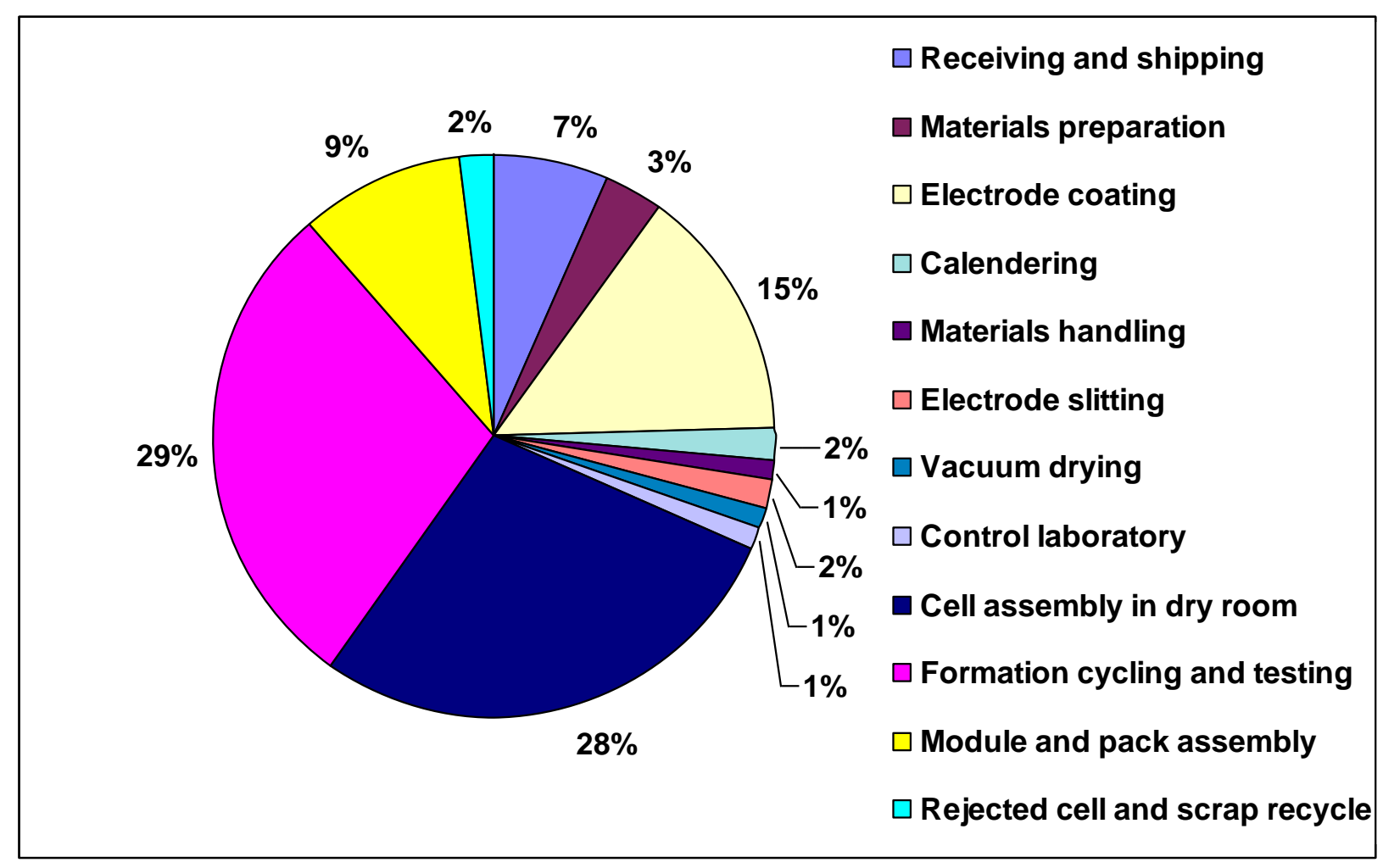

Figure 5.3 Breakdown of installed capital equipment costs for the baseline plant 


\subsection{Plant Investment Costs}

In this model, the calculated investment costs are defined as those directly related with building and operating the plant (Table 5.6). Other costs that may require investment, such as research and development, are added separately to the unit cost of the battery. The largest investment cost is for the installed capital equipment. Each cost item for the battery under design is adjusted from the estimate of the baseline plant. The plant cost is done in a similar way with a cost of $\$ 3,000$ per square meter $(\$ 280 / \mathrm{sq}$. ft) including land and utilities. The high cost for land and utilities accounts for both the area of the manufacturing facility as well as other land requirements such as office buildings and waste water treatment requirements. Launch costs include plant start-up, employee training and materials that are lost or recycled in early stages of production, beyond the normal amounts. Launch costs are estimated to be $5 \%$ of annual materials costs plus $10 \%$ of annual direct labor and variable overhead (Section 5.6). Working capital is needed to cover the costs of payroll, receivables, and the inventories of raw materials, work in progress and finished product. These working capital costs are partially offset by bills that are payable. We estimate the working capital to be $15 \%$ of the annual variable costs.

Table 5.6 Battery pack manufacturing investment costs

\begin{tabular}{|l|l|l|}
\hline \multicolumn{1}{|c|}{ Investment Costs } & \multicolumn{1}{|c|}{ Description } & \multicolumn{1}{c|}{ Method of Calculation } \\
\hline Capital Equipment & $\begin{array}{l}\text { Equipment costs including } \\
\text { installation }\end{array}$ & $\begin{array}{l}\text { Estimates of costs for each } \\
\text { processing step at baseline rates } \\
\text { adjusted for actual rates. }\end{array}$ \\
\hline Plant Floor Space & $\begin{array}{l}\text { Space includes aisles and space } \\
\text { for unfinished processing } \\
\text { inventory plus land and utility } \\
\text { costs. }\end{array}$ & $\begin{array}{l}\text { Estimates of costs for each } \\
\text { processing step at baseline rates } \\
\text { adjusted for actual rates. }\end{array}$ \\
\hline Launch Costs & $\begin{array}{l}\text { Plant start-up, training, out-of- } \\
\text { spec product. }\end{array}$ & $\begin{array}{l}5 \% \text { of annual materials cost, } \\
10 \% \text { of direct labor plus } \\
\text { variable overhead. }\end{array}$ \\
\hline Working Capital & $\begin{array}{l}\text { Cash to meet payroll, } \\
\text { receivables, inventories of raw } \\
\text { materials and of unfinished and } \\
\text { finished product, minus } \\
\text { payables. }\end{array}$ & $15 \%$ of annual variable costs. \\
\hline
\end{tabular}

\subsection{Unit Costs for Battery Pack}

The unit costs of the battery pack are calculated as summarized in Table 5.7.

\subsubsection{Variable Costs}

The costs of the materials and purchased items are based on the costs discussed in section 5.2, and the annual amounts of materials are adjusted for the yields of materials (section 5.3) and yield of cells. The direct labor is the sum of the labor cost for each step in the process, which are 
each calculated for the baseline plant and adjusted for the rate associated with the battery under study. Variable overhead is the cost of indirect materials and labor, utilities, and plant maintenance. It is estimated to cost $40 \%$ of direct labor costs and $20 \%$ of total depreciation.

\subsubsection{Fixed Expenses}

Fixed expenses include General, Sales, and Administration (GSA), research and development, and depreciation. The cost of GSA includes the plant office, taxes on income and property, cost of sales and insurance. It is estimated by the model as $25 \%$ of direct overhead and depreciation. Research and development (R\&D) must be carried out to ensure that the battery packs that are produced in the plant and the means of production continue to be competitive in the world market with respect to performance and price. The greater the investment in the plant and its equipment, the greater is the need to be successful in the R\&D effort. Thus, the expenditure has been set at $40 \%$ of the depreciation expense. Depreciation expense provides funding available for future investment in this plant or another venture to replace deteriorating plant and equipment. The equipment and plant are depreciated at straight-line rates for 6-year life (16.7\% per year) and 20-year life (5\% per year).

Table 5.7 Unit cost of battery pack

\begin{tabular}{|c|c|c|}
\hline Variable Costs & Description & Method of Calculation \\
\hline $\begin{array}{l}\text { Materials and Purchased } \\
\text { Items }\end{array}$ & $\begin{array}{l}\text { All materials and purchased } \\
\text { items in finished product and } \\
\text { lost in processing. }\end{array}$ & $\begin{array}{l}\text { Based on prices of materials, } \\
\text { cost equations for purchased } \\
\text { items and yields. }\end{array}$ \\
\hline Direct Labor & $\begin{array}{l}\text { Labor costs for operations and } \\
\text { immediate supervision. }\end{array}$ & $\begin{array}{l}\text { Estimates of costs for each } \\
\text { processing step at baseline rates } \\
\text { adjusted for actual rates. }\end{array}$ \\
\hline Variable Overhead & $\begin{array}{l}\text { Indirect materials, labor, } \\
\text { utilities, plant maintenance }\end{array}$ & $\begin{array}{l}40 \% \text { of direct labor cost plus } \\
20 \% \text { of depreciation }\end{array}$ \\
\hline \multicolumn{3}{|l|}{ Fixed Expenses } \\
\hline $\begin{array}{l}\text { General, Sales, and } \\
\text { Administration (GSA) }\end{array}$ & $\begin{array}{l}\text { Plant office, taxes on income } \\
\text { and property, cost of sales and } \\
\text { insurance expenses. }\end{array}$ & $\begin{array}{l}25 \% \text { of direct labor and variable } \\
\text { overhead plus } 25 \% \text { of } \\
\text { depreciation. }\end{array}$ \\
\hline Research and Development & $\begin{array}{l}\text { On-going research needed to } \\
\text { upgrade product and maintain } \\
\text { competitive position. }\end{array}$ & $40 \%$ of depreciation \\
\hline Depreciation & $\begin{array}{l}\text { Provides funds for new } \\
\text { investments to replace those in } \\
\text { current equipment and plant. }\end{array}$ & $\begin{array}{l}16.7 \% \text { of capital equipment cost } \\
\text { plus } 5 \% \text { of plant floor space } \\
\text { cost. }\end{array}$ \\
\hline Profit & $\begin{array}{l}\text { Return on invested capital after } \\
\text { taxes. }\end{array}$ & $5 \%$ of total investment costs. \\
\hline Warranty & $\begin{array}{l}\text { Funds set aside for reimbursing } \\
\text { customers for battery pack } \\
\text { failures. }\end{array}$ & $\begin{array}{l}5.6 \% \text { added to price based on } \\
\text { present worth of projected } \\
\text { payments. }\end{array}$ \\
\hline
\end{tabular}




\subsubsection{Profits}

The profit goal for this type of venture varies with the financial structure of the company, especially regarding long-term debt. For the model, the profit is set to provide a $5 \%$ return on the total investment, which is an approximate average for mature manufacturing as vehicle battery production is expected to be in 2020. In general, the chosen cost structure and the resulting margin are similar to a Tier 1 supplier in the automotive industry.

\subsubsection{Battery Pack Warranty Costs}

If a battery module or an entire pack fails, the replacement will cost much more than the original price paid by the OEM. It is important that such events are rare, but provision must be made to reimburse the vehicle owner, especially in the early years of the projected battery life. The extra costs of replacing the battery will result from labor for testing and replacing the battery, inventory costs for stocking replacement batteries, and servicing the battery controller if the new battery is slightly different than the old battery. It is likely that the battery manufacturer will be responsible for the cost of the new battery, which we assume will be equal to the cost of the original battery. The other costs of replacing the battery, to the extent that they are covered by the warranty, are assumed here to be covered by the automobile manufacturer and the dealer. The goal for average battery life is 15 years and a warranted life of 10 years, with full replacement in the first five years and shared cost of replacement for the last five years seems appropriate. The vehicle owner would pay an increasing share of the cost from between $0 \%$ at 5 years to $100 \%$ at 10 or more years. With these assumptions, the cost to the battery manufacturer will be equal to the present worth of the future costs of the new battery or modules as provided in the warranty. The rate of battery failure will vary over the life of the battery with a slightly higher rate early in life, then a low failure rate followed by a gradually increasing failure rate. For purposes of calculation we assume a failure rate of $1.0 \%$ per year throughout the warranty period. With an internal rate of return of $8 \%$ and calculated on a monthly basis, the present value of the future costs would be about $5.6 \%$ of the price of the battery before adding the warranty cost.

\subsection{Summary of Baseline Battery Cost}

The spreadsheet version of the model, which is discussed in more detail in sections 6 and 7, provides a summary sheet which is illustrated in Table 5.8 for the cost of the baseline battery and that of three others. This breakdown of the battery costs, with a brief summary of the design values, illustrates the effects of the cost factors. The second battery has twice the power of the baseline battery and the third battery has the same power as the baseline battery, but twice the capacity. The number of cells is the same for each battery. The energy storage is slightly higher for the battery with double power because the voltage would be slightly higher during the discharge to determine capacity. The battery with double the capacity has about the same number of electrodes; although, the electrodes are longer and wider in dimension, because the cell thickness is maintained. This results in a slightly higher resistance in the current-collector structure. The higher impedance lowers the voltage during the discharge capacity measurements and results in slightly less than twice the energy storage of the baseline battery. 
Table 5.8. Summary of results for cost of baseline battery and that of similar batteries with double the power and double the capacity of the baseline battery

Baseline

Double Power

Double Capacity Double Modules

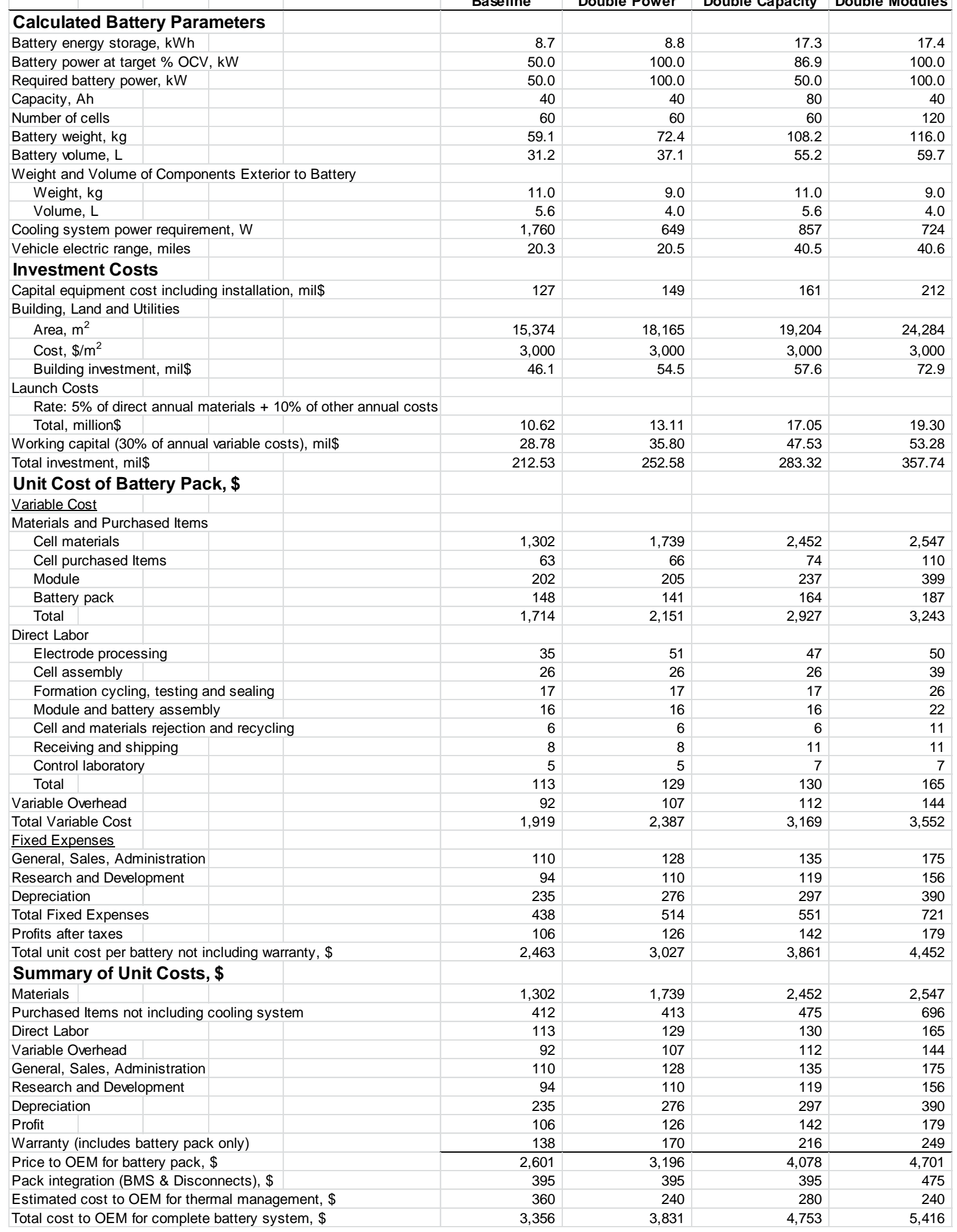


Doubling the power does not add as much cost to the materials and purchased parts as doubling the cell capacity. Most of the labor costs for the first three batteries are similar with the major difference being for the labor cost for electrode processing. The double power battery requires greater labor costs principally for coating the larger electrode area. Capital equipment and depreciation costs are higher for both the high power and high capacity battery packs. The increases in capital equipment cost for the high-power battery are for coating, calendering, materials handling and vacuum drying equipment. For the high-capacity battery, the main additional capital equipment costs are for the materials mixing, binder solvent recovery, cell stacking and formation cycling steps in the process.

Overall, doubling the power of the battery increases the price of the battery pack by only $23 \%$. Doubling the capacity of the cells increases the cost by $57 \%$, considerably more than for doubling the power. Alternatively, doubling the number of baseline cells and modules within a larger battery jacket (two rows of modules instead of one, twice the voltage, energy, and power) would increase the cost by $81 \%$.

The summary of unit costs for the baseline battery pack, which is shown at the bottom of Table 5.8, is illustrated in Fig. 5.4. The materials and purchased items are the largest costs for the battery. For larger levels of production, these costs are even more dominant because the scale factors for these items are close to one.

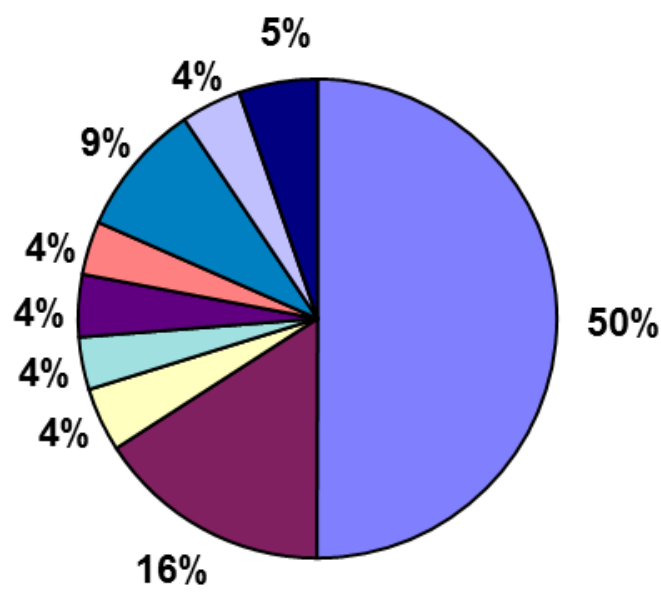

口Materials

$\square$ Purchased Items not including cooling system

口Direct Labor

口Variable Overhead

-General, Sales, Adm inistration

$\square$ Research and Development

口Depreciation

$\square$ Profit

Warranty (includes battery pack only)

Figure 5.4 Breakdown of unit costs for baseline battery with total price to OEM of $\$ 2600$. The total cost to the OEM, including pack integration components, is $\$ 3,360$. 


\section{Description of the Spreadsheet Model and Instructions for Use}

\subsection{Background}

Historically, the model has been based on Microsoft ${ }^{\circledR}$ Office Excel spreadsheets. The flexibility afforded by a spreadsheet approach has been extremely useful to the development of the calculations. Until now, the model had been in a constant state of development. Changes to parameters and equations were made rapidly and frequently. The publication of this report represents the first time a version of the model will be "frozen" for open distribution to the public. Advances will continue to be made with the model, such as those discussed in the last section of this report. However, distributions of the revised model will be made in an orderly fashion rather than the continuous improvement approach taken over the last number of years.

\subsection{Instructions}

The following subsections are a brief explanation of how one may operate the spreadsheet based model. The user is advised to save the original document separately as a back-up copy. Corruption of the calculation is possible and will likely occur during use by someone unfamiliar with the model.

\subsubsection{Enabling Calculation}

This Microsoft ${ }^{\circledR}$ Office Excel workbook requires the use of iteration. To enable this feature in Office 2003, go to the "Tools" drop-down menu and select "Options." On the calculation tab, check the box next to "Iteration" and change the maximum number of iterations to 1000 (Figure 6.1). Perhaps most importantly, ensure the calculation is set to automatic and not manual. If the iteration is not turned on, the software will present an error complaining about circular references. If the model is opened while a different Excel spreadsheet is in use, the software will also warn of an error. Simply close all Excel windows except for the model; alternatively, one could re-enable the iterative function as discussed above. In newer versions of Excel such as the Office 2010 edition, the iterative function may be enabled by going to File > Options > Formulas. 



Figure 6.1 Automatic iteration must be enabled for the spreadsheet model to function. The top screen shot was taken from Microsoft ${ }^{\circledR}$ Office Excel 2003 edition and the lower image is from the 2010 edition. 


\subsubsection{System Selection Worksheet}

The cell chemistry is selected by copying the system designated at the top of a column, for instance NCA-G in cell F3, pasting it into cell E3 (Figure 6.2). Any of the values in row E can be overridden by entering the desired value in column L. For example, the maximum electrode thickness may be overridden by placing a new value in cell L53. The selection of the cell chemistry also includes the associated prices at the bottom of the page. These prices can also be overridden by entering the desired values in column L. A full screen shot of the system selection worksheet is in Figure 6.3. An alternative cell couple, NMC333-G, is pasted into column O (Figure 6.2) as an example of another commercially relevant battery chemistry.

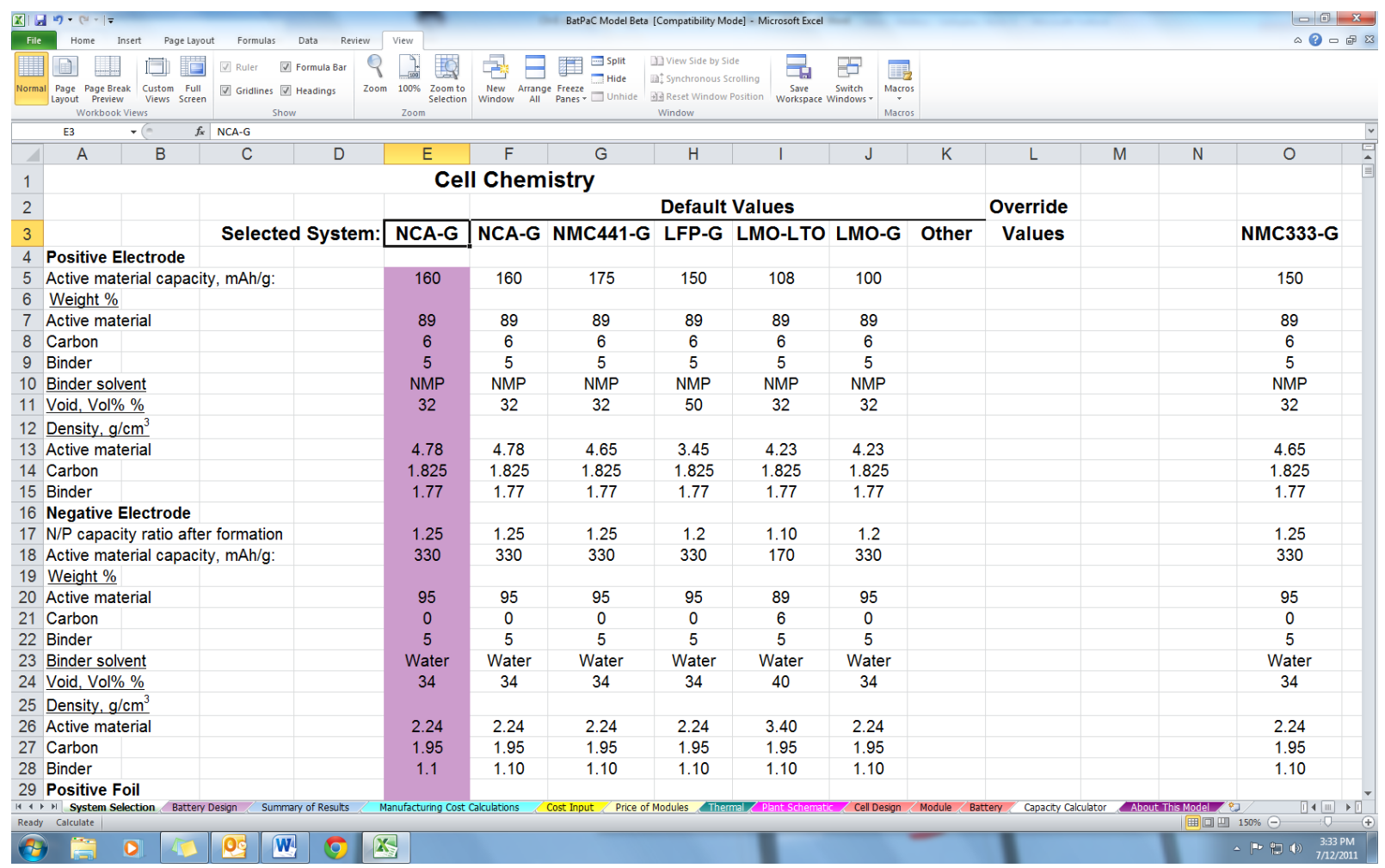

Figure 6.2 The specific cell chemistry for the battery design is selected on the System Selection worksheet. Any value may be overridden by entering a value in column L.

\subsubsection{Battery Design Worksheet}

The Battery Design worksheet designs five or more batteries for any type of electric-drive vehicle (Figure 6.4-6.6). The calculated designs are specific for the end battery requirements specified by the user. From the result, the amounts of materials and the purchased items required for manufacture are easily available to be used in the manufacturing cost calculations found on subsequent worksheets. Although a cell and module format is assumed, the exact format (prismatic, pouch, can, etc) of the battery does not have a dominant effect on the cost for a set cell chemistry system. Our experience teaches us that the amounts of electrode materials and the number, capacity and electrode area of the cells, are the determining cost factors. Nevertheless, a specific design format was selected and is shown on the Cell Design worksheet to provide a basis for calculating the entire cell and battery related costs. 


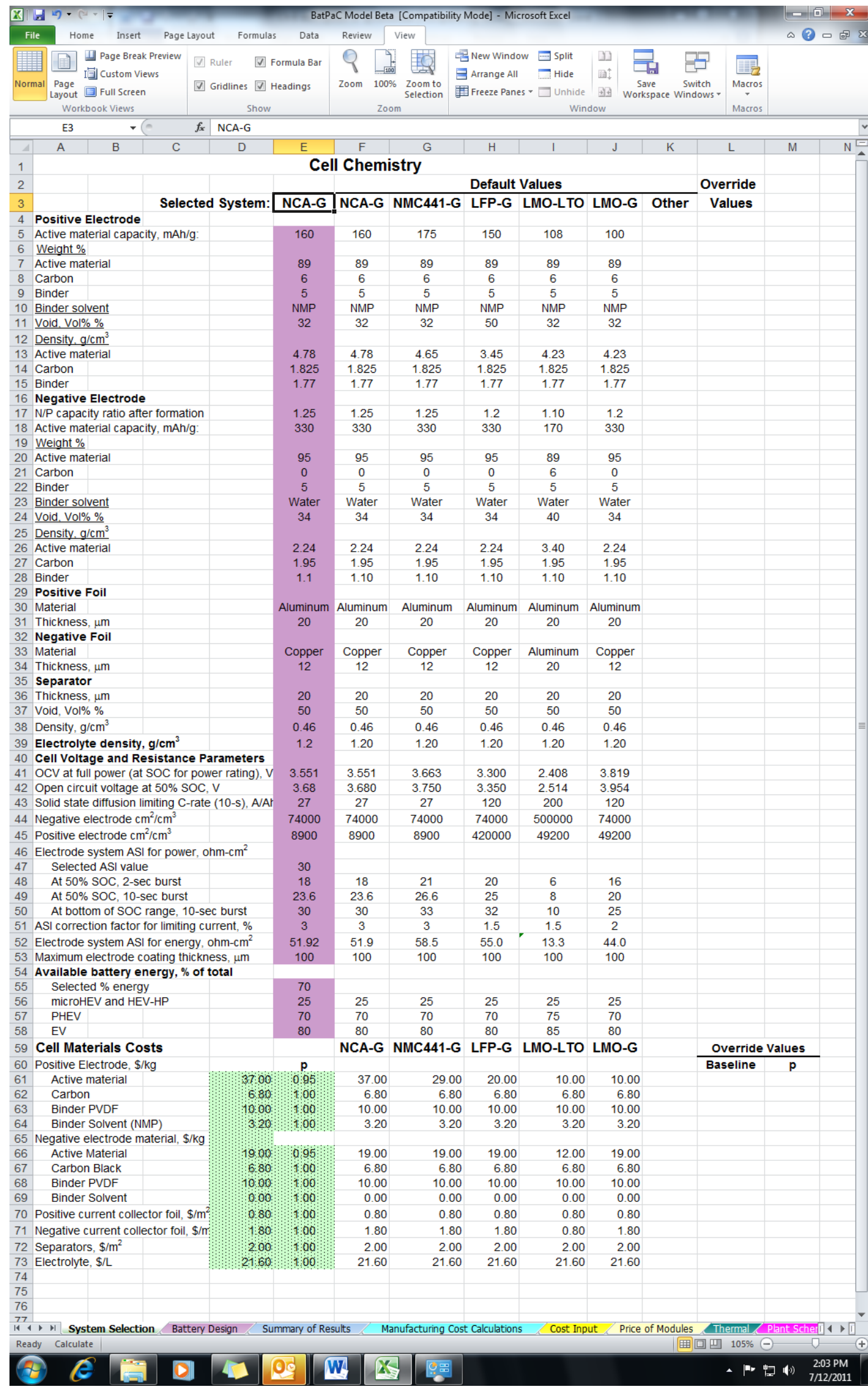

Figure 6.3 System Selection worksheet 


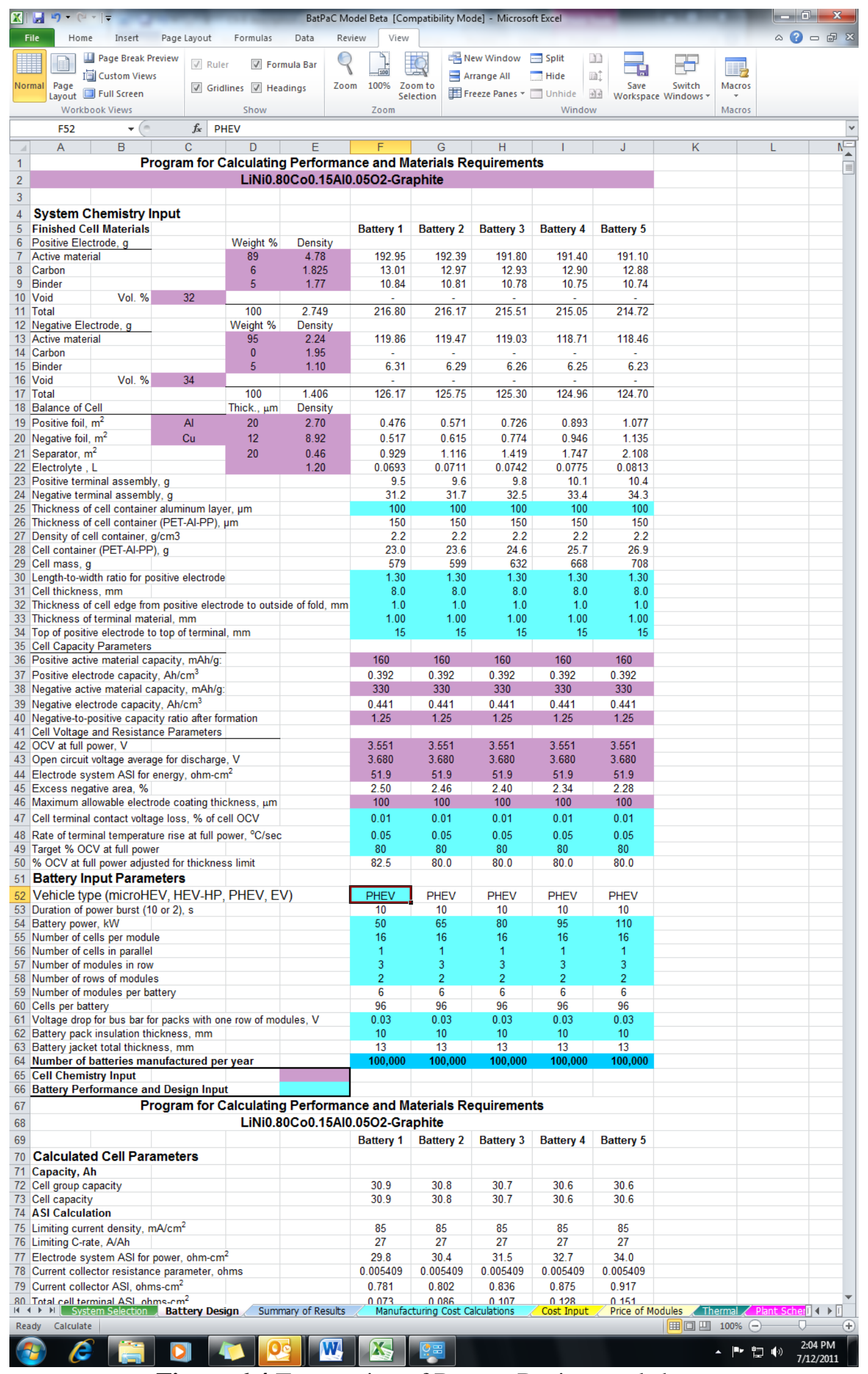

Figure 6.4 Top portion of Battery Design worksheet. 


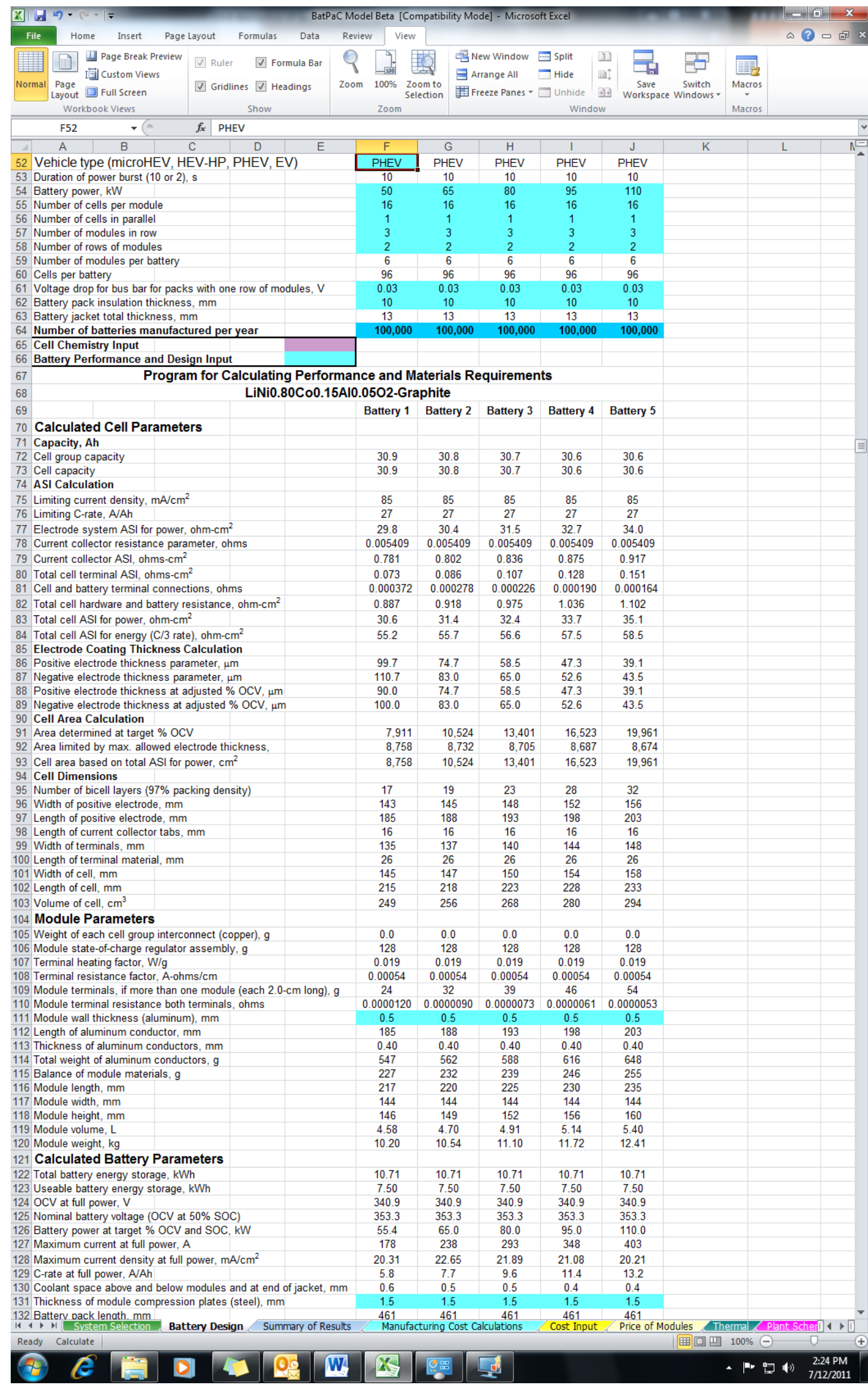

Figure 6.5 Middle portion of Battery Design worksheet 
The Battery Design worksheet automatically receives input from the System Selection worksheet. These values are shown in purple (Figures 6.4 and 6.6) and must not be altered on the Battery Design worksheet. As explained above, cell chemistry values may be adjusted on the System Selection worksheet. The operator provides battery design input in the aqua colored cells (Figures 6.4 and 6.6). The battery input parameters on lines 54 to 58 (Figure 6.4) and lines 162 to 164 (Figure 6.6) are the only input values that the operator is required to provide to study a group of batteries. The type of vehicle battery (microHEV, HEV-HP, PHEV, or EV) on line 52 in Figure 6.4, is another important variable to be specified. One performs the selection by typing the name of the vehicle battery type in cell F52. While the correct spelling is important, capitalization is not. This selection automatically determines the state of charge at which full power is designated (thus, the open-circuit voltage and ASI for full power) and the length of the power burst (2 seconds for microHEV and 10 seconds for all others). It is expected that the majority of the remaining default values should serve well for most batteries; however, the user may also change to their exact specifications.

The cell capacity (lines 162 to 164 in Figure 6.6) can be set in any of three ways: (1) directly specifying the capacity (Ah) on line 162, (2) specifying the total battery energy on line 163 or (3) specifying the electric range of the vehicle (miles). Only one of the three lines should be filled in and the others should be blank. The model will follow the directions of the top-most line with non-zero values.

The number of batteries manufactured per year is selected on line 64 in Figure 6.4. Changing this value from the default value of 100,000 , which is the manufacturing rate for the baseline plant, will change the manufacturing cost.

If it is desired to study more than five batteries in the same workbook it is only necessary to add additional columns by copying the battery 5 column to the right as many times as desired. Care should be taken that the appropriate values are maintained when the cells are copied over. The aqua colored cells are typically the source of any problems. The same column additions must also be done for all other worksheets containing calculations.

\subsubsection{Remaining Worksheets}

The cost calculations are done on the Manufacturing Cost worksheet and the results for the model are shown on the Summary of Results worksheet (Figure 6.7). No parameters need to be entered on these worksheets by the operator; all of the input for these worksheets is from the Battery Design and the Cost Input worksheets. Tables for presentations or for preparing graphs of the data can be assembled at the bottom of either the Battery Design or the Summary of Results worksheet. These tables can be transferred to a blank worksheet for more complex studies. For instance, results for different cell chemistries can be copied and pasted (special paste, values and numbers formats) to a blank worksheet. On the last worksheets, the cell, module, and battery design, as well as the baseline plant are sketched. 


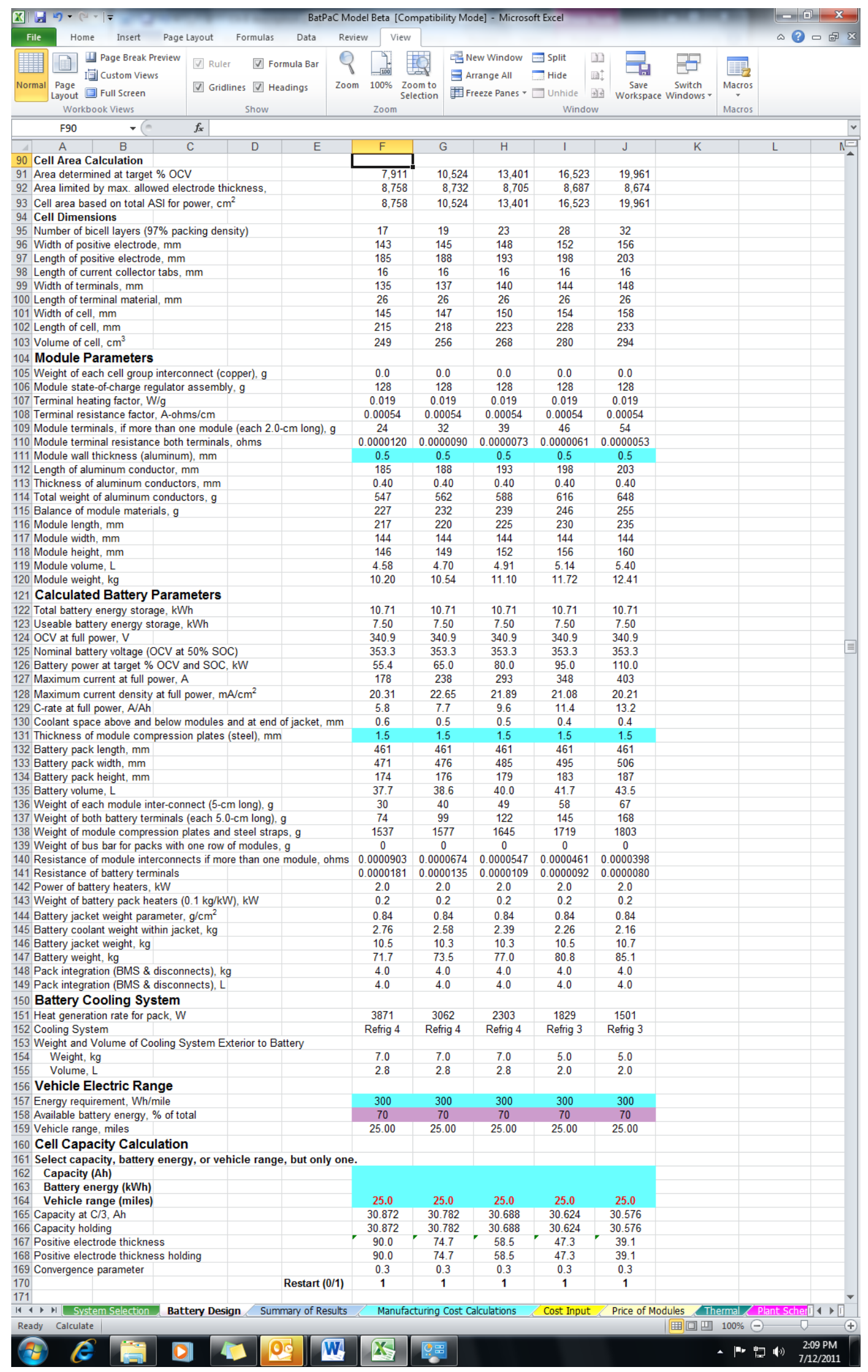

Figure 6.6 Bottom portion of Battery Design worksheet 


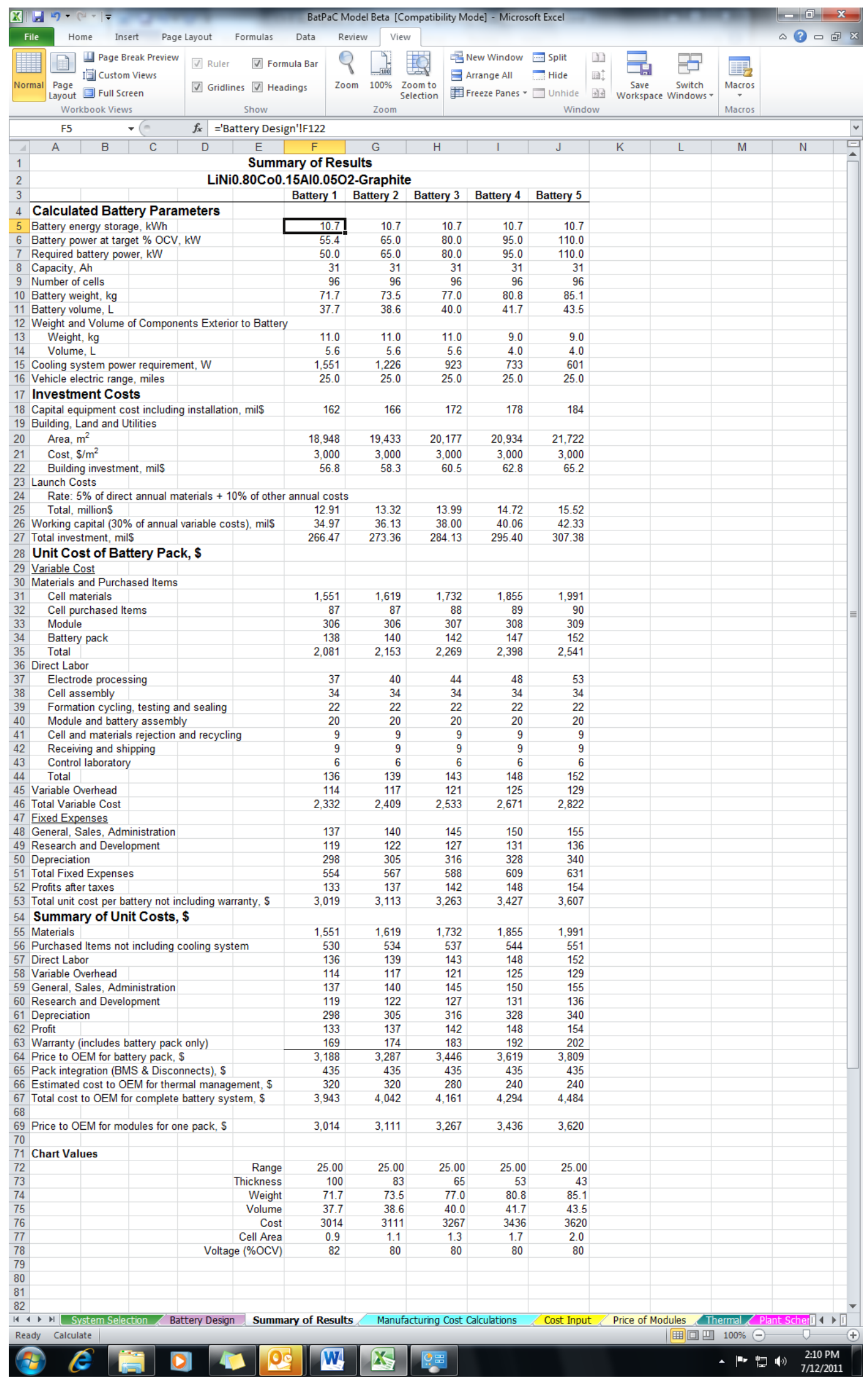

Figure 6.7 Summary of Results worksheet 


\subsection{Battery Design Format Requirements}

As the battery design is based off an assumed format (Section 2), certain design requirements are necessary to ensure the modeled battery is physically realistic. The dimensions of the calculated battery pack should be examined. Some final designs may benefit from changing the cell aspect ratio, $H / W$, to fit the end-use application. One example would be, to reduce the height of the battery pack by increasing the cell $H / W$ ratio. Also, for a set number of cells in the pack, changing the number of rows of modules, allows for adjustment of the pack dimensions.

\subsection{Troubleshooting and General Advice}

The spreadsheet iterates to find the solution and this sometimes causes error messages to appear after an entry is changed. These errors can usually be removed by first correcting any erroneous entries (non-numeric, two decimal points, etc.). Then the cells may be reset to default values by entering a " 0 " (i.e. zero) in the restart cell, F170 in Figure 6.6. Finally, entering a "1" in F170 restarts the iteration process leading to a successfully converged answer.

At some point, a user will ask the model to design a battery that is outside the bounds of what is allowable for the selected cell chemistry. The most common error is when too large of a P/E ratio is requested. Two different physical limitations are approached with increasing P/E ratio. First, the electrode thickness is shrinking. At some point, the value will become unrealistic and eventually approach 0 crashing the calculation. At the same time, the $\mathrm{C}$-rate for the active material is approaching the limiting C-rate defined in the Cell Chemistry Worksheet. As this value is approached, the ASI will increase to larger and larger values, which thus demands smaller and smaller electrode thicknesses. Eventually, the calculation will crash.

Common sense approaches to resolve these issues are to use lower designed power or higher designed energy. The C-rate and electrode thickness are easily viewed in the model output. These are found on the Battery Design worksheet in row 129 for the C-rate and rows 88 and 89 for the electrode thickness. Therefore, the user may try designs of increasing $\mathrm{P} / \mathrm{E}$ ratios and watch to see how the electrode thickness and C-rate is changing. Different cell chemistries will have different sensitivities to the $\mathrm{P} / \mathrm{E}$ ratio depending on the defined limiting $\mathrm{C}$-rate, $r_{C, \text { lim }}$, and calculated ASI for power. What is possible with the LMO-G system will not always be possible with the NCA-G system. P/E ratios that satisfy the expression in Eq. 6.1 generally result in successful battery designs. Higher P/E ratios are allowable in some situations. Note that selecting the microHEV design doubles the allowable C-rate since only two second pulses are used. The limiting C-rate, $r_{\mathrm{C}, \mathrm{lim}}$, may be found in cell E43 on the System Selection worksheet and is carried over to row 76 in the Battery Design worksheet.

$$
\frac{P}{E}<\frac{r_{C, \text { lim }}}{1.35}
$$

\subsection{Suggested Number of Cells, Modules, and Performance Inputs}

Table 6.1 presents some suggestions for the required inputs into the design model that might change depending on the type of vehicle battery being designed. These values are only 
suggestions, but tend to be similar to practices used today or projected to be used in the future by industry. If the calculated cell capacity is higher than $60 \mathrm{Ah}$, the user should consider the inclusion of parallel cells as an additional parameter to examine. The default energy usage rate in $\mathrm{BatPaC}$ is $300 \mathrm{Wh} / \mathrm{mi}$. This rate may be used to size the energy requirement based on a desired electric range for the vehicle by specifying the distance in row 164 on the Battery Design worksheet.

Table 6.1 General suggestions for range of input parameters that change with battery type

\begin{tabular}{|l|c|c|c|c|}
\hline battery type & modules/battery & OCV @ 50\% SOC & Power $(\mathrm{kW})$ & Energy $(\mathrm{kWh})$ \\
\hline HEV-25 & $1-4$ & $40-200$ & 25 & $0.6-1.5$ \\
\hline HEV-HP & $2-4$ & $160-260$ & $25-80$ & $1-2$ \\
\hline PHEV & $4-6$ & $290-360$ & $40-160$ & $4-30$ \\
\hline EV & $4-6$ & $290-360$ & $80-160$ & $20-200$ \\
\hline
\end{tabular}

\subsection{Entering a New Material Couple}

The user of the model may wish to examine an electrochemical couple that is not included as one of the options available in the model. We list below a brief explanation on how to properly enter new materials into BatPaC. Various properties may be calculated, found in literature or measured in the laboratory. The self-consistency of the data used is very important.

Experimentally measured values required:

1. Half cell formation cycling data from positive and negative electrode

2. Half cell cycling data from positive and negative electrode at $\mathrm{C} / 3$ rate

3. Full cell open-circuit voltage measurement at $50 \%$ and $25 \%$ SOC

4. Full cell ASI measurement for $5 \mathrm{C}$ pulse at $50 \%$ and $25 \% \mathrm{SOC}$

5. Full cell ASI at $50 \%$ SOC during a $\mathrm{C} / 3$ discharge

6. Electrode void fractions, active material densities, electrode component weight percent

7. Estimated interfacial area from surface area (preferred) or particle size measurements

The ASI calculation includes some additional parameters that become important as the designed $\mathrm{P} / \mathrm{E}$ ratio increases above $10 \mathrm{~h}^{-1}$ or the electrode thicknesses decrease below 30 microns. The user is referred to section 3.4 and the supporting manuscript from Gallagher et al. ${ }^{20}$ for the parameter estimation process. An exchange current of $0.15 \mathrm{~mA} / \mathrm{cm}^{2}$, normalized to the surface area calculated using the BET method from nitrogen absorption experiments, is used in the model in row 77 in the Battery Design worksheet. While the exact value of the exchange current will vary from the material to material, the general behavior of the ASI will be preserved with this assumption. If lower P/E ratio designs are desired, the exact valuation of the exchange current, interfacial area, and limiting C-rate are less important. However, the experimental ASI measurement should then come from a cell with similar P/E ratio (electrode loading). Electrode thicknesses 40 microns or larger should be used to minimize the contribution of interfacial impedance to the ASI measurement. Otherwise the "ASI correction factor" may not accurately remove the interfacial component. A reasonable approach for a first approximation of the ASI parameters may be to select the same values for a similar material. For example, if the new material is based on nano-sized primary particles, then the parameters for LFP or LTO may be 
close enough. The ASI does depend on a large number of factors and a full determination of the parameters is important to capture all of the physical behavior of the cell couple. If the desire of user is to reproduce an existing cell, then many of the parameters may be estimated from the electrochemical characterization of the full cell data. These electrochemical results typically require a teardown of the cell to measure the area of the electrodes and their loadings/thicknesses.

The available lithium for cycling in a full cell configuration may be calculated from half cell measurements. The calculation method may be found in the Capacity Calculator worksheet in the spreadsheet model and is detailed below. Alternatively, the reversible capacity of the full cell in the experiment may be normalized to the mass of the positive and negative electrodes while carefully accounting for the negative to positive capacity ratio. The first cycle efficiency of a positive or negative electrode based half-cell may be defined as the ratio of the first discharge capacity divided by the first charge capacity, Equation 6.2. We have assumed the first discharge capacity is equivalent to the reversible capacity when measured against lithium foil (half-cell arrangement).

$$
\eta_{j}^{1 s t}=\frac{Q_{j}^{r e v}}{Q_{j}^{1 s t}}
$$

The quantity of lithium consumed from the positive electrode in the negative electrode SEI, $Q^{\text {sei }}$, may be calculated from Equation 6.3. Here, $[\mathrm{N} / \mathrm{P}]$ is the negative to positive capacity ratio.

$$
Q^{s e i}=[\mathrm{N} / \mathrm{P}] \frac{Q_{P}^{r e v}}{Q_{N}^{r e v}}\left(Q_{N}^{1 s t}-Q_{N}^{r e v}\right)=\frac{m_{N}}{m_{P}} Q_{N}^{i r r e v}
$$

After one full cycle, the remaining lithium in the positive electrode available for cycling, $Q_{\mathrm{P}}{ }^{\text {act }}$, in a full-cell configuration (positive electrode versus non-prelithiated negative electrode) may be calculated by choosing the minimum value determined in Equation 6.4 below. Here we see the possibility that the positive electrode is unable to accept the full amount of lithium released during the first charge cycle. This so called "irreversible capacity" of the positive electrode results in lithium residing in the negative electrode. While this excess lithium may require additional negative electrode capacity, it also provides some beneficial aspects to cycle and calendar life. ${ }^{50}$ We have chosen to set the $[\mathrm{N} / \mathrm{P}]=1.25$ for layered oxides positive electrodes (NCA, NMC441, NMC333) due to their tendency to have a lower first cycle efficiency $\sim 88 \%$. The lithium manganese spinel and lithium iron phosphate cells have a high first cycle efficency and thus we selected a $[\mathrm{N} / \mathrm{P}]=1.20$. For positive electrodes with a high first cycle efficiency, the reversible capacity of the cell is reduced by the lithium consumed in the graphite electrode SEI during the formation cycle. Conversely, the lithium titanate spinel negative electrode does not form an SEI and is significantly safer than the graphite electrode as discussed in Chapter 5. Thefore the $[\mathrm{N} / \mathrm{P}]$ ratio is set to 1.1 for the cells based on lithium titanate spinel.

$$
Q_{P}^{a c t}=\operatorname{MIN}\left\{Q_{P}^{r e v}\left(1+\left(\frac{1-\eta_{P}^{1 s t}}{\eta_{P}^{1 s t}}\right)-[\mathrm{N} / \mathrm{P}]\left(\frac{1-\eta_{N}^{1 s t}}{\eta_{N}^{1 s t}}\right)\right), Q_{P}^{r e v}\right\}
$$




\section{Illustrated Results}

The BatPaC model may be used to study the effects of battery parameters on the performance and the manufactured cost of the designed battery packs. A few examples are given below for the effects of various parameters on battery pack volume, weight and cost.

\subsection{Number of Cells in Series}

For a set battery pack power, the number of cells in the pack has substantial effects on the price of the pack, the pack voltage and the maximum current. These effects are illustrated (Figure 7.1) for NMC441-Gr PHEV25 batteries (providing 25-mile electric range) with 60-kW power at a $[\mathrm{V} / \mathrm{U}]=0.8$. The price of the pack increases by $17 \%$ in changing the number of series-connected cells in the pack from 32 to 96 and the entire pack integrated cost increases by $15.7 \%$. The integrated cost includes additions to the vehicle air-conditioning system to provide for battery cooling and the battery management system with disconnects. The change in the maximum current, resulting from differing pack voltages, would also affect the cost of the motor and the electronic converter and controller, but in the opposite direction. As a result of these offsetting effects on the total cost of the electric drivetrain, a study is required to determine the optimum current at rated power as a function of the total battery pack power and other parameters (see the Future Work section).

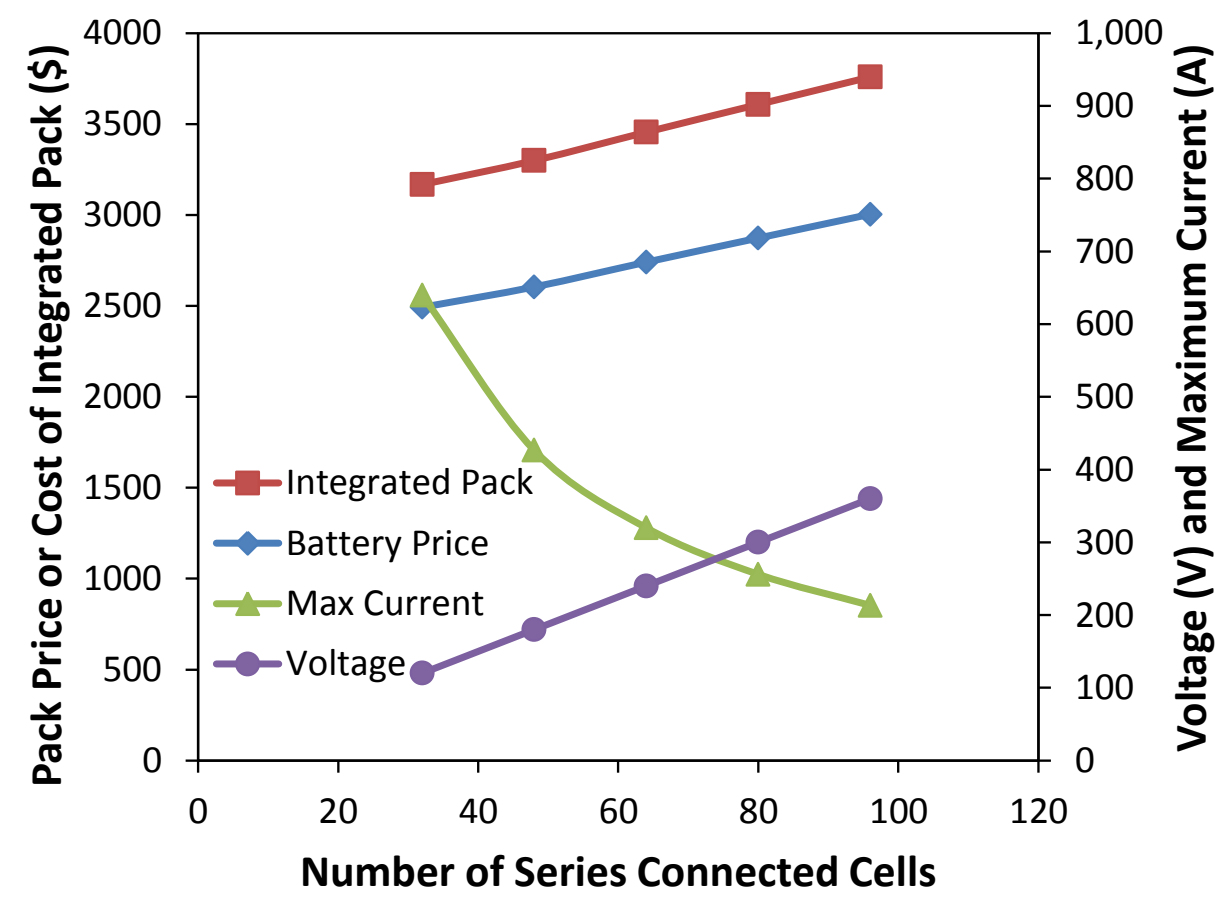

Figure 7.1 The effect of the number of series-connected cells for NMC441-Gr, 60-kW, PHEV25 packs with $10.7 \mathrm{kWh}$ total energy (70\% useable).

Current PHEV battery technology uses battery packs containing 80-96 series connected cells. However, these series connections are often composed of parallel cell groups. For instance, the battery used in the first production model of the Chevrolet Volt is in a 3P-96S configuration. ${ }^{21}$ 
Three low capacity cells are connected in parallel forming a parallel cell group. Then 96 parallel cell groups are connected in series. The cost savings from moving to larger format cells with only series connections is discussed later in this section.

\subsection{Cathode Materials}

Lithium-ion batteries for high mileage PHEVs and EVs do not require a high P/E ratio or low ASI to meet their goals. The most important material properties for performance are high specific capacity (mAh/g), high cell voltage, and high electrode density. Graphite electrode is near universal in commercial cells as a negative electrode, although not all graphite is the same. Here we consider changes in the positive electrode that result in significantly different calculated batteries. To compare the performance of EV battery packs made from various Li-ion chemistries, we designed the packs to provide $150 \mathrm{~kW}$ at $360 \mathrm{~V}(25 \%$ SOC) for a $[\mathrm{V} / \mathrm{U}]=0.8$. Each pack consisted of six modules containing 16, 16, and 18 cells for the cell chemistries LMOGr, NMC441-Gr, and LFP-Gr, respectively. This calculation assumes that large capacity cells may be reliably produced. Moving to a parallel connection of smaller capacity cells would result in higher cost as discussed later in the section.

The NMC441-Gr system has excellent energy density and low cost (Fig. 7.2 and 7.3). The LMOGr system is less energy dense than the NMC441-Gr couple, but equivalent in calculated price to the OEM. The LFP-Gr system results in a battery that is larger and more expensive than the other two chemistries. The mass-specific cathode raw material prices are 29,20 , and $10 \$ / \mathrm{kg}$ for NMC441, LFP and LMO respectively. The differences in cathode materials costs do not directly translate to the end cost of the battery. The performance (exhibited by specific capacity and voltage) affect the quantity of both active and inactive material required. The NMC441 material achieves $175 \mathrm{mAh} / \mathrm{g}$ at a good cell voltage and is representative of an advanced, although close to commercialization, layered oxide cathode. ${ }^{51}$ The combination in voltage and capacity results in a superior energy density compared to the other cathodes. The LMO cathode has similar cell voltage to NMC441 and low raw material cost but also a low specific capacity of $100 \mathrm{mAh} / \mathrm{g}$. This low capacity results in a positive electrode loading limited by the maximum achievable electrode thickness $\sim 100$ microns. The LFP electrode has moderate capacity, $150 \mathrm{mAh} / \mathrm{g}$, and raw material cost, but exhibits a lower cell voltage and electrode density. These poor performance characteristics result in a low energy density battery with a high price.

\subsection{Parallel-Connected Cell Groups and Electrode Thickness Limits}

BatPaC also allows the user to create parallel cell groups and to set a maximum electrode thickness. The effect these two unique design factors have on battery price are illustrated below in Figure 7.4 for the LMO-Gr and NMC441-Gr systems. In this illustration, the PHEV battery pack design parameters are $100 \mathrm{~kW}$ of power at a $[\mathrm{V} / \mathrm{U}]=0.8$ and $17 \mathrm{kWh}$ of total energy. The nominal battery pack voltage (OCV at $50 \%$ SOC) is around $360 \mathrm{~V}$ from 96 cell groups connected in series. The number of cells in the parallel cell group is varied from a single cell (no parallel connections) to four. Two maximum electrode thicknesses of 100 and 200 microns are shown for the LMO-Gr chemistry. In contrast to the NMC441-Gr, the LMO-Gr chemistry benefits from allowing larger electrode thicknesses. The thickness of the positive electrode is limiting the LMO-Gr chemistry while the thickness of the negative electrode limits the NMC441-Gr 


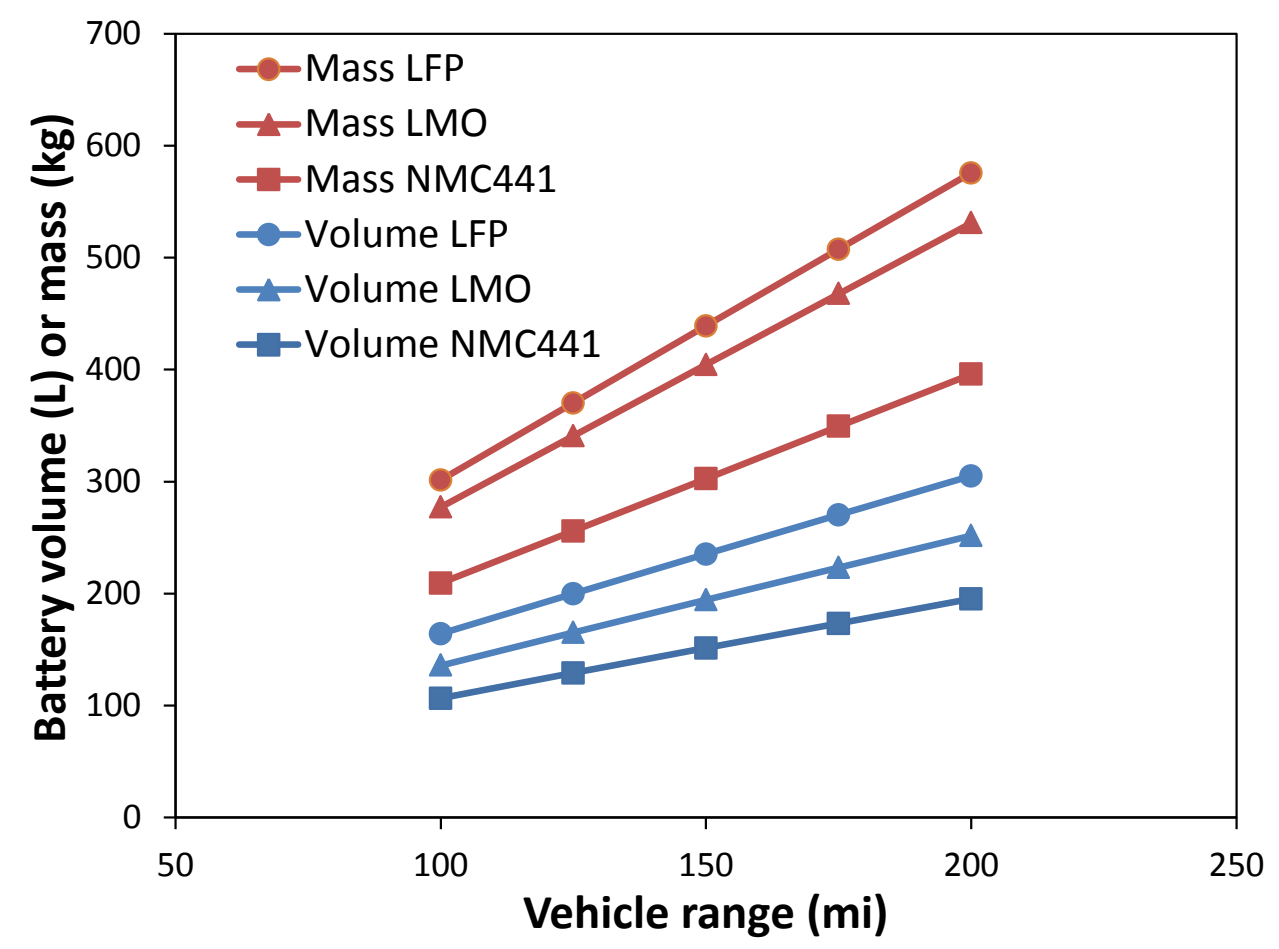

Figure 7.2 Mass and volume of electric vehicle battery packs with lithium iron phosphate (LFP), lithium manganese-spinel (LMO) and lithium nickel-manganese-cobalt oxide (NMC441) positive electrodes versus graphite designed to deliver $150 \mathrm{~kW}$ of power at $360 \mathrm{~V}$ (25\% SOC).

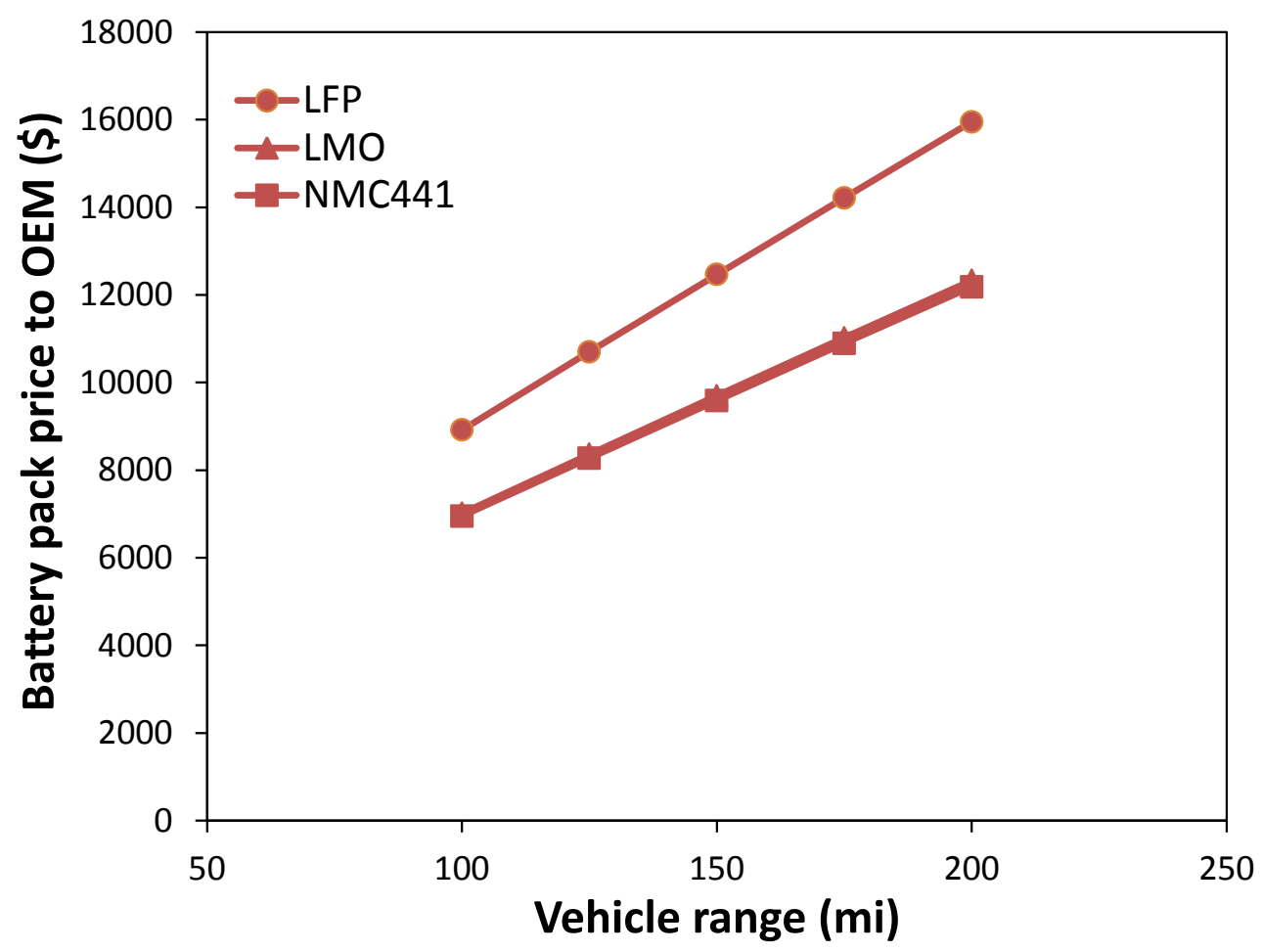

Figure 7.3 Battery pack price to OEM for LFP-Gr, LMO-Gr and NMC441-Gr battery packs for same designs as in Fig. 7.2. NMC441-Gr and LMO-Gr result in nearly the same price. 
chemistry. The calculated value for the NMC441-Gr system never exceeds 100 microns for this $\mathrm{P} / \mathrm{E}$ ratio. The LMO-Gr is the least expensive in all cases. However, the difference between the two chemistries lessens with smaller limiting electrode thickness. The costs will become even closer for lower designed P/E ratios. In general, thicker electrodes reduce the cost of the battery pack by lessening the amount of inactive materials used (separator, current collector, etc). Moving to 300 microns allows for greater savings in the LMO-Gr design but not the NMC441Gr design. However, a lower P/E ratio design for NMC441-Gr would take advantage of electrode thicknesses greater than 200 microns.

The cell capacity is shown for the NMC441-Gr case limited to 100 microns. While the exact values will change with cell chemistry, they will all be similar. The cell capacity is reduced by one half as a single cell is added in parallel. This approach is commonly used by cell manufacturers and OEMs that cannot reliably produce or successfully operate cells of high capacity for transportation applications. However, this approach also increases the price of the battery pack. In this example, the price is increased by $\sim \$ 500$ when an additional string of cells is incorporated in a parallel arrangement.

The model calculations show that the lowest cost battery pack will utilize thick electrodes and large capacity cells. In current practice, these two approaches have yet to be successfully implemented within the entire community. In the challenge of lowering costs, it is useful to point out the largest gains come from the initial advances (e.g. moving from 100 to 200 micron limit). After that point, the benefits are diminishing.

\subsection{Manufacturing Scale}

The effects of manufacturing scale come into the cost calculation even if the annual number of packs produced is unchanged, but the design is altered (e.g. power is increased). For a fixed design, the effect of changing the scale of operations depends on the fraction of the total price that is made up of materials costs. Unit materials costs change little with scale whereas the costs per pack for labor, capital and plant area may decline substantially with increasing production rates, especially at low production rates, Fig. 7.5.

The lines in the graphs are for the best-fit power relationships through the data with power factors of $-0.076,-0.077,-0.147$, and -0.211 from the top curve to that at the bottom. The least negative power factor is for the battery pack with the highest fraction of materials cost in the total pack cost. The more negative power factors result from a decreasing contribution of materials cost as a fraction of the total pack cost. These power factors for equations of the cost of a single unit can be converted to factors relating the total annual cost of manufacturing similar to Eq. 5.2 by adding 1.0 to each power factor. Thus the factors become $0.924,0.923,0.853$, and 0.789. These large factors show only a small to moderate effect of scale. When the power curves are compared to the points in each of the graphs of Fig. 7.5, it is apparent that the scale factors approach one as the scale increases. This is because the model assigns a value of 0.95 for the active materials and 1.0 for the balance of the materials. As the production level increases and the materials costs become a larger fraction of the total price of the battery, the scaling power approaches 1.0 and the effect of scale become very small. Likewise, the effect of scale on battery price is much larger for HEV batteries than for EVs because materials costs constitute a smaller 
portion of the total cost for HEV batteries. Increasing the production rate for HEV batteries will result in a more dramatic reduction in cost than increasing the production rate for EV batteries.

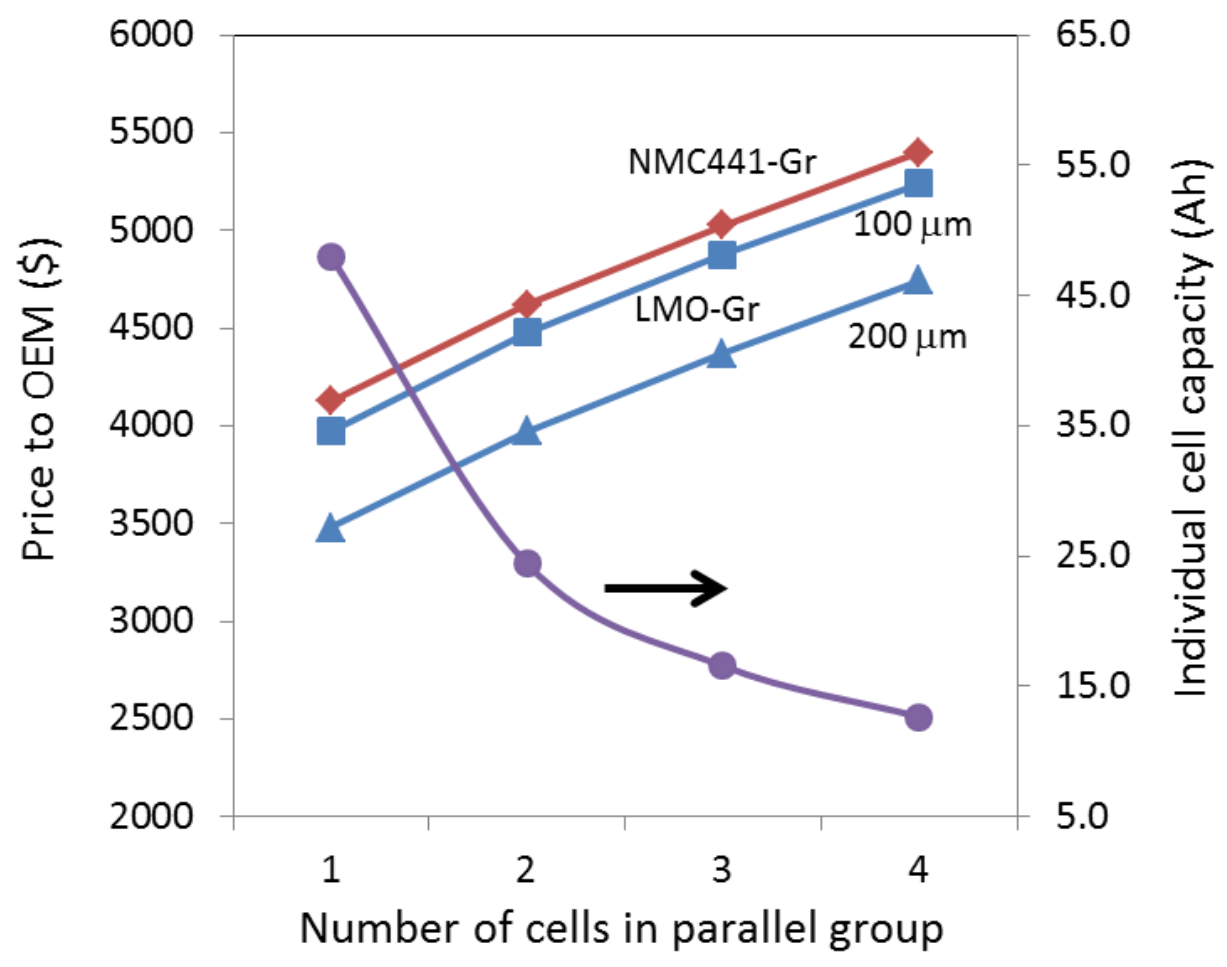

Figure 7.4 Battery pack cost as a function of number of parallel cells and for different maximum electrode thicknesses. The electrode thicknesses $(100$ or $200 \mu \mathrm{m})$ represent the limitation not the exact value calculated by the model. The cell capacity is also shown for the NMC441-Gr battery. 

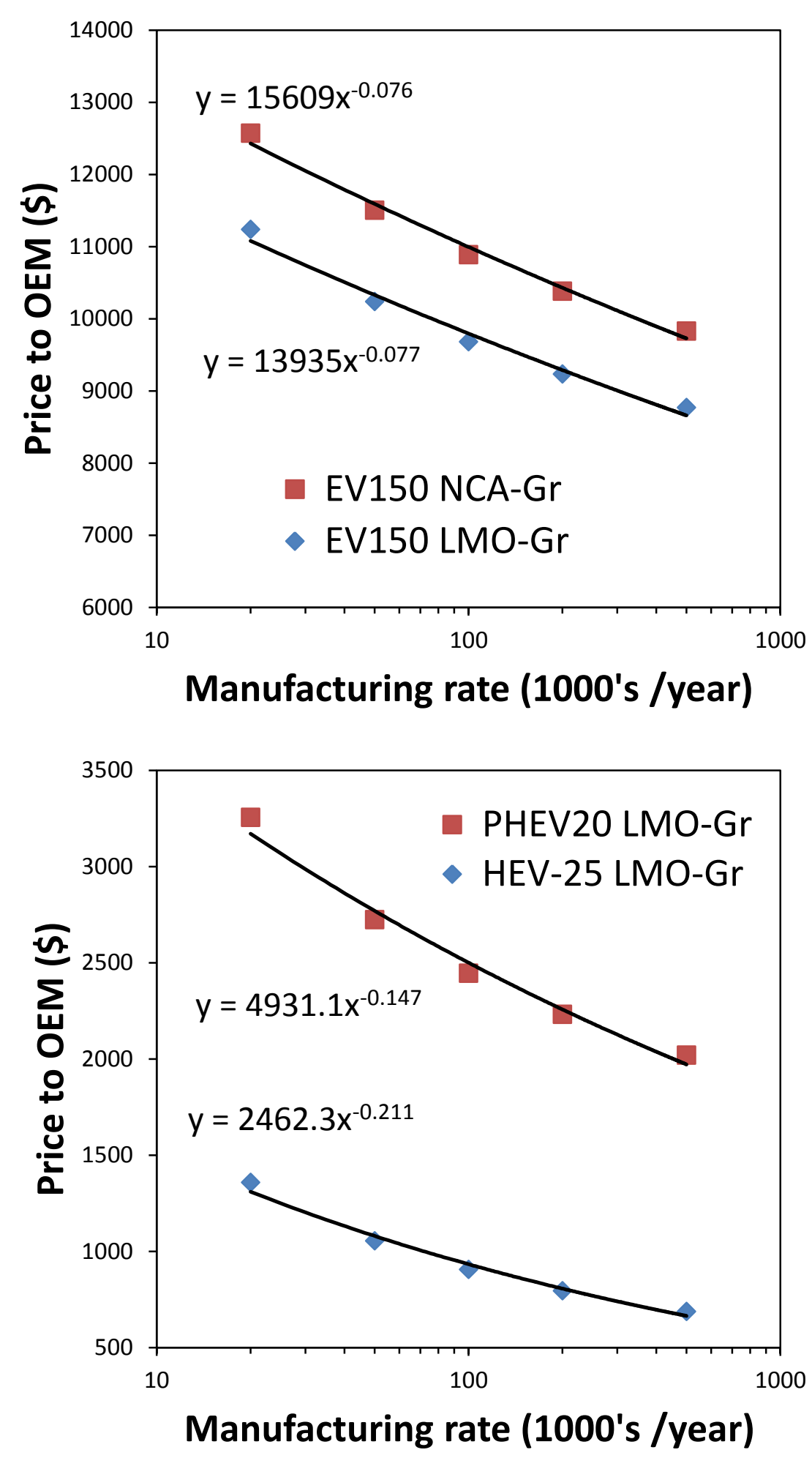

Figure 7.5 The effects of manufacturing rate on the price calculated by the model for battery packs of various cell chemistries, power capabilities and vehicle types. The EV and PHEV batteries are composed of 96 cells and the HEV-25 is composed of 48 cells. 


\section{Future Work}

\subsection{Initial Power Designed at Differing Fractions of the Open-Circuit Voltage}

The objective of this study is to evaluate the various benefits and costs associated with over- or under- sizing the initial power of the battery utilizing Argonne National Laboratory's BatPaC (battery performance and cost model) and Autonomie (vehicle model). The fraction of the opencircuit voltage at which initial designed battery power is achieved has a direct impact on heat generation during operation, performance under cold conditions, and acceptable power fade. The vehicle focus will be on PHEVs for a mid-size vehicle glider and also a small SUV. Coupling the vehicle and battery models will allow for a complete study evaluating the benefits and tradeoffs associated with this critical design parameter. This work will be carried out in a cooperative effort with Argonne's Transportation Technology R\&D Center, which will perform vehicle simulation tests to determine the rate of heat generation in the battery pack.

The end result of this study will be quantitative justification for designing a battery at a set fraction of the open-circuit voltage. The justification will likely depend on battery chemistry and powertrain type as differing architectures lead to differing benefits. These benefits may lead to changes in the system design to maximize net present value. A secondary, but just as important, benefit will be extrapolation of thermal management requirements from heat generation and cold temperature performance calculated from various levels of sizing the battery.

\subsection{Optimum Battery Voltage for Minimum Drivetrain Cost}

For a set cell chemistry and set battery pack power, the cost of the pack increases as the number of cells and the pack voltage are increased (Fig. 7.1). The additional cost results primarily from the cost of additional state-of-charge equalization circuits and the additional number of cells needing formation cycling and testing. The increase in battery pack cost is almost linear with the increase in the number of cells. As the number of cells is decreased, the pack current at maximum power becomes very high and the cost of the balance of the drivetrain increases at an accelerating rate. Thus, there must be a number of cells and an associated pack current at maximum power for which the total cost of the drivetrain is at a minimum. This optimum current will increase with the pack power because the slope of the cost-versus-current curve increases with increasing power and, therefore, the optimum current will also increase.

A study is needed to determine the cost of electric motors and the electronic control equipment required for the vehicle and battery pack as a function of power and maximum current capability. Once appropriate cost curves are established, we will determine equations relating the optimum battery current to the desired battery power taking into account the battery chemistry. We intend to do this study with the cooperation of Argonne's Transportation Technology R\&D Center. 


\subsection{Multipurpose Battery Manufacturing Plants}

Our cost modeling is based on the concept that a manufacturing plant is constructed to produce a single type of battery pack at a predetermined level of production. In practice, manufacturers will have to produce several types of batteries within the same manufacturing plant and the levels of production may fluctuate. We intend to investigate how this increased flexibility requirement will affect the various manufacturing costs. For example, the cell filling and sealing equipment may be required to handle cells of different dimensions. This would most likely increase the capital cost for this equipment. Alternatively, additional packaging and sealing lines might be needed. We intend to evaluate combinations of vehicle battery packs that are easily integrated into the same plant. The manufacturing cost will most likely increase after these considerations are built into the model.

\subsection{Stand-Alone Graphical User Interface for Model}

The spreadsheet program described here-in allows versatility in designing the battery and in calculating the costs, but like all complex spreadsheet programs it is not user-friendly to those unfamiliar with the details of calculation. In addition, the model is easily corrupted by a poor choice of input parameters. As a result, the final spreadsheet program will be converted to a stand-alone user-friendly application. Visual Basic for Applications will be used to hard code in the model calculations and to also create the graphical interface. The new user interface should allow for a wide distribution of the model while maintaining the ability to change the vast majority of input parameters. The retention of this flexibility should make the model a valuable tool for those interested in batteries regardless of the specific material property or manufacturing cost structure the user seeks to analyze. 


\section{Statement of Copyright}

\section{BatPaC (Battery Performance and Cost Model) SOFTWARE COPYRIGHT NOTIFICATION}

(C) COPYRIGHT 2011 UCHICAGO ARGONNE, LLC All rights reserved. The BatPaC, version 1.0 software, manual and supporting documentation are protectable under copyright laws of the United States.

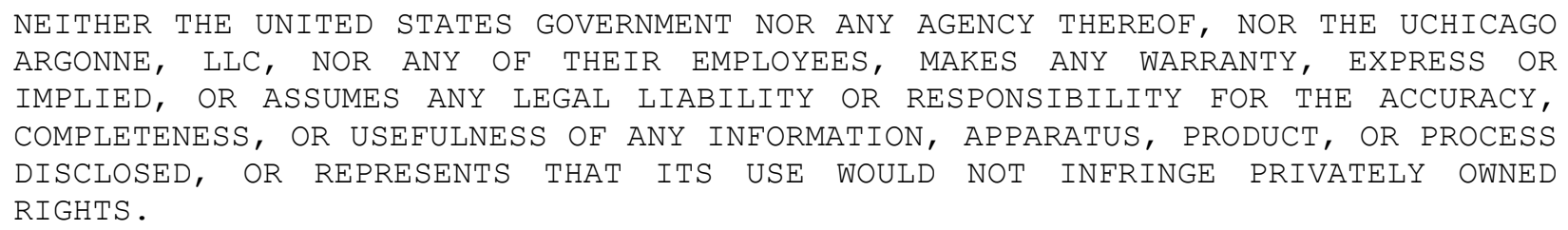




\section{REFERENCES}

1. M. Anderman, F. Kalhammer, and D. MacArthur. "Advanced Batteries for Electric Vehicles: An Assessment of Performance, Cost, and Availability." California Air Resources Board, June (2000). Available from http://www.arb.ca.gov/msprog/zevprog/2000review/btap report.doc (accessed on December 17, 2010).

2. B. Barnett, D. Ofer, C. McCoy, Y. Yang, T. Rhodes, B. Oh, M. Hastbacka, J. Rempel, and S. Sririramulu "PHEV Battery Cost Assessment," 2009 DOE Merit Review, May (2009). Available from http://www1.eere.energy.gov/vehiclesandfuels/pdfs/merit_review_2009/energy_storage/ es_02_barnett.pdf (accessed on December 11, 2010).

3. B. Barnett, J. Rempel, D. Ofer, B. Oh, S. Sriramulu, J. Sinha, M. Hastbacka, and C. McCoy, "PHEV Battery Cost Assessment," 2010 DOE Merit Review, June (2010). Available from http://www1.eere.energy.gov/vehiclesandfuels/pdfs/merit_review_2010/electrochemical _storage/es001_barnett_2010_o.pdf (accessed on December 11, 2010).

4. A. Dinger, R. Martin, X. Mosquet, M. Rabl, D. Rizoulis, M. Russo, and G. Sticher, "Batteries for Electric Vehicles: Challenges, Opportunities, and the Outlook to 2020." The Boston Consulting Group, Available from http://www.bcg.com/documents/file36615.pdf (accessed on December 11, 2010).

5. L. Gaines and R. Cuenca, "Costs of Lithium-Ion Batteries for Vehicles," Center for Transportation Research, Energy Systems Division, Argonne National Laboratory, ANL/ESD42, Argonne, IL May (2000).

6. F.R. Kalhammer, B.M. Kopf, D.H. Swan, V.P. Roan, M.P. Walsh, "Status and Prospects for Zero Emissions Vehicle Technology: Report of the ARB Independent Expert Panel 2007," California Air Resources Board, April (2007). Available from http://www.arb.ca.gov/ msprog/zevprog/zevreview/zev_panel_report.pdf (accessed on December 17, 2010).

7. M. A. Kromer and J. B. Heywood, "Electric Powertrains: Opportunities and Challenges in the U.S. Light-Duty Vehicle Fleet," Sloan Automotive Laboratory, Laboratory for Energy and the Environment, Massachusetts Institute of Technology, LFEE 2007-03 RP, Cambridge, MA (2007).

8. P. Mock, "Assessment of Future Li-Ion Battery Production Costs," presented at Plug-in 2009, Long Beach, CA, (2009).

9. National Research Council of the National Academies, "Transitions to Alternative Transportation Technologies - Plug-in Hybrid Electric Vehicles," The National Academies Press, Washington, D.C. (2010). Available from http://www.nap.edu/catalog.php?record_id= 12826 (accessed on December 17, 2010).

10. TIAX LLC, "Cost Assessment for Plug-In Hybrid Vehicles (SOW-4656)," Report to US DOE Office of Transportation Technology, October (2007). 
11. M. Anderman "The Plug-In Hybrid and Electric Vehicle Opportunity Report: A critical assessment of the emerging market and its key underlying technology: Li-Ion batteries," Advanced Automotive Batteries, May (2010).

12. P.A. Nelson, D.J. Santini, J. Barnes, "Factors Determining the Manufacturing Costs of Lithium-Ion Batteries for PHEVs." International Electric Vehicles Symposium EVS-24, Stavanger, Norway, (2009).

13. D.J. Santini, K.G. Gallagher, P.A. Nelson, "Modeling the Manufacturing Costs of LithiumIon Batteries for HEVs, PHEVs, and EVs," International Electric Vehicles Symposium EVS-25, Shenzhen, China, (2010).

14. K.G. Gallagher, P.A. Nelson, D.W. Dees, "PHEV battery cost assessment" 2011 DOE Merit Review Presentation Washington, DC May 9-12 (2011). Available from http://www1.eere. energy.gov/vehiclesandfuels/pdfs/merit_review_2011/electrochemical_storage/es111_gallagher_ 2011_o.pdf (Accessed on July 12, 2011).

15. P. Nelson, I. Bloom, K. Amine, G. Henriksen, "Design modeling of lithium-ion battery performance," Journal of Power Sources, 110, 437 (2002).

16. P. Nelson, D. Dees, K. Amine, G. Henriksen, "Modeling thermal management of lithium-ion PNGV batteries," Journal of Power Sources, 110, 349 (2002).

17. G.L. Henriksen, K. Amine, J. Liu, and P.A. Nelson, "Materials Cost Evaluation Report for High-Power Li-Ion HEV Batteries,” Electrochemical Technology Program, Chemical Technology Division, Argonne National Laboratory, ANL-03/05, Argonne, IL (2002).

18. P. Nelson, K. Amine, A. Rousseau, H. Yomoto, "Advanced Lithium-Ion Batteries for Plug-in Hybrid-Electric Vehicles", International Electric Vehicles Symposium, EVS-23, Anaheim, Ca (2007).

19. P. Nelson, "Modeling the Manufacturing Costs of Lithium-Ion Batteries for PHEVs," presented at Plug-in 2009, Long Beach, CA, (2009).

20. K.G. Gallagher, P.A. Nelson, and D.W. Dees, "Simplified Calculation of the Area Specific Impedance for Battery Design,” Journal of Power Sources, 1962289 (2011).

21. "Chevrolet Volt: Development Story of the Pioneering Electrified Vehicle" ed. Lindsay Brooke, SAE International, Warrendale, PA pgs 215 (2011)

22. A.N. Jansen, K. Amine, and G. L. Henriksen, "Low-Cost Flexible Packaging for High-Power Li-Ion HEV Batteries," Electrochemical Technology Program, Chemical Technology Division, Argonne National Laboratory, ANL-04/09, Argonne, IL (2004). 
23. P.A Nelson and A.N. Jansen, "Comparative Costs of Flexible Package Cells and Rigid Cells for Lithium-Ion Hybrid Electric Vehicle Batteries,” Electrochemical Technology Program, Chemical Technology Division, Argonne National Laboratory, ANL-06/43, Argonne, IL (2006).

24. J. Euler and W. Nonnenmacher, "Stromverteilun in Porösen Elektroden," Electrochimica Acta, 2268 (1960).

25. J.S. Newman and C.W. Tobias, "Theoretical Analysis of Current Distributions in Porous Electrodes," Journal of the Electrochemical Society, 1091183 (1962).

26. "Diagnostic Examination of Generation 2 Lithium-Ion Cells and Assessment of Performance Degradation Mechanisms," Chemical Engineering Division, Argonne National Laboratory, ANL-05/21, Argonne, IL (2005).

27. D. Dees, E. Gunen, D. Abraham, A. Jansen, and J. Prakash, "Electrochemical Modeling of Lithium-Ion Positive Electrodes during Hybrid Pulse Power Characterization Tests" Journal of the Electrochemical Society, 155 (8) A603 (2008).

28. D. Dees, E. Gunen, D. Abraham, A. Jansen, and J. Prakash, "Alternating current impedance electrochemical modeling of lithium-ion positive electrodes," Journal of the Electrochemical Society, 152 (7),A1409 (2005).

29. D. Abraham, S. Kawauchi, and D. Dees, "Modeling the impedance versus voltage characteristics of $\mathrm{LiNi}_{0.8} \mathrm{Co}_{0.15} \mathrm{Al}_{0.05} \mathrm{O}_{2}$," Electrochimica Acta, 53 2121-2129 (2008).

30. D. P. Abraham, S. D. Poppen, A. N. Jansen, J. Liu, and D. W. Dees, "Application of a lithium-tin reference electrode to determine electrode contributions to impedance rise in highpower lithium-ion cells," Electrochimica Acta, 494763 (2004).

31. D. P. Abraham, E. M. Reynolds, E. Sammann, A. N. Jansen, and D. W. Dees, "Aging characteristics of high-power lithium-ion cells with LiNi0.8Co0.15A10.05O2 and Li4/3Ti5/3O4 electrodes," Electrochimica Acta, 51, 502 (2005).

32. D.P. Abraham, J. Liu, C.H. Chen, Y.E. Hyung, M. Stoll, N. Elsen, S. MacLaren, R. Twesten, R. Haasch, E. Sammann, I. Petrov, K. Amine, G. Henriksen, Journal of Power Sources, 119-121 511 (2003).

33. D. P. Abraham, R. D. Twesten, M. Balasubramanian, J. Kropf, D. Fischer, J. McBreen, I. Petrov, and K. Amine, "Microscopy and spectroscopy of lithium nickel oxide-based particles used in high power lithium-ion cells," Journal of the Electrochemical Society, 150 (11) A1450 (2003).

34. A.M. Andersson, D.P. Abraham, R. Haasch, S. MacLaren, J. Liu, K. Amine, "Surface characterization of electrodes from high power lithium-ion batteries," Journal of the Electrochemical Society, 149 A1358 (2002). 
35. D. Abraham, J. Knuth, D. Dees, I. Bloom, and J. Christophersen, "Performance degradation of high-power lithium-ion cells - Electrochemistry of harvested electrodes," Journal of Power Sources, 170465 (2007).

36. J. Newman and K. E. Thomas-Alyea, "Electrochemical Systems," 3rd ed., Wiley Interscience, New York (2004).

37. Wei Lai, Can K. Erdonmez, Thomas F. Marinis, Caroline K. Bjune, Nancy J. Dudney, Fan $\mathrm{Xu}$, Ryan Wartena, and Yet-Ming Chiang, "Ultrahigh-Energy-Density Microbatteries Enabled by New Electrode Architecture and Micropackaging Design," Advanced Materials, 22, E139E144 (2010).

38. Pankaj Arora, Marc Doyle, and Ralph E. White, "Mathematical Modeling of the Lithium Deoposition Overcharge Reaction in Lithium-Ion Batteries Using Carbon-Based Negative Electrodes," Journal of the Electrochemical Society, 146 (10) 3542-3553 (1999).

39. Y. Chen and J.W. Evans, "Thermal Analysis of Lithium-Ion Batteries" Journal of the Electrochemical Society, 143 (9) 2708-2712 (1996).

40. S.C. Chen, C.C. Wan, and Y.Y. Wan, "Thermal Analysis of lithium-ion batteries" Journal of Power Sources 140 111-124 (2005).

41. H. Maleki, S.A. Hallaj, J.R. Selman, R.B. Dinwiddie, and H. Wang, "Thermal Properties of Lithium-Ion Battery and Components" Journal of the Electrochemical Society, 146 (3) 947-954 (1999).

42. M. Sievers, U. Sievers, and S.S. Mao "Thermal modelling of new Li-ion cell design modifications" Forsch Ingenieurwes 74 215-231 (2010).

43. T.M. Bandhauer, S. Garimella, and T.F. Fuller "A Critical Review of Thermal Issues in Lithium-Ion Batteries" Journal of the Electrochemical Society, 158 (3) R1-R25 (2011).

44. R. Byron Bird, Warren E. Stewart, and Edwin N. Lightfoot, "Transport Phenomena," $2^{\text {nd }}$ Ed. John Wiley \& Sons, Inc, New York, NY (2002).

45. R.K. Shah and A.L. London, "Laminar Flow Forced Convection in Ducts" Advances in Heat Transfer Supplement, Academies Press, New York, NY (1978).

46. R. Siegel, E.M. Sparrow, and T. M. Hallman, "Steady Laminar Flow Heat Transfer in a Circular Tube with Prescribed Wall Heat Flux," Applied Scientific Research, Section A, 7 386392 (1958).

47. M. Nickolay and H. Martin, "Improved approximation for the Nusselt number for hydrodynamically developed laminar flow between parallel plates," International Journal of Heat and Mass Transfer, 45 3263-3266 (2002). 
48. United States Geological Survery, Commodity Statistics and Information, Available from http://minerals.usgs.gov/minerals/pubs/commodity/ (accessed on December 17, 2010).

49. R.H. Perry, D.W. Green, and J.O. Maloney, Perry's Chemical Engineers' Handbook, Sixth Edition, pp: 25-68 (1984).

50. M. Broussely, Ph. Biensan, F. Bonhomme, Ph. Blanchard, S. Herreyre, K. Nechev, and R.J. Staniewicz, "Main aging mechanisms in Li ion batteries," Journal of Power Sources, 146 90-96 (2005).

51. Sun-Ho Kang, Wenquan Lu, Kevin G. Gallagher, Sang-Ho Park, and Vilas G. Pol, "Study of $\mathrm{Li}_{1+\mathrm{x}}\left(\mathrm{Mn}_{4 / 9} \mathrm{Co}_{1 / 9} \mathrm{Ni}_{4 / 9}\right)_{1-\mathrm{x}} \mathrm{O}_{2}$ Cathode Materials for Vehicle Battery Applications" Journal of the Electrochemical Society, 158 (8) A936-A941 (2011). 


\section{Appendix A: BatPaC v1.0 Variation Study}

\section{Summary}

The following ranges in Table A1 are suggested as an initial approximation to account for variation that will occur in the cost inputs and possible design limitations in $\mathrm{BatPaC}$. The larger uncertainty for LMO in PHEV and EV batteries is due to an interaction with the electrode thickness limitation. Future versions of $\mathrm{BatPaC}$ will include error estimation within the model.

Table A1. Suggested confidence bounds as a percentage of the calculated point estimate for a graphite based $\mathrm{Li}$-ion battery using the default inputs in $\mathrm{BatPaC}$.

\begin{tabular}{|l|l|c|c|}
\hline & & \multicolumn{2}{|c|}{ Confidence Interval } \\
\hline Battery type & Cathodes & lower & upper \\
\hline HEV & LMO, LFP, NCA, NMC & $-10 \%$ & $10 \%$ \\
\hline PHEV, EV & NMC, NCA & $-10 \%$ & $20 \%$ \\
\hline PHEV, EV & LMO, LFP & $-20 \%$ & $35 \%$ \\
\hline
\end{tabular}

\section{Discussion}

The general approach in this variation study is to produce a distribution of cost inputs and analyze a range of battery designs to capture the spread in calculated battery price if the default cost inputs or design parameters are in error. The eight largest cost contributions comprising the battery price to the OEM, shown in Table A2, were evaluated to determine the range of possible values and the likely form of the distribution, normal or log-normal. For normal distributions, the standard deviation was approximated as $1 / 4$ of the range of values. The parameters for log-normal distributions were hand-fit to set the minimum and maximum at the outer range of the $95 \%$ confidence interval. Equations A1 and A2 were used to create the distribution for each cost input, $C_{i j}$, from independent sets of 3000 normally distributed random numbers, $r_{i j}$. Here, $C_{i}$ is the mean and $\sigma_{i}$ is the standard deviation for the normal distribution of cost input $i$. Additionally, $\mu_{\mathrm{i}}$ is the location parameter and $\alpha_{i}$ is the scale parameter for the log-normal distribution. Each collection of cost inputs was used to produce an end battery price to the OEM. The battery designs used in this study are detailed in Table A3.

$$
\begin{array}{cr}
C_{i j}=C_{i, \text { mean }}+r_{i j} \sigma_{\bar{i}} & \text { normal } \\
C_{i j}=\exp \left(\mu_{i, \text { mean }}+r_{i j} \alpha_{i}\right) & \text { log-normal }
\end{array}
$$

The variation in calculated price solely due to cost input estimates results in a near-normal distribution of values. The results may be adequately summarized by the calculated mean and standard deviation. Only the cases of the default design limitations are shown in Table A4 (100 micron limit, 1 cell in cell group). A value of $+/-10 \%$ would adequately capture the $95 \%$ confidence interval of the calculated price distributions for all battery chemistries and battery types. 
Table A2. Cost input ranges and distributions used in variation study

\begin{tabular}{|l|c|c|c|c|c|c|c|c|}
\hline Item & low & medium & high & distribution & mean & std dev & location & scale \\
\hline Separator & 0.75 & 2 & 4 & log-normal & & & 0.75 & 0.3 \\
\hline Copper foil & 1 & 1.8 & 2.6 & normal & 1.8 & 0.4 & & \\
\hline Electrolyte & 18 & 21.6 & 25.2 & normal & 21.6 & 1.8 & & \\
\hline Graphite anode & 12 & 19 & 25 & normal & 19 & 3.25 & & \\
\hline LMO cathode & 8 & 10 & 16 & log-normal & & & 2.35 & 0.15 \\
\hline NMC cathode & 22 & 29 & 34 & normal & 29 & 3 & & \\
\hline NCA cathode & 22 & 37 & 42 & normal & 37 & 5 & \\
\hline LFP cathode & 10 & 20 & 30 & normal & 20 & 5 & & \\
\hline SOC controller & 1.5 & 2.5 & 3.5 & normal & 2.5 & 0.5 & & \\
\hline Coating capital & 5 & 8 & 12 & normal & 8 & 1.75 & & \\
\hline Formation capital & 20 & 30 & 50 & log-normal & & & 3.45 & 0.2 \\
\hline
\end{tabular}

Table A3. Battery designs considered in variation study

\begin{tabular}{|l|c|c|c|}
\hline Battery type & HEV-HP & PHEV25 & EV100 \\
\hline Power (kW) & 40 & 65 & 115 \\
\hline Energy (kWh) & 1.5 & 10.7 & 30 \\
\hline Range @ 300 Wh/mi & 1 & 25 & 80 \\
\hline Number of cells & 72 & 96 & 96 \\
\hline Number of modules & 4 & 6 & 6 \\
\hline Cells in parallel group & 1 & 1 & 1,2 \\
\hline Electrode thickness limit (micron) & 100 & $50,100,150$ & $70,100,200$ \\
\hline Cathode chemistries & LMO, LFP & LMO, NMC441, NCA & LMO, NMC441, NCA \\
\hline
\end{tabular}

Table A4. Distribution in calculated price from cost input variation

\begin{tabular}{|l|l|c|c|c|}
\hline battery & cathode & mean & std deviation & $\mathbf{2} \sigma /$ mean \\
\hline HEV & LMO & 1268 & 49 & 0.08 \\
\hline HEV & LFP & 1475 & 65 & 0.09 \\
\hline PHEV25 & LMO & 2995 & 134 & 0.09 \\
\hline PHEV25 & NMC441 & 3087 & 128 & 0.08 \\
\hline PHEV25 & NCA & 3325 & 153 & 0.09 \\
\hline EV100 & LMO & 6051 & 339 & 0.11 \\
\hline EV100 & NMC441 & 5927 & 279 & 0.09 \\
\hline EV100 & NCA & 6648 & 364 & 0.11 \\
\hline
\end{tabular}


Quantifying the error in calculated price due to the relative success or failure of certain design criteria is more difficult. We have chosen to vary the electrode thickness limitation for the PHEV and EV calculations. In addition, the EV battery was also calculated in a 2P-96S configuration (2 cells in parallel) to capture the possibility of smaller capacity cells while maintaining the 100 micron thickness limit. No design changes were analyzed for the HEVs. Treating each of the battery design occurrences as equally probable, the calculated population of each of the chemistries becomes a skewed distribution. Capturing the skewed and sometime bi-modal distribution in a simple statistical fashion is not straightforward. We suggest the use of a distribution parameter, $\varepsilon$, to establish the outer limits of a $95 \%$ confidence interval from the point estimate, $P_{o}$, created from the default values. This parameter is used in an empirical fashion in Equation A3 and A4. The factor of 1.05 is used to capture the increase in the mean of the population as compared to a spot estimate using the default inputs. The distribution parameters used in this study are twice the value of the standard deviation divided by the mean.

$$
\begin{aligned}
& P_{97.5}=1.05 P_{\circ}(1+\varepsilon) \\
& P_{2.5}=1.05 P_{\circ} /(1+\varepsilon)
\end{aligned}
$$

The NMC441 and NCA cathodes for PHEV and EV data sets may be captured using a distribution parameter of 0.15 . The LMO cathode requires a distribution parameter of 0.28 . The larger variation of the LMO cathode results from interaction with the limiting electrode thickness. A similar behavior is expected for LFP in energy batteries as this cathode also has a low volumetric capacity. The NMC441 and NCA cathodes have a significantly higher volumetric capacity and thus are less sensitive to this limitation. Figures A1-A3 present the variation of the PHEV and EV trials with the suggested confidence bounds highlighted by red lines and calculated point estimates from the default inputs are represented by the black line. 

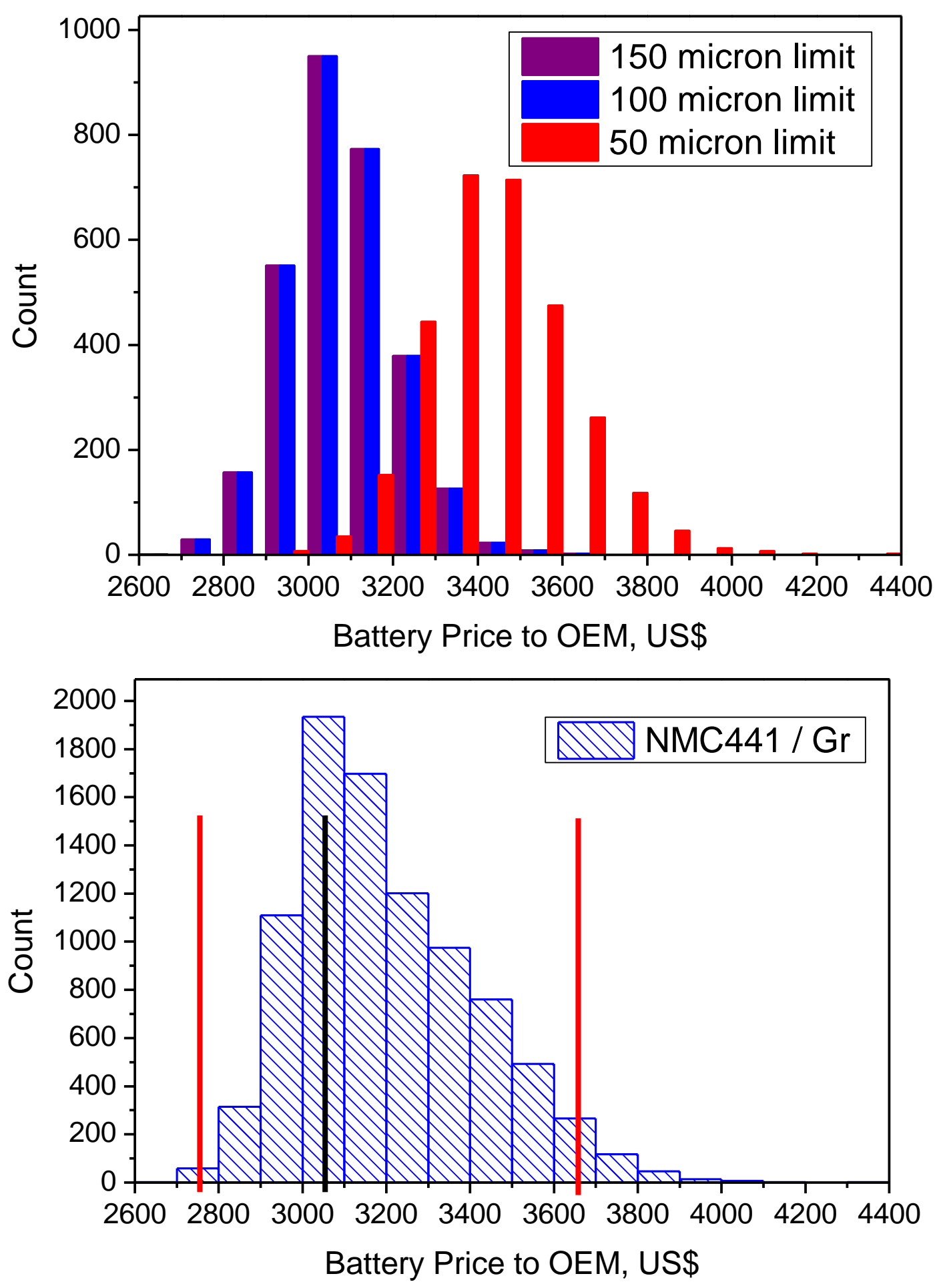

Figure A1. PHEV25 price distributions for NMC441 / Gr batteries. Red lines denote suggested upper and lower bounds for confidence interval. Black line represents price calculated from default values. 

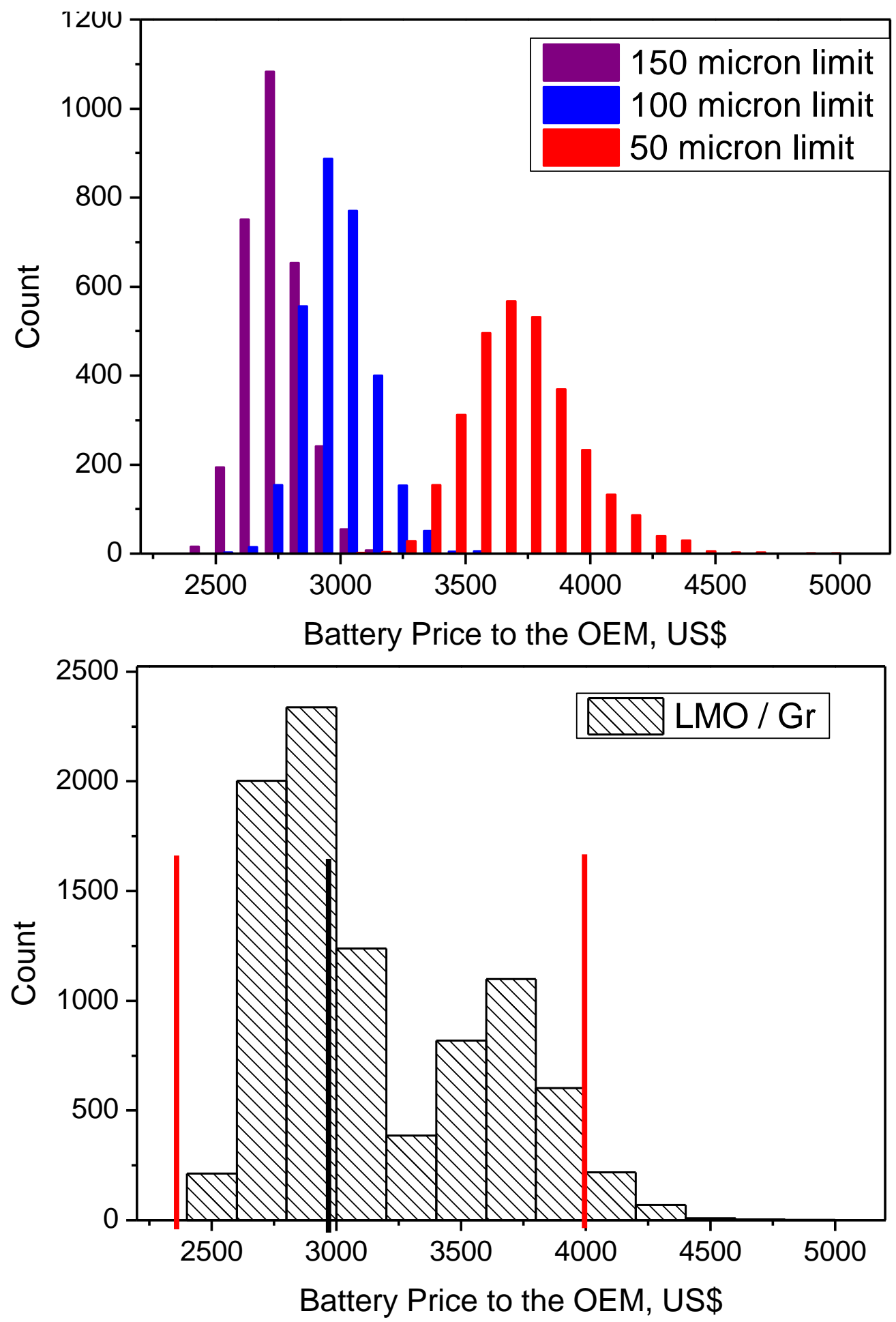

Figure A2. PHEV25 price distributions for LMO / Gr batteries. Red lines denote suggested upper and lower bounds for confidence interval. Black line represents price calculated from default values. 

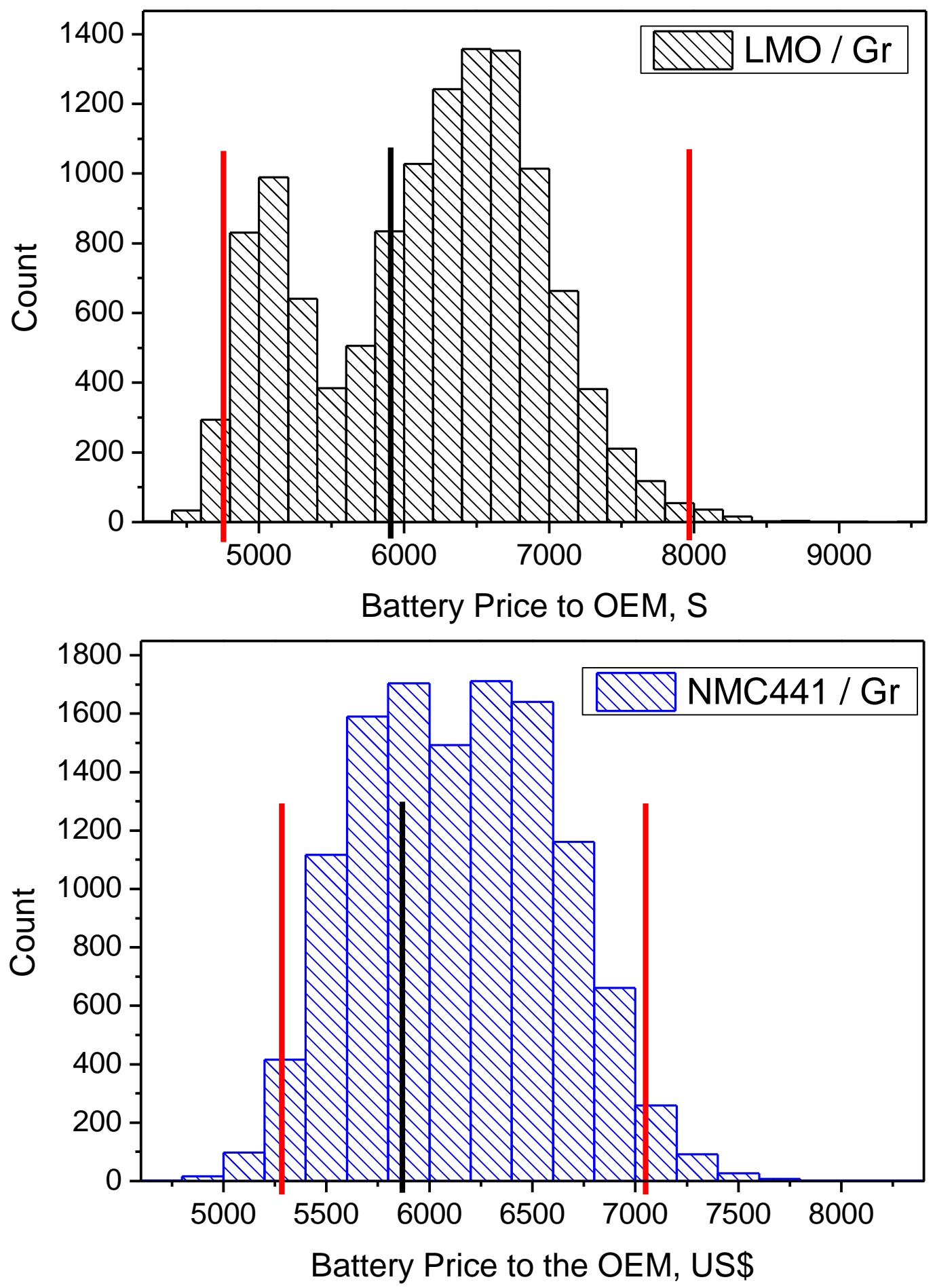

Figure A3. EV100 distributions for LMO / Gr and NMC441 / Gr batteries. Red lines denote suggested upper and lower bounds for confidence interval. Black line represents price calculated from default values. 
Argonne

Chemical Sciences and Engineering Division

Argonne National Laboratory

9700 South Cass Avenue, Bldg. 205

Argonne, IL 60439-4837

www.anl.gov 